George Moura Colares

\title{
Programa para análise da interação solo-estrutura no projeto de edifícios
}

Dissertação apresentada à Escola de Engenharia de São Carlos da Universidade de São Paulo, como parte dos requisitos para obtenção do Título de Mestre em Engenharia de Estruturas.

Orientador: Prof. Dr. Libânio Miranda Pinheiro

São Carlos

2006 
Dedico, de maneira muito singela, cada página, cada linha, cada palavra, cada letra, cada dia, cada hora, cada minuto e cada segundo que compõem este trabalho primeiramente a DEUS. Ser onipotente, onipresente e Pai do Todo-Poderoso JESUS; à mulher da minha vida, Ana Maria de Andrade Ribeiro, pelo amor infindável, paciência abundante, compreensão, carinho e apoio que tem demonstrado ao longo dos, quase, seis anos de namoro, mesmo não estando presente fisicamente em virtude da distância, sempre esteve, e estará por toda a minha vida, no meu coração; aos meus pais, Francisco Wilson e Miriam Moura, eternas referências, pelo amor eterno e apoio irrestrito em todas as ocasiões, e a quem devo minha vida e meu caráter; aos meus irmãos, Guilherme e Gustavo, pelo amor fraternal, carinho e incentivo inesgotáveis; à minha tia, Tereza de Jesus, pelas incansáveis orações e bênçãos; a Mauro Gonçalves, Jussara de Mesquita, Mauro Filho e Eduardo Sampaio, pelo acolhimento inigualável, tolerância e ensinamentos nos dois anos de convivência. 


\section{AGRADECIMENTOS}

Dedico, agradeço e presto todas as homenagens possíveis a DEUS e Nosso Senhor JESUS CRISTO, por ter me dado saúde, capacidade e força para realizar este trabalho.

Ao meu atencioso, paciente, dedicado e companheiro orientador, Prof. Libânio Miranda Pinheiro, pela orientação e ensinamentos humano e profissional. Também agradeço ao Prof. Nelson Aoki, pela ajuda, integral disponibilidade e prontidão para contribuir no desenvolvimento da pesquisa.

De modo particular, agradeço aos amigos Dr. Rodrigo Ribeiro Paccola e Dr. Valério Silva Almeida, pela enorme paciência, inúmeras sugestões, dicas e contribuições, sem as quais não teria sido possível prosseguir na elaboração do trabalho.

Sou grato ao Prof. Wilson Sérgio Venturini, ao Prof. João Batista de Paiva e ao Prof. Humberto Breves Coda, pelos inúmeros auxílios prestados na solução de questões, imprescindíveis para continuação da pesquisa.

Agradeço aos amigos e colegas de Departamento, pela agradável convivência, e aos colegas de futebol, pelos momentos de descontração. Em especial aos doutorandos Caio Gorla, Alexandre Butler, Alexandre Freitas; aos amigos de turma Eimair Bottega, Ricardo Parente, Gustavo Codá, Eduardo Toledo, Edson Leonel, Elian Moreira; e aos companheiros de sala Fernando Fontes, César Ataíde e Manoel Dênis, pela amizade sincera e verdadeira, pelo apoio, ajuda e contribuições.

Ao Instituto Militar de Engenharia (IME), particularmente aos professores do Departamento de Engenharia de Fortificação e Construção, pela formação profissional e ensinamentos, durante o curso de graduação. 
"É melhor tentar e falhar, que preocupar-se e ver a vida passar; é melhor tentar, ainda que em vão, que sentar-se fazendo nada até o final. Eu prefiro na chuva caminhar, que em dias tristes em casa me esconder. Prefiro ser feliz, embora louco, que em conformidade viver."

Martin Luther King 


\section{RESUMO}

COLARES, G. M. (2006). Programa para análise da interação solo-estrutura no projeto de edifícios. Dissertação (Mestrado) - Escola de Engenharia de São Carlos, Universidade de São Paulo, São Carlos, 2006.

Apresenta-se uma ferramenta para análise de edifícios de concreto armado assentados sobre sapatas, capaz de avaliar os efeitos decorrentes da deformabilidade do maciço de solos nas peças da superestrutura (lajes, vigas e pilares) e nos elementos estruturais de fundação (EEF). O software possibilita uma análise mais refinada das solicitações e, conseqüentemente, do real comportamento mecânico da estrutura. O programa ISE (Interação Solo-Estrutura), desenvolvido em linguagem FORTRAN, realiza o cálculo dos deslocamentos segundo o método proposto por Aoki \& Lopes em 1975, que por sua vez faz uso das equações apresentadas por Mindlin em 1936, com base na Teoria da Elasticidade. Devido à grande variabilidade, o solo é tratado como meio heterogêneo, recorrendo-se ao procedimento sugerido por Steinbrenner, em 1934, para cálculo de recalques em meios estratificados. O Método dos Elementos Finitos (MEF) é empregado na modelagem dos EEF como elementos de casca planos, para determinação das componentes de deslocamentos u, v e w. A compatibilização de deslocamentos, na região de contato entre a superfície de assentamento e a face inferior das sapatas, é condição necessária e suficiente para garantir o equilíbrio e a continuidade. Com o intuito de tornar mais amigável o uso do código computacional, é criada uma interface gráfica em Delphi e gerado um arquivo com extensão DXF, possibilitando a visualização da geometria do sistema de fundação. A elaboração de exemplos comprova a validade da formulação desenvolvida, por meio da comparação com resultados de outras metodologias presentes na literatura.

Palavras-chave: interação solo-estrutura; edifícios; recalques; redistribuição de esforços; comportamento estrutural. 


\section{ABSTRACT}

COLARES, G. M. (2006). Soil-structure interaction analyzing program in the building design. M.Sc. Dissertation - Escola de Engenharia de São Carlos, Universidade de São Paulo, São Carlos, 2006.

This work presents a tool for reinforced concrete building based in direct foundation analysis able to evaluate effects in the superstructure constituent (slab, beams and columns) and foundation structural elements (FSE) resulting from soil deformability, making possible an efforts sophisticated analysis and real mechanical behavior of the structure. The program SSI (Soil-Structure Interaction), developed in FORTRAN language, calculates displacements increases by the Aoki \& Lopes's method. Proposed in 1975, the method uses de Mindlin's equations showed in 1936 and based in the Theory of Elasticity. Due great variability, the soil is treated like a heterogeneous medium, appealing to the Steinbrenner proceeding suggested in 1934, for the estimate of displacements in multilayers medium. The Finite Element Method (FEM) is used in FSE modeling as shell elements for determination of displacements components $\mathrm{u}, \mathrm{v}$ and $\mathrm{w}$. The displacements compatibilization in contact zone between surface support and FSE below side is necessary and sufficient condition for equilibrium guarantee and continuity. Turning more friendly the software use, a graphical interface, in Delphi, is made and created a DXF file, making possible the geometry visualization of foundation system. The examples elaboration prove the developed formulation validity through results comparison with others methodologies.

Keywords: soil-structure interaction; building; displacements; efforts redistribution; structural behavior. 


\section{SUMÁRIO}

1 - INTRODUÇÃ

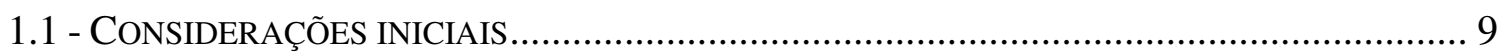

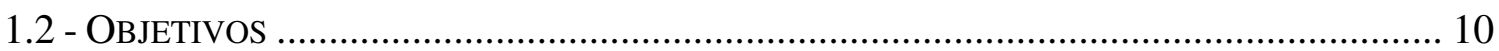

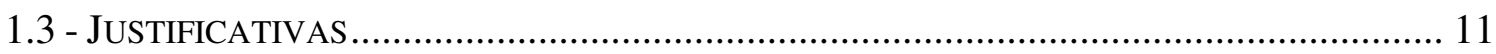

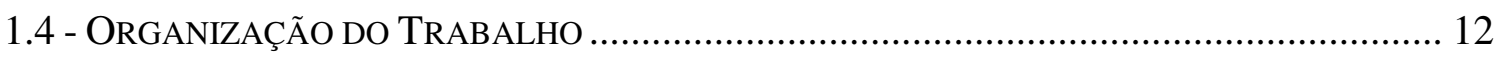

2 - CONCEITOS FUNDAMENTAIS.......................................................13

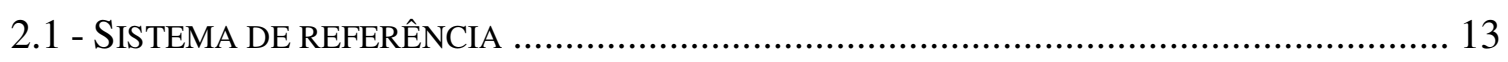

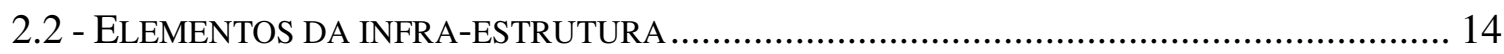

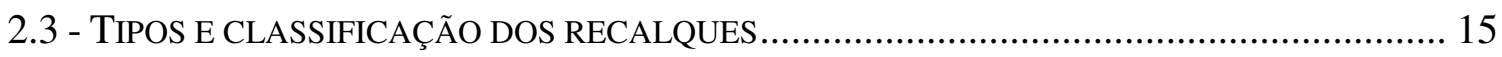

3 - INTERAÇÃO SOLO-ESTRUTURA.............................................................19

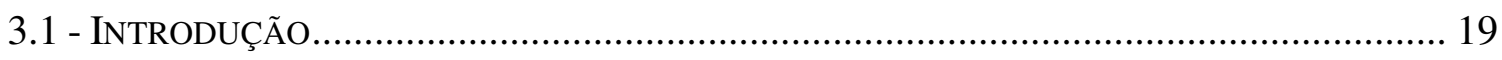

3.2 - FATORES DE INFLUÊNCIA NA INTERAÇÃO SOLO-ESTRUTURA ................................... 20

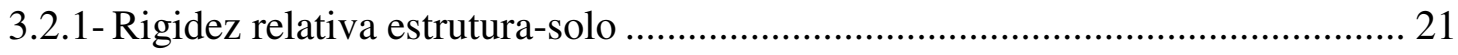

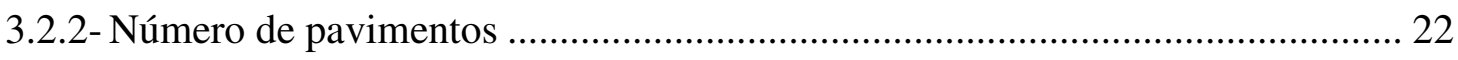

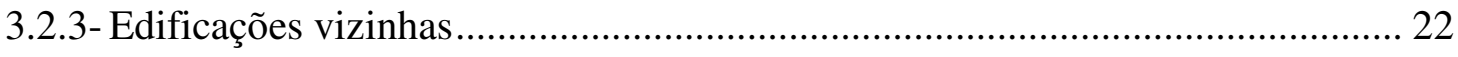

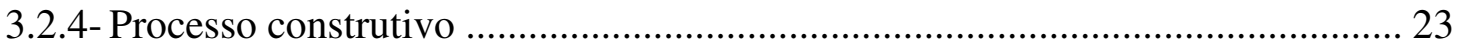

3.3 - METOdOLOGIAS PARA ANÁLISE DA INTERAÇÃO SOLO-ESTRUTURA .......................... 25

4 - MODELOS DO SOLO.....................................................................................27

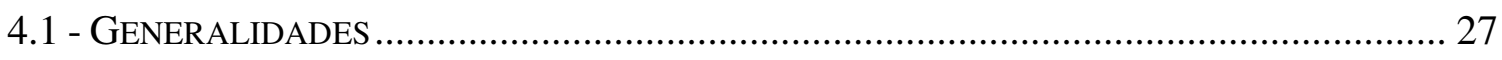

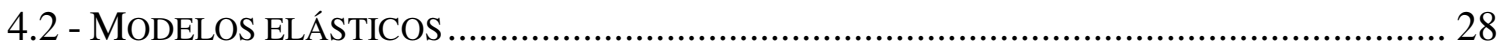

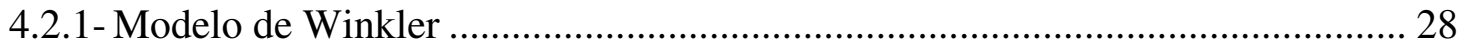

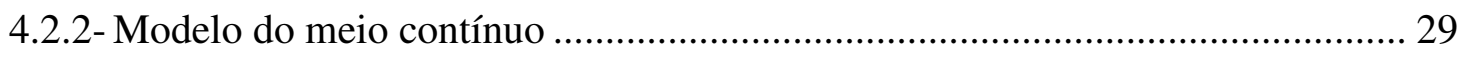

4.2.3- Modelo elástico de dois parâmetros ............................................................. 35

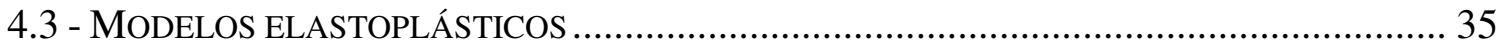

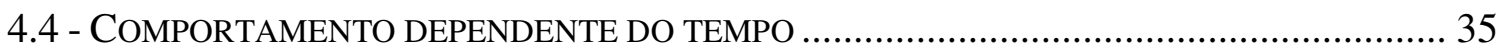




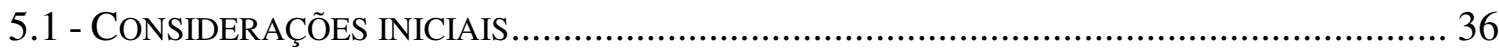

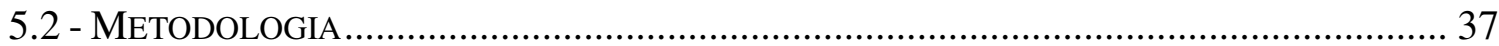

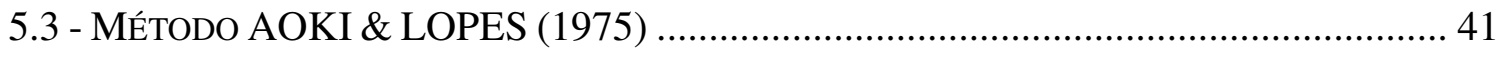

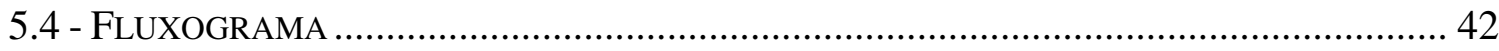

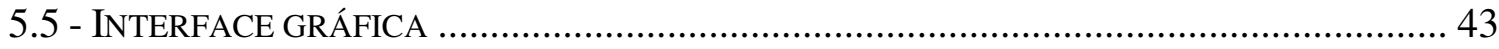

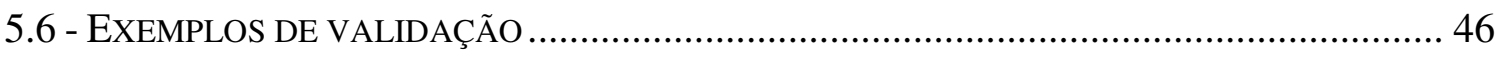

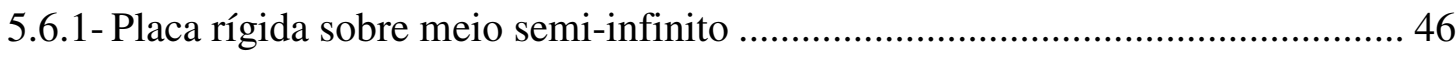

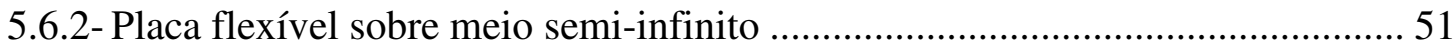

5.6.3- Placa com diferentes espessuras carregada uniformemente............................ 54

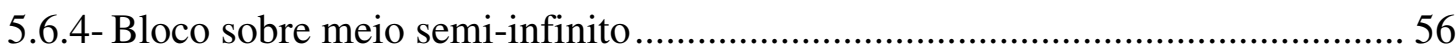

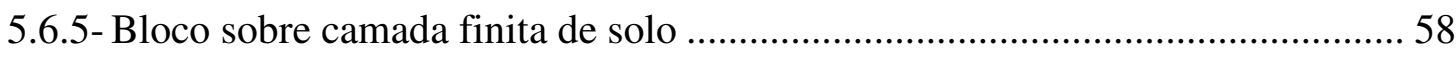

5.6.6- Blocos apoiados sobre meio semi-infinito ....................................................... 59

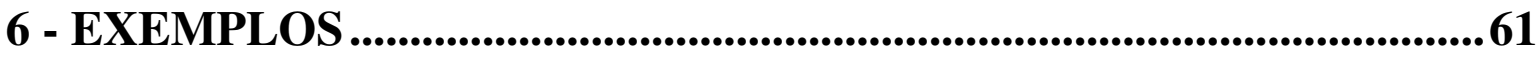

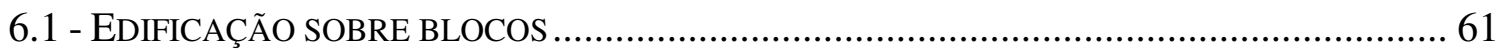

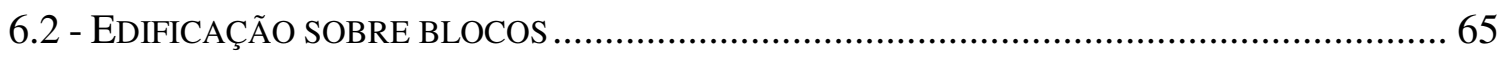

7 - CONCLUSÃO ..........................................................................................72

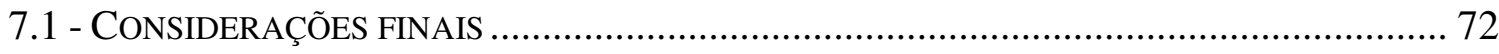

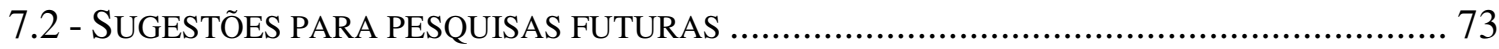

8 - REFERÊNCIAS BIBLIOGRÁFICAS .......................................................74

9 - ANEXOS....................................................................................................80 


\section{1 - INTRODUÇÃO}

No cenário atual da Engenharia Civil, a área de Estruturas tem buscado incessantemente projetar de forma cada vez mais sofisticada sem, no entanto, despreocupar-se com a otimização, traduzida pela economia.

Os programas computacionais, cada dia mais acessíveis e potentes, assumiram papel incontestável no cotidiano dos profissionais da Engenharia, possibilitando maior eficiência nos empreendimentos.

\section{1 - Considerações iniciais}

Convencionalmente, o engenheiro estrutural admite que os apoios da superestrutura sejam engastados na base. A suposição de que o sistema de fundação apresenta comportamento rígido e indeslocável não condiz com a realidade geotécnica. Sob tal hipótese, o projetista calcula e fornece ao engenheiro de fundação as forças, provenientes da superestrutura, que serão transmitidas aos elementos estruturais de fundação que, por sua vez, repassa às camadas de solo que os envolve e serve de base. De posse desses valores e das características geológico-geotécnicas do maciço de solos, o profissional geotécnico determina as áreas e as cotas de assentamento dos elementos isolados de fundação direta ou, a seção transversal e a profundidade da ponta do elemento isolado de fundação que funciona por atrito lateral e ponta.

Chama-se interação solo-estrutura o mecanismo de influência mútua superestruturasistema de fundação. O processo inicia-se na fase de construção e continua até que se atinja um estado de equilíbrio, em que as tensões e as deformações estão estabilizadas, tanto da estrutura como do maciço de solos. 


\section{2 - Objetivos}

Esta pesquisa insere-se no conjunto dos inúmeros trabalhos que, nos últimos anos, vêm abordando a interação solo-estrutura, segundo os aspectos de interesse do Departamento de Engenharia de Estruturas e do Departamento de Geotecnia da EESC USP. O diferencial de contribuição está em buscar a ligação definitiva com a prática, de toda teoria já desenvolvida, na análise estrutural de edifícios, em ambos ramos da Engenharia Civil.

Visando um conhecimento mais realista do comportamento mecânico das edificações, o trabalho tem como objetivo mais que analisar os efeitos, já consagrados, da interação com o solo na análise estrutural de edifícios: pretende-se elaborar um programa, desenvolvido com base no método de AOKI \& LOPES (1975), que utiliza as equações de MINDLIN (1936), e no procedimento de STEINBRENNER (1934) para cálculo de recalques em meio estratificados.

O código computacional permite avaliar para um número desejado de pontos (função da discretização desejada), os campos de deslocamentos e de tensões que surgem no maciço de solos e no elemento estrutural de fundação, em virtude do carregamento aplicado pela estrutura.

O emprego de um software (SAP 2000, por exemplo), para dimensionamento de elementos da superestrutura e análise estrutural, possibilita a determinação das reações de apoio sob a hipótese de maciço indeslocável (apoios engastados). Tais valores são usados como dados de entrada no algoritmo de cálculo de recalques e de tensões.

Com o método refinado, pela consideração da deformabilidade do maciço, pretendese, tanto pelo fator de segurança, possibilitar a previsão de possíveis danos e patologias às estruturas, quanto pelo fator econômico, viabilizar projetos menos onerosos.

Para ilustrar o efeito da deformabilidade do maciço sobre a estrutura e validar a metodologia desenvolvida, estudo de casos serão elaborados para se evidenciar, na prática, os aspectos relevantes da interação solo-estrutura, avaliando-se a variação das solicitações nos elementos da superestrutura. 


\section{3 - Justificativas}

Vários são os casos de edificações que apresentaram algum tipo deformidade em decorrência de alterações não previstas no comportamento mecânico idealizado na análise estrutural. Não se deve esquecer que o comportamento e a vida de uma construção dependem preponderantemente de sua fundação. Daí os japoneses usarem, simbolicamente, a palavra "matrimônio" quando se referem à relação fundação-construção.

Dentre eles a Torre de Pisa é o mais conhecido. Sua construção foi iniciada em 1173 e durou quase dois séculos. Seu peso é de aproximadamente 14.500 t e sua altura, da ordem de $58 \mathrm{~m}$. A sua fundação é do tipo superficial, repousando sobre solo heterogêneo. Se permanecesse na vertical, despertaria no solo uma pressão de $514 \mathrm{kN} / \mathrm{m}^{2}$, porém, devido à inclinação, chega a $961 \mathrm{kN} / \mathrm{m}^{2}$. Atualmente o recalque diferencial é de $1,8 \mathrm{~m}$. Até 1690 a velocidade de recalque era de $2 \mathrm{~mm} / \mathrm{ano}$; entre 1800 e 1900 reduziu-se para $1 \mathrm{~mm} / \mathrm{ano}$ e no Século XX chegou a $0,7 \mathrm{~mm} / \mathrm{ano}$. O seu desaprumo chegou a quase $10 \%$ da sua altura. Atualmente foram tomadas providências para impedir o tombamento desse importante monumento.

Os recalques observados na cidade do México são igualmente importantes. Eles são devidos à sobrecarga do solo e à modificação no regime hidrológico. A cidade do México, fundada pelos astecas no meio de um lago, repousa sobre uma camada superior com mais de $30 \mathrm{~m}$ de argila muito mole, originando as condições mais difíceis, talvez do mundo, para a execução de fundações. A esse fato alia-se o constante rebaixamento do nível de água (que também provoca recalques), decorrentes da necessidade de extração de grande volume de água para abastecimento da numerosa população.

Em Santos, há uma camada de areia de cerca de dez metros, bastante rígida, onde se assenta grande parte dos elementos estruturais de fundação dos edifícios. Mas, a areia é seguida por, aproximadamente, $40 \mathrm{~m}$ de argila compressível, ainda moderna em termos geológicos, que cede sob a pressão de edificações. O solo santista repete, em maior ou menor grau, uma formação comum a quase todo litoral brasileiro que depende de a faixa litorânea se encontrar ou não diante de mar aberto. A calmaria diante das baías ou praias protegidas por ilhas acentua o problema, já que em mar aberto a velocidade das ondas só permite depositar areia, bem mais resistente que a argila. 
A cidade de São Paulo também tem seus exemplos de recalques, como o Edifício Copam, que exigiu obras de reforço. Mas um deles, a sede da Companhia Paulista de Seguros, acabou se tornando um sucesso tecnológico internacional. Já no final da construção dos 26 andares, o prédio começou a apresentar uma inclinação considerável e ameaçadora em um dos lados. As sondagens realizadas no terreno não haviam detectado diferenças, no solo e uma construção ao lado provocou o escorregamento imprevisto no terreno. Para salvar o edifício, foi adotada a solução mais sofisticada para a época. Foi preciso congelar o solo, transformado-o em rocha sólida até que as fundações fossem reforçadas. O prédio foi, então, devolvido ao seu prumo através de macacos hidráulicos.

\section{4 - Organização do Trabalho}

Os capítulos foram elaborados e organizados segundo uma seqüência lógica de idéias, de forma a facilitar a leitura e possibilitar o melhor entendimento do assunto abordado.

No capítulo 1 são apresentadas algumas considerações iniciais sobre o tema, além dos objetivos estabelecidos e das justificativas que motivaram a pesquisa.

O capítulo 2 trata de uma breve revisão da literatura, enfatizando os trabalhos relacionados com os aspectos relevantes, efeitos da deformabilidade do solo e técnicas para consideração da interação solo-estrutura.

Alguns métodos de previsão de recalques são descritos no capítulo 3, dando maior atenção ao método de AOKI \& LOPES (1975). Ainda nesse capítulo apresentam-se as equações de MINDLIN (1936), para o problema de força aplicada no interior de sólido elástico-linear semi-infinito, e o procedimento de STEINBRENNER (1934), para cálculo de recalques em meios estratificados.

De forma resumida e com o intuito apenas de destacar alguns itens mais importantes, no capítulo 4 são mostradas características do programa computacional implementado, fluxograma e interface gráfica criada.

No capítulo 5 são mostrados exemplos de aplicação do programa juntamente com a comparação dos resultados com outras metodologias constantes na literatura.

Finalmente, o capítulo 6 é destinado a conclusões, considerações finais, sugestões e propostas para trabalhos futuros. 


\section{2 - CONCEITOS FUNDAMENTAIS}

\section{1 - Sistema de referência}

O estudo da interação solo-estrutura exige um sistema de referência comum. No entanto, é usual os engenheiros estruturais e os de fundações admitirem sistemas de referência diferentes entre si. A superestrutura é referenciada segundo um sistema de coordenadas localizado na base de um dos pilares. Já o sistema de fundação é localizado a partir de eixos XYZ situados na superfície do terreno. O mais coerente é tomar um lugar geométrico dos pontos abaixo da superfície do maciço de solos, em profundidade que possa ser considerado indeslocável (Figura 2.1).

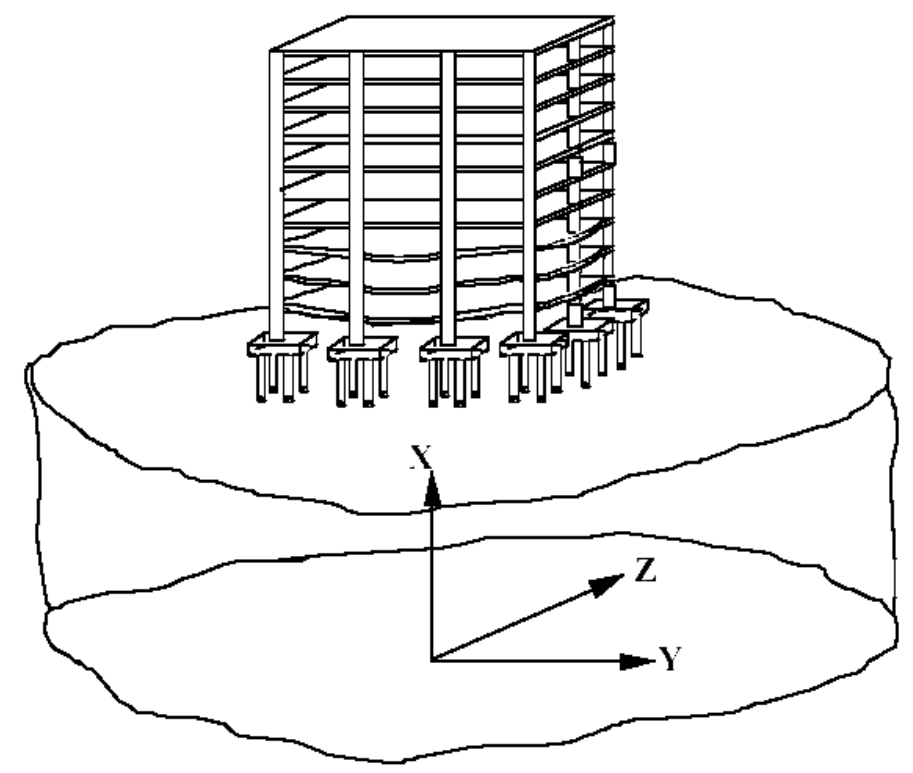

Figura 2.1 - Sistema de referência indeslocável (IWAMOTO, 2000) 


\section{2 - Elementos da infra-estrutura}

Um sistema de fundação é composto por elementos isolados, os quais são definidos como conjuntos formados pelos elementos estruturais de fundação juntamente com o maciço de solo que os circunvizinha e que serve como apoio para a superfície de contato com o solo.

Os elementos estruturais (sapatas, estacas, tubulões, etc.) são responsáveis por transmitir os esforços da estrutura para o terreno, atendendo às condições de segurança e de economia (Figura 2.2). A forma adequada de transmissão desses esforços deve atender dois requisitos básicos: (i) segurança com relação à ruptura e (ii) recalques compatíveis com a estrutura. O primeiro conceito significa que o solo de assentamento da fundação não pode entrar em colapso, ou ruptura. O segundo estabelece que, mesmo que os esforços apresentem segurança com relação à ruptura, os recalques precisam ser compatíveis com aqueles tolerados pela estrutura.

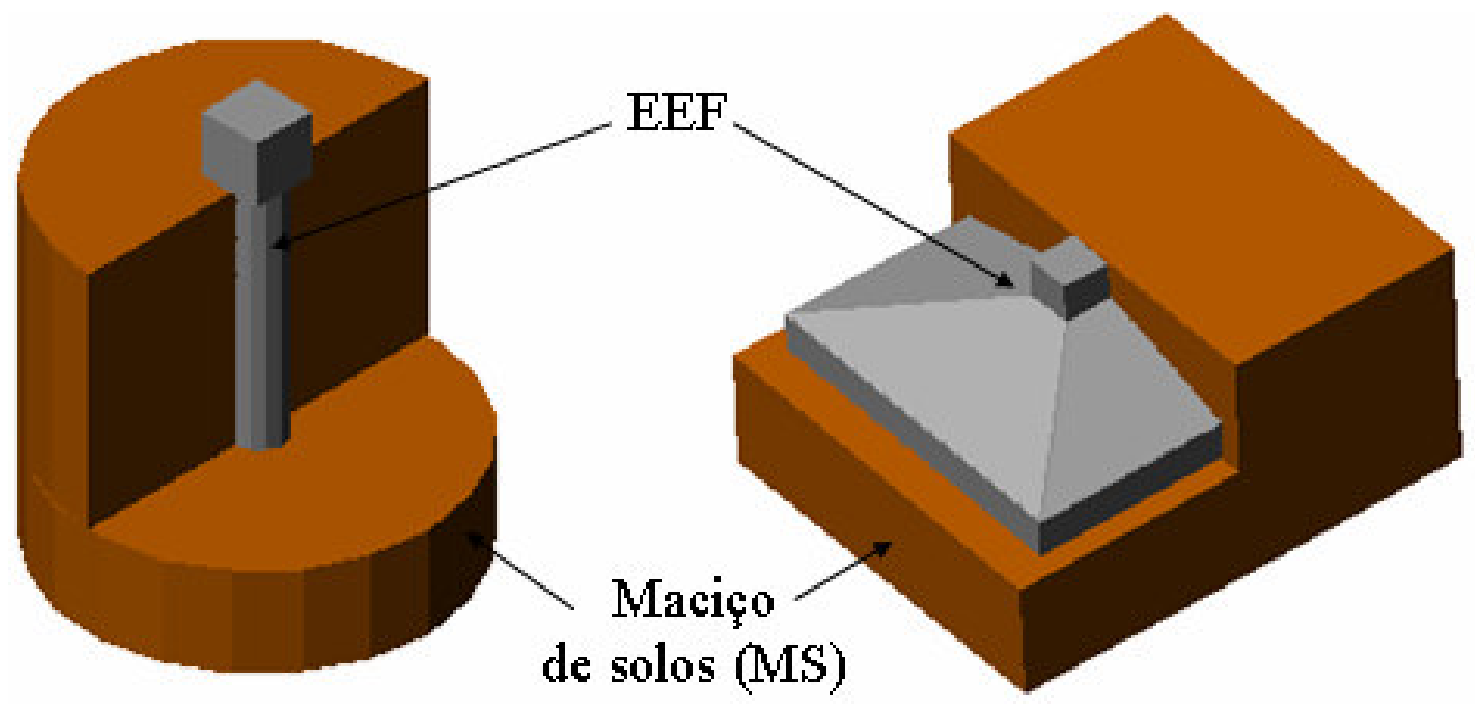

Figura 2.2 - Elementos isolados de fundação

O fato de um sistema de fundação apresentar segurança à ruptura não garante um bom desempenho, pois há necessidade de se verificar se os recalques, absolutos e diferenciais, satisfazem as condições de funcionalidade, desempenho e segurança. 


\section{3 - Tipos e classificação dos recalques}

Os recalques, apesar de já terem sido bastante estudados, ainda desafiam as teorias. Boa parte das dificuldades impostas à sua previsão advém da própria heterogeneidade do solo. Portanto, melhoria das técnicas de investigação do solo, modelos representativos mais bem elaborados e análise interativa com a estrutura são vias para se conseguir uma determinação mais precisa dos recalques.

O recalque absoluto $(\rho)$, também chamado de total, é definido pelo deslocamento vertical descendente de um elemento estrutural de fundação. A diferença entre os recalques absolutos de dois quaisquer elementos denomina-se recalque diferencial.

O recalque absoluto $(\rho)$ pode ser decomposto em duas parcelas básicas:

$$
\rho=\rho_{\mathrm{i}}+\rho_{\mathrm{c}}
$$

Na Eq.(2.1), $\rho_{c}$ é o recalque devido ao adensamento da massa de solo e $\rho_{\mathrm{i}}$ é o recalque imediato.

O recalque de adensamento, típico das argilas saturadas sob carregamentos permanentes, resulta de deformações volumétricas, exprimidas pela redução do índice de vazios. $\mathrm{O}$ adensamento se processa com a dissipação do excesso de pressão neutra gerado pelo carregamento, lentamente com o decorrer do tempo, pois a baixa permeabilidade das argilas dificulta a migração da água intersticial.

Para cálculo dos recalques por adensamento de camada compressível profunda é necessário o conhecimento do peso específico das camadas $(\gamma)$, da profundidade no nível d'água, do índice de vazios $\left(\mathrm{e}_{0}\right)$, do índice de compressão $\left(\mathrm{C}_{\mathrm{c}}\right)$, do índice de recompressão $\left(\mathrm{C}_{\mathrm{r}}\right)$, da tensão de sobreadensamento $\left(\sigma_{\mathrm{p}}\right)$, da espessura e da profundidade da camada compressível (H), como mostrado em ALONSO (1989).

Não é objeto desta pesquisa o cálculo de recalque de adensamento, mas este deslocamento não pode ser ignorado no caso de elementos estruturais de fundação direta em argilas saturadas. Como regra geral, as sapatas e os tubulões podem ser apoiados em argilas, desde que sejam argilas sobreadensadas. Sempre que possível, deve-se limitar a tensão admissível em fundações diretas ao valor da tensão de pré-adensamento.

Contrariamente ao adensamento, o recalque imediato, como o próprio nome sugere, processa-se em tempo muito curto, quase simultaneamente à aplicação do carregamento, correspondendo a uma fração menor de deslocamento. 
Por usar hipóteses da Teoria da Elasticidade, o recalque imediato também é chamado de recalque elástico. Entretanto, os solos não são materiais elásticos e, em conseqüência, os recalques imediatos geralmente não são totalmente recuperáveis com o descarregamento. Por isso, a designação recalque elástico não é recomendável. Mas o uso da Teoria da Elasticidade justifica-se pelo fato de ser bem razoável a hipótese de comportamento tensão-deformação elástico linear até níveis de tensões inferiores à tensão admissível, pela aplicação dos fatores de segurança.

Na Figura 2.3 representam-se dois elementos estruturais de fundação sujeitos às forças P1 e P2, assentes sobre um solo estratificado. Sob ação das cargas, o recalque absoluto do primeiro elemento será $\mathrm{r}_{1}$ e o do segundo, $\mathrm{r}_{2}$. O recalque diferencial $(\delta)$ é dado pela Eq.(2.2):

$$
\delta=\mathrm{r}_{1}-\mathrm{r}_{2}
$$

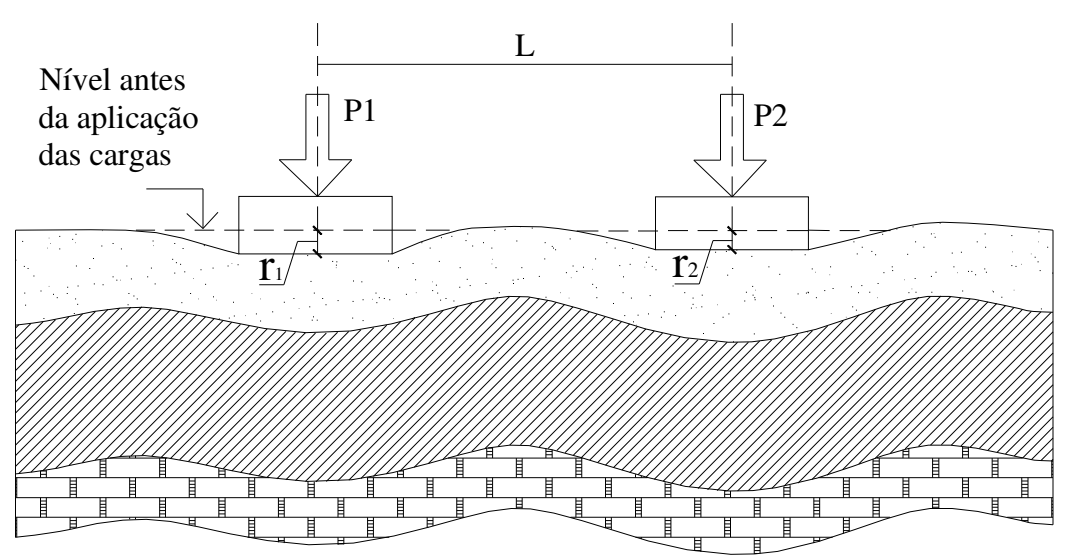

Figura 2.3 - Recalques absolutos e diferenciais (ALONSO, 1989)

O conceito de recalque admissível em prédios está ligado à tradição. Os valores admissíveis são fixados pelos especialistas envolvidos com projeto, execução e acompanhamento do desempenho da obra. Seus valores decorrem da experiência, local, ou seja, para determinados tipos de estruturas e tipos de solos, tais valores de recalque podem ser considerados aceitáveis e, portanto, admissíveis.

Define-se como recalque diferencial específico, também denominado de distorção angular, a razão entre o recalque diferencial $\delta$ entre dois pilares e a distância L entre os seus centros, como mostra a Eq.(2.3):

$$
\delta_{\mathrm{esp}}=\frac{\delta}{L}
$$


Com base em observações de cerca de centenas de edifícios, SKEMPTON \& MACDONALD (1956) associaram a ocorrência de danos com valores limites para a distorção angular (Figura 2.3). Muitas outras publicações importantes se seguiram, como, por exemplo, BJERRUM (1963), apud NOVAIS FERREIRA (1976).

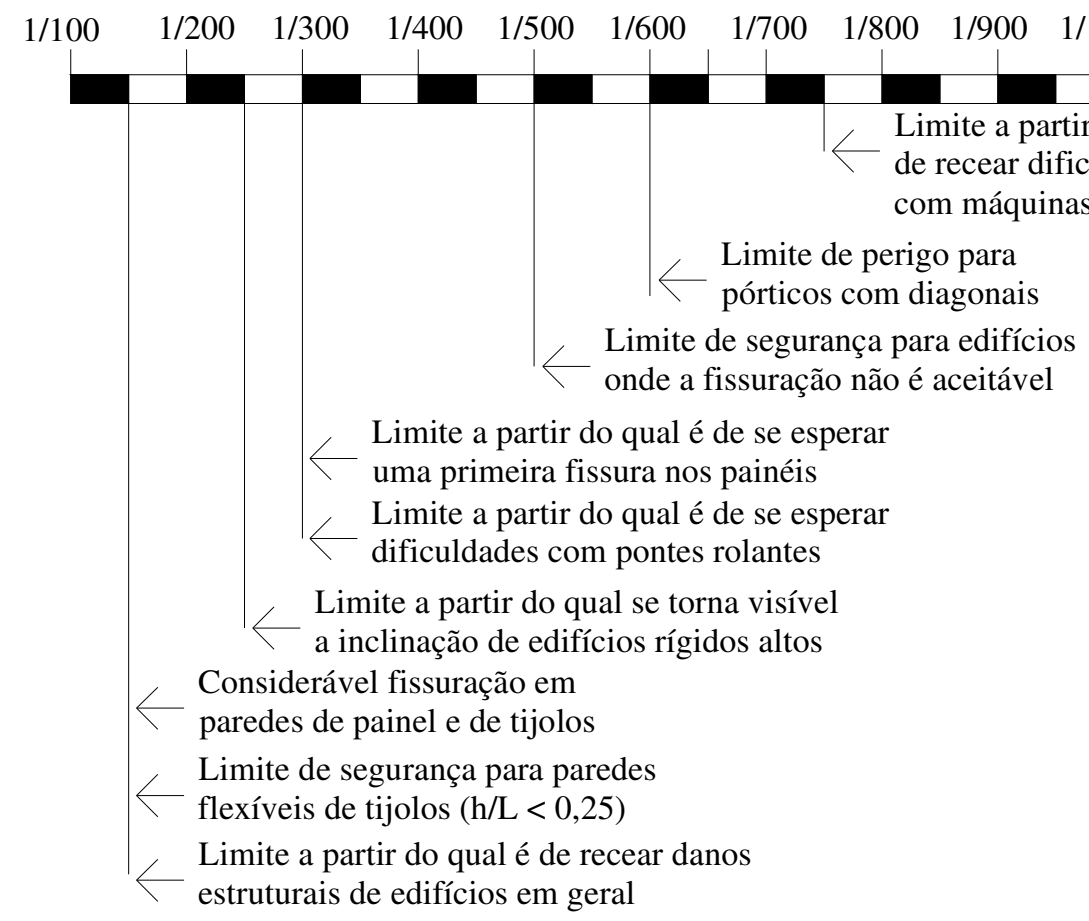

Figura 2.4 - Distorções angulares limites SKEMPTON \& MACDONALD (1956)

Resumidamente, tem-se:

- $\quad \delta_{\text {esp }}=1 / 300-$ trincas em paredes de edifícios

- $\delta_{\text {esp }}=1 / 150-$ danos estruturais em vigas e pilares de edifícios correntes

Esses valores devem ser usados com cautela, pois a distorção angular depende de vários fatores, como: tipo e características do solo, tipo de elemento estrutural de fundação, tipo, porte, função e rigidez da superestrutura e propriedades dos materiais empregados.

Os danos em edificações, provocados por recalques, podem ser classificados em estéticos, funcionais e estruturais (Figura 2.5).

Os danos estéticos são aqueles que afetam apenas o aspecto visual da obra, não comprometendo seu uso ou sua estabilidade. São exemplos de danos estéticos: fissuras em paredes de alvenaria de vedação; pequeno desaprumo da edificação devido à rotação de corpo rígido ("tilting”). 
Os danos funcionais comprometem o uso da edificação. São exemplos deste tipo de dano: dificuldade de abrir portas e janelas; problemas com elevadores; danos às ligações com o exterior (tubulações de esgoto, rampas, escadas); desaprumo acentuado; problemas de drenagem.

Danos estruturais são os que prejudicam os elementos estruturais e podem, dependendo da sua extensão, causar ruína da edificação. São exemplos deste tipo de dano: trincas em vigas, lajes e pilares; trincas em alvenarias estruturais.

\begin{tabular}{|c|l|}
\hline Tipo de recalque & \multicolumn{1}{|c|}{ Danos associados } \\
\hline Uniforme & $\begin{array}{l}\text { Danos arquiteônicos (estéticos e } \\
\text { funcionais), dependendo da } \\
\text { grandeza dos recalques. } \\
\text { Danos às ligações com o } \\
\text { exterior (instalações, rampa, } \\
\text { escada). }\end{array}$ \\
\hline Não uniforme; sem distorção & $\begin{array}{l}\text { Danos arquiteônicos: } \\
\text { desaprumo em prédios } \\
\text { altos, etc. }\end{array}$ \\
\hline Não uniforme; com distorção & $\begin{array}{l}\text { Danos arquitetônicos: } \\
\text { fissuração, distorção de } \\
\text { vãos, etc. } \\
\text { Danos estruturais: } \\
\text { fissuras em vigas, } \\
\text { etc. }\end{array}$ \\
\hline
\end{tabular}

Figura 2.5 - Tipos de recalques em edificações e os danos associados (LOPES, 1988) 


\section{3 - INTERAÇÃO SOLO-ESTRUTURA}

\section{1 - Introdução}

O termo interação solo-estrutura compreende um vasto campo de estudo e pode incluir todos os tipos de estruturas e o solo sobre o qual são construídas. Estruturas como prédios, pontes, silos e muros de arrimos caracterizam esse tipo de tratamento.

Vários trabalhos já foram escritos sobre a interação da estrutura com o solo, abrangendo os mais diversos tipos de estruturas e situações de ocorrência do mecanismo, como mostra a Figura 3.1.

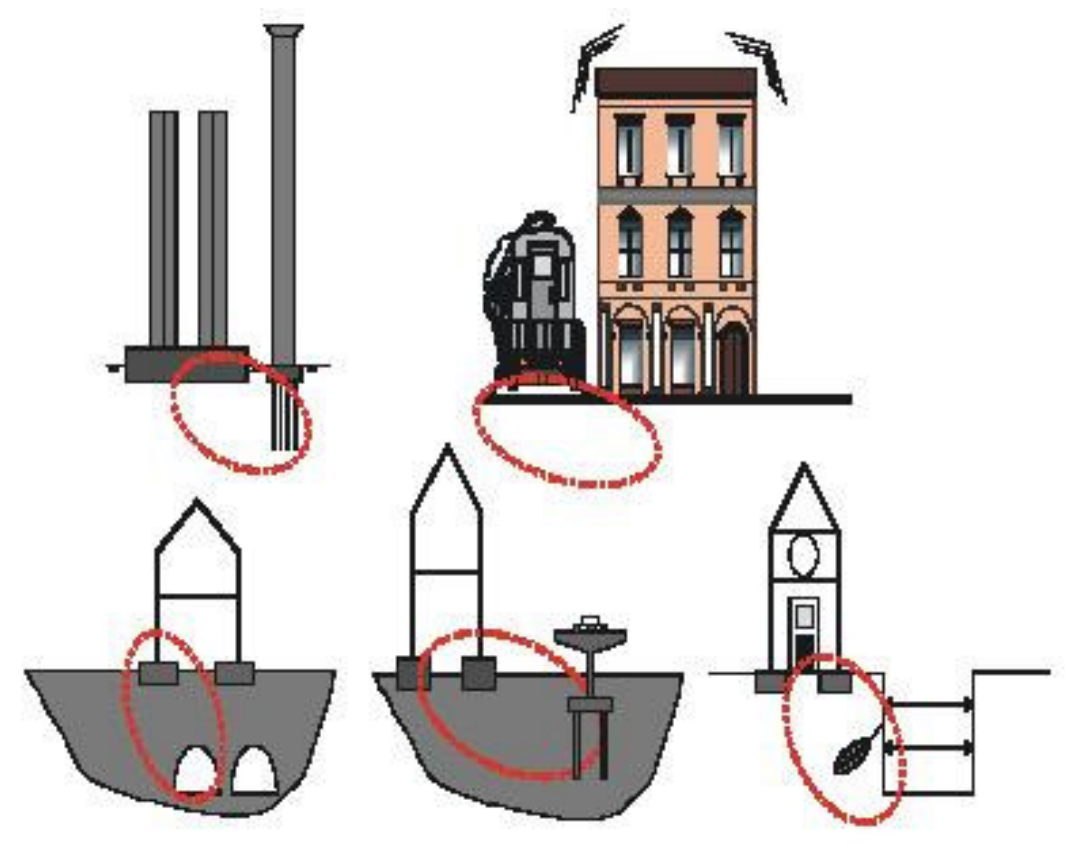

Figura 3.1 - Situações de ocorrência do mecanismo da interação solo-estrutura 


\section{2 - Fatores de influência na interação solo-estrutura}

Genericamente, o mecanismo de interação solo-estrutura gera uma redistribuição de esforços nos elementos estruturais, de modo mais evidente nos pilares, em que ocorre a transferência de esforços dos pilares mais carregados para os menos carregados, o que pode causar o esmagamento dessas peças, em virtude da sobrecarga não prevista no dimensionamento convencional. Semelhante, e conseqüente, alteração ocorre com os valores dos recalques, sendo os diferenciais mais afetados do que os totais (Figura 3.2). Essa, sem dúvida, é a conclusão mais evidente nos trabalhos de MEYERHOF (1953), GOSHY (1978), AOKI (1997), GUSMÃO (1990 e 1994), GUSMÃO E GUSMÃO FILHO (1994a) e MOURA (1995).

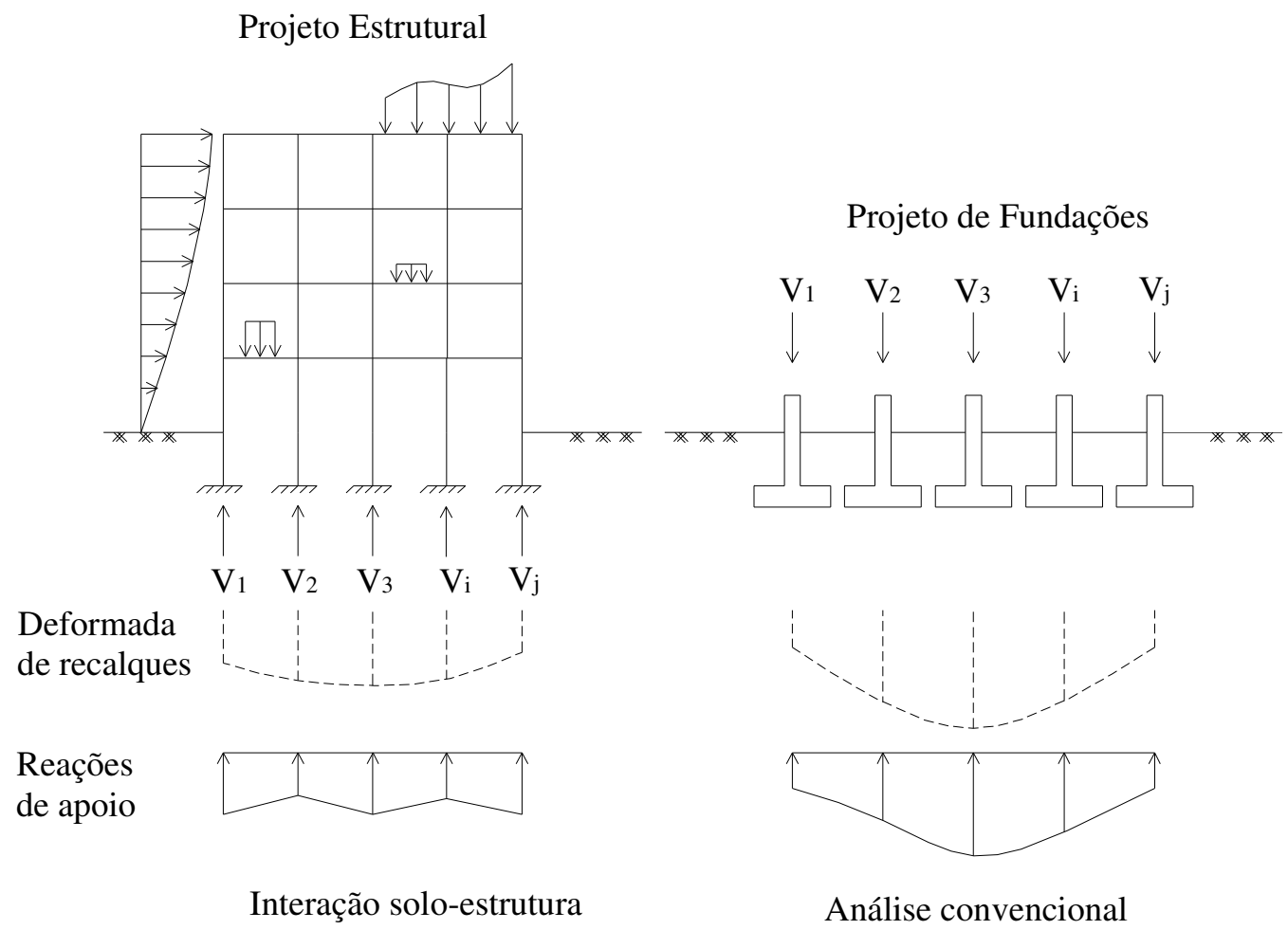

Figura 3.2 -Elaboração dos projetos estrutural e de fundações (Adaptado de GUSMÃO, 1990 e 1994)

Diversos são os fatores, ligados tanto ao sistema de fundação quanto à superestrutura, que afetam, com maior ou menor intensidade, os efeitos do mecanismo da interação solo-estrutura. O número de andares, o processo construtivo e a forma da planta baixa da edificação, a configuração e a profundidade da superfície indeformável são alguns dos principais itens. 


\subsection{1- Rigidez relativa estrutura-solo}

A solidariedade, decorrente da ligação física, entre lajes, vigas e pilares confere ao edifício considerável rigidez, promovendo recalques diferenciais bem menos acentuados do que os calculados normalmente, e uma deformada de recalques mais suave.

LOPES \& GUSMÃO (1991), após analisarem o comportamento de um pórtico, modelado como edifício de concreto armado, apoiado sobre meio elástico, propuseram, segundo a Eq.(3.1), o parâmetro rigidez relativa estrutura-solo $\left(\mathrm{K}_{\mathrm{ss}}\right)$ para avaliar, de forma aproximada, a variação da ordem de grandeza dos recalques.

$$
K_{s s}=\frac{E_{c} I_{b}}{E_{s} l^{4}}
$$

$\mathrm{E}_{\mathrm{c}}$ - módulo de elasticidade do material da estrutura

$\mathrm{E}_{\mathrm{s}}$ - módulo de elasticidade do solo

$\mathrm{I}_{\mathrm{b}}$ - momento de inércia da viga típica

1 - comprimento do vão entre pilares

Corroborando as observações do trabalho de MEYERHOR (1953), LOPES \& GUSMÃO (1991) concluíram que, como mostra a Figura 3.3, o aumento do valor da rigidez relativa estrutura-solo $\left(\mathrm{K}_{\mathrm{ss}}\right)$ reduz os valores dos recalques, afetando de modo mais acentuado o recalque diferencial.

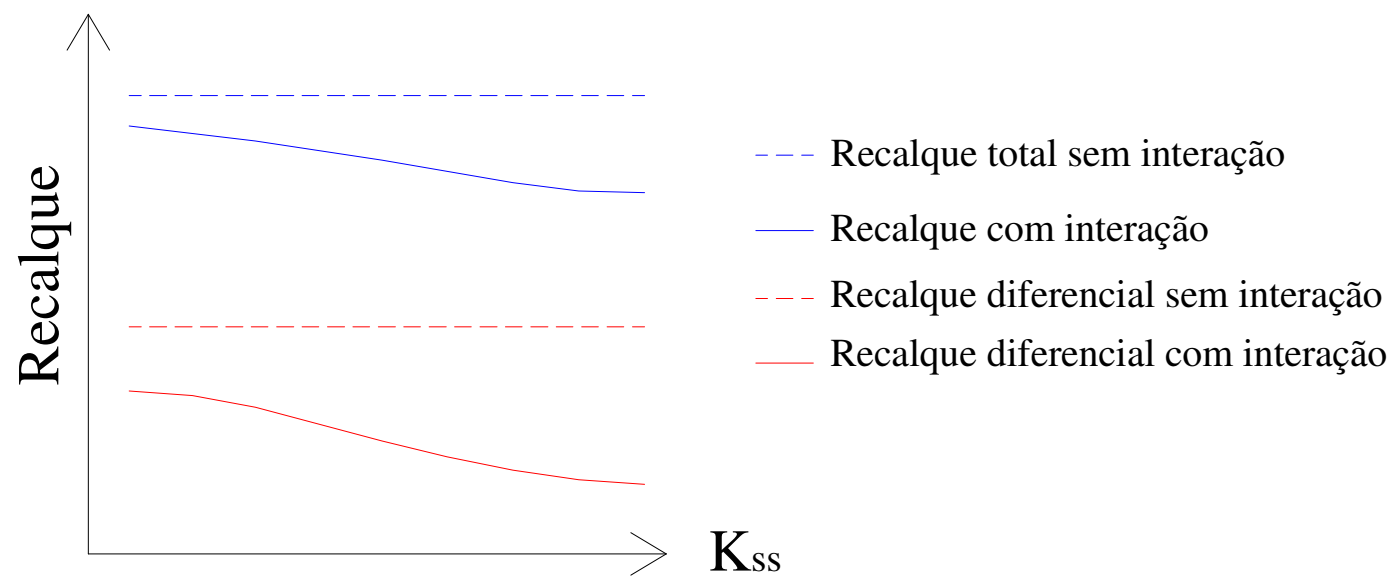

Figura 3.3 - Recalque versus rigidez relativa estrutura-solo (LOPES \& GUSMÃO, 1991) 


\subsection{2- Número de pavimentos}

$\mathrm{O}$ aumento do número de pavimentos de um edifício conduz a uma estrutura global mais rígida. No entanto essa relação não apresenta comportamento linear monótono, ou seja, os primeiros pavimentos exercem influência significativamente maior que os últimos.

Ainda em LOPES \& GUSMÃO (1991), os autores fixaram o valor de $\mathrm{K}_{\mathrm{ss}} \mathrm{e}$ variaram o número de pavimentos do pórtico. Os recalques diferenciais sofreram diminuição com o aumento do número de pavimentos. No mesmo trabalho, uma análise baseada no aumento gradativo do número de pavimentos mostrou que os primeiros andares exercem maior influência nos valores dos recalques diferenciais.

Segundo GUSMÃO \& GUSMÃO FILHO (1994), aumentando-se o número de pavimentos de um edifício, de maneira progressiva, a rigidez da estrutura tende a um valor limite tal que o aumento do número de andares não altera a parcela de força nos pilares, devido ao mecanismo de interação solo-estrutura, e faz com que os recalques, a partir desse ponto, tornem-se dependentes apenas do carregamento.

MOURA (1995) afirma que as solicitações nos elementos da superestrutura, principalmente os momentos fletores nas vigas e nos pilares, originadas pela interação com o solo, são mais significantes nos primeiros andares e diminuem nos pavimentos superiores.

\subsection{3- Edificações vizinhas}

Os resultados de REIS (2000) mostram que os recalques calculados, considerando a influência do grupo de edifícios, foram maiores que os obtidos considerando cada bloco isolado. Por outro lado, o efeito de grupo diminuiu com o aumento da distância entre os blocos vizinhos e os pontos em que os recalques foram calculados.

RIBEIRO (2005) analisa, através de ferramenta computacional, primeiramente um bloco assentado sobre meio elástico, linear e semi-infinito e, em seguida, dois blocos, idênticos ao primeiro, apoiados sobre o mesmo meio contínuo. No primeiro caso, o deslocamento obtido para o centro do bloco foi de aproximadamente 9,26 cm. Já para a segunda situação, o valor encontrado foi de $9,88 \mathrm{~cm}$. Isso mostra considerável influência (aproximadamente 7\%) de um bloco sobre o outro. 


\subsection{4- Processo construtivo}

A grande maioria dos trabalhos, experimentais e numéricos, sobre interação soloestrutura adota a simplificação de que todo o carregamento só atuará sobre a estrutura após sua completa construção. No entanto, conforme foi dito nos itens 3.2.1- e 3.2.2-, a rigidez da estrutura apresenta significativo acréscimo com o aumento do número de andares, portanto a seqüência construtiva assume importante papel no mecanismo de interação soloestrutura.

FONTE et al (1994) analisaram, segundo três modelos, um edifício de quatorze andares. Os autores inferiram que o modelo convencional, com carregamento ao final da construção e sem considerar a interação com o solo, mostra recalques diferenciais maiores. Entretanto, a análise que considera o mecanismo da interação solo-estrutura e aplica carregamento instantâneo, ou seja, um meio termo, fornece valores de recalques diferenciais. Os resultados mais próximos foram alcançados quando se considera o efeito da interação e aplicação gradual do carregamento, isto é, o modelo mais realista.

GUSMÃO \& GUSMÃO FILHO (1994) monitoraram prédios, desde o início das obras, na cidade do Recife - PE, e as leituras indicaram um aumento dos recalques como conseqüência do aumento das forças atuantes nos pilares. À medida que a construção progredia, a rigidez da estrutura também aumentava, com a tendência à uniformização dos recalques e a redistribuição das cargas (Figura 3.4).

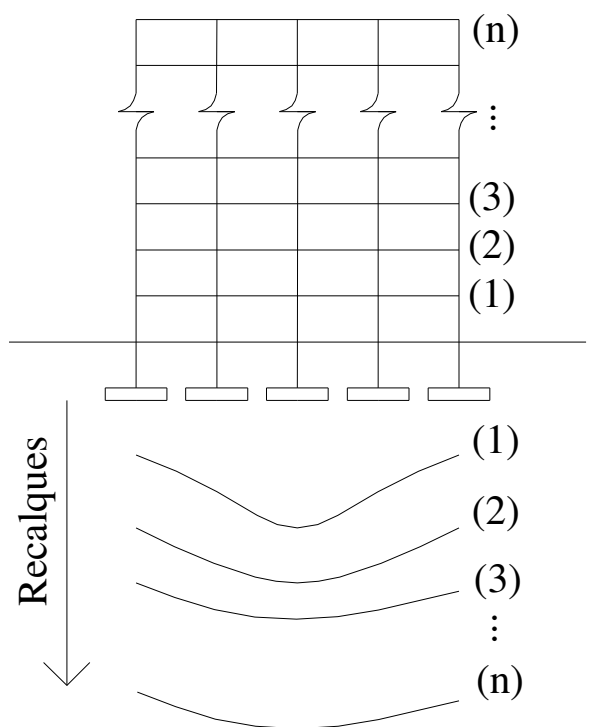

Figura 3.4 - Influência da construção nos recalques (GUSMÃO \& GUSMÃO FILHO, 1994) 
DANZIGER et al (2000) chamam a atenção para o fato de que, nos procedimentos nacionais da engenharia de fundações, as medidas de recalque só acontecessem quando aparecem problemas visuais (rachaduras, trincas) ou de funcionalidade (emperramento de portas e janelas) nas edificações, não sendo prática rotineira nos empreendimentos de engenharia. Por essa razão, os autores destacam a importância de incorporar o monitoramento de recalques desde o início da construção, como forma de garantir o controle e o desempenho das fundações.

GONÇALVES (2004) verifica como ocorre a distribuição de forças em pilares, por ação da deformabilidade do solo, por meio de monitoramento de recalques e de deformações, desde o início da construção de um edifício situado na cidade do Rio de Janeiro - RJ. Para comparação com as medições realizadas, a estrutura foi modelada em elementos finitos no software SAP $2000^{\circledR}$, em cada uma das etapas da seqüência construtiva, o que possibilitou a checagem das forças nos pilares, supondo apoios indeslocáveis e prescrevendo os deslocamentos medidos. No mesmo trabalho é feita uma comparação entre os recalques medidos e os calculados pelos métodos de BARATA (1984), SCHMERTMANN (1970) e AOKI \& LOPES (1975).

GUSMÃO et al (2004) apresenta um trabalho de monitoramento de três edifícios, apoiados sobre sapatas, em João Pessoa - PB, desde o início da construção, e posterior comparação dos valores de recalques medidos com os valores calculados pelos métodos de BARATA (1984), BURLAND \& BURBIDGE (1985), SCHMERTMANN et al (1978) e SCHULTZE \& SHERIF (1973). Os recalques foram previstos sem considerar a rigidez da superestrutura e a interferência dos bulbos de tensões de elementos estruturais de fundação vizinhos.

RUSSO NETO (2005) realizou trabalho pioneiro ao instrumentar pilares de uma estrutura de concreto pré-moldado apoiada em fundações do tipo estaca cravada. As solicitações normais nos pilares foram avaliadas indiretamente, por meio da variação de comprimento. $\mathrm{O}$ autor propôs uma metodologia para interpretação das medidas levando em conta as variações dos fatores ambientais e a reologia do concreto, conduzindo a uma boa concordância entre os valores medidos e os valores fornecidos pelo cálculo estrutural. 


\section{3 - Metodologias para análise da interação solo-estrutura}

O método da viga de rigidez à flexão equivalente Eq.(3.2), para estimar a contribuição da superestrutura, formada por pórticos de concreto armado com ou sem painéis de fechamento em alvenaria, nos recalques totais e diferenciais dos elementos isolados de fundação, foi elaborado por MEYERHOF (1953), apontando que o maciço de solos juntamente com a infra-estrutura e a superestrutura poderiam ser entendidos como um sistema único.

$$
\mathrm{E}_{\mathrm{c}} \mathrm{I}=\Sigma\left(\mathrm{E}_{\mathrm{c}} \mathrm{I}_{\mathrm{v}}\right)+\Sigma\left(\mathrm{E}_{\mathrm{a}} \mathrm{I}_{\mathrm{a}}\right)
$$

$\mathrm{E}_{\mathrm{c}} \mathrm{I}=$ rigidez equivalente da viga à flexão

$\Sigma\left(\mathrm{E}_{\mathrm{c}} \mathrm{I}_{\mathrm{v}}\right)=$ somatório das rigidezes das vigas

$\Sigma\left(\mathrm{E}_{\mathrm{a}} \mathrm{I}_{\mathrm{a}}\right)=$ somatório das rigidezes dos painéis de alvenaria

CHAMECKI (1956) elaborou um processo iterativo de convergência para consideração da interação solo-estrutura. O primeiro passo é, admitindo a hipótese de apoios indeslocáveis, determinar as reações $\left(\mathrm{R}_{0}\right)$ da estrutura. Em seguida calculam-se os recalques $\left(\rho_{0}\right)$, com os valores de $\mathrm{R}_{0}$, sem levar em conta a rigidez da estrutura. Os coeficientes de transferência de força são estabelecidos pela imposição de deslocamentos unitários nos apoios. A metodologia sistematizada permite que, a cada iteração, sejam determinadas as novas reações de apoio e os correspondentes valores de recalques. $\mathrm{O}$ processo é repetido até que haja uma convergência dos valores das reações de apoio e dos recalques, segundo uma tolerância desejada.

Em POULOS (1975) é desenvolvida uma formulação, bastante intuitiva e baseada nos conceitos da álgebra matricial, para estimar os recalques considerando a superestrutura e o sistema de fundação como um conjunto único.

A análise é baseada em duas equações:

- Equação de ligação superestrutura-sistema de fundação: que relaciona o comportamento da superestrutura com os recalques de apoio, como mostra a Eq.(3.3):

$$
\{\boldsymbol{V}\}=\left\{\boldsymbol{V}_{0}\right\}+[\boldsymbol{S M}]\{\delta\}
$$


- Equação do sistema de fundação: referente ao comportamento dos elementos estruturais de fundação e do solo, função das reações e das propriedades do solo, segundo a Eq.(3.4):

$$
\{\delta\}=[F M]\{V\}
$$

$\{\boldsymbol{V}\}$ - Vetor das reações de apoio considerando a interação solo-estrutura.

$\left\{\boldsymbol{V}_{0}\right\}$ - Vetor das reações para a condição de apoios indeslocáveis.

[SM]- Matriz de rigidez da estrutura, determinada pela imposição de deslocamentos unitários nas três direções de cada apoio.

$\{\delta\}$ - Vetor dos deslocamentos (translações e rotações) dos apoios.

[FM]- Matriz de flexibilidade do sistema de fundação ou matriz de influência do solo, determinada pela imposição de forças unitárias nas três direções de cada apoio.

Combinando a Eq.(3.3) com a Eq.(3.4), tem-se:

$$
\left\{\boldsymbol{V}_{\boldsymbol{0}}\right\}=(\boldsymbol{I}-[\boldsymbol{S M}][\boldsymbol{F M}])\{\boldsymbol{V}\}
$$

Observando a Eq.(3.5), nota-se que todos os termos são conhecidos, a menos do vetor $\{\mathrm{V}\}$. Assim a solução da equação matricial permite conhecer o vetor $\{\mathrm{V}\}$ das reações em cada apoio. Conhecido $\{\mathrm{V}\}$, volta-se na Eq.(3.4) e determina-se o vetor $\{\delta\}$ dos deslocamentos em cada apoio.

Considerando um modelo estrutural tridimensional, o vetor de reações $\{\mathrm{V}\}$ é composto por seis componentes de reação, sendo três forças e três momentos, e o vetor de deslocamentos $\{\delta\}$ é formado de três translações e três rotações para cada apoio. Para $n$ apoios da estrutura, os vetores $\{\mathrm{V}\}$ e $\{\delta\}$ terão ordem $6 n$, enquanto as matrizes de rigidez [SM] e de flexibilidade [FM] serão quadradas $6 n \times 6 n$.

A grande diversidade de formas para abordagem do mecanismo de interação soloestrutura está no modo de composição da matriz [FM] de flexibilidade do solo, pois inúmeras são as maneiras modelar o comportamento do solo, como será visto nos próximos itens. 


\section{4 - MODELOS DO SOLO}

\section{1 - Generalidades}

O comportamento do maciço de solos submetido a carregamentos externos constitui um fator de importância fundamental na análise do mecanismo de interação solo-estrutura. Cada avaliação depende da forma da curva tensão-deformação, descrição matemática das propriedades mecânicas, ou seja, equações constitutivas adotadas para o solo.

Teoricamente, o completo conhecimento da relação $\sigma-\varepsilon$ fornece, a qualquer tempo e sobre qualquer condição de carregamento, os valores de tensão e deformação. No entanto, na prática, devido à grande variabilidade natural das propriedades dos solos, há um desvio de previsão.

A complexidade inerente ao comportamento real dos solos tem levado ao desenvolvimento de inúmeros modelos de previsão, especialmente para a análise da interação solo-estrutura. Para cada modelo de comportamento adotado para o solo, ou outro material, os resultados obtidos apresentam, dentro de certo limite de condições e operação, boa concordância com as respostas dos problemas práticos. Os modelos de previsão têm mostrado ser de grande utilidade na análise dos problemas de interação solo-estrutura. A escolha de determinado modelo de comportamento para o solo nos problemas de interação solo-estrutura depende de fatores como tipo de solo, condições in situ, tipo de elemento estrutural de fundação e natureza do carregamento externo. A resposta ou característica de cada modelo de comportamento é avaliada pela superfície deformada, quando da aplicação de um sistema de forças externas. A superfície deformada representa os deslocamentos da superfície limitante do solo que está em contato com o elemento estrutural de fundação ou da superfície de contato solo-elemento estrutural de fundação. 


\section{2 - Modelos elásticos}

Do ponto de vista físico, um material ou meio perfeitamente elástico se deforma quando submetido a um sistema de forças externas, mas cessado o carregamento, o material ou o meio recupera totalmente sua forma original, não havendo deformações permanentes, ou seja, a curva de descarregamento coincide exatamente com a curva de carregamento. Os modelos elásticos podem ser lineares, caso em que a relação entre a força aplicada e o deslocamento resultante é dada por funções lineares, e não-lineares, situações em que as funções descritivas da relação força-deslocamento são não-lineares.

\subsection{1- Modelo de Winkler}

O modelo de comportamento do solo, proposto por Winkler, admite que o deslocamento $w$ de qualquer ponto situado na superfície do solo é diretamente proporcional ao carregamento $q$ aplicado no ponto e independe de outros carregamentos externos, aplicados em outros pontos do solo. A Eq.(4.1), onde $k$ é o módulo de reação do solo, representa a descrição matemática do modelo.

$$
q(\mathrm{x}, \mathrm{y})=k \cdot w(\mathrm{x}, \mathrm{y})
$$

Fisicamente o modelo de Winkler consiste em um sistema mutuamente independente de molas com constante $k$. Uma das hipóteses assumidas no modelo é que os deslocamentos são determinados para pontos imediatamente abaixo da região carregada, sendo nulos os deslocamentos fora dessa área. Tal simplificação pode, dependendo do problema analisado, produzir grandes desvios das respostas. Como mostra a Figura 4.1, os deslocamentos da região carregada serão constantes se o solo estiver submetido a um carregamento infinitamente rígido ou a um carregamento flexível uniformemente distribuído.
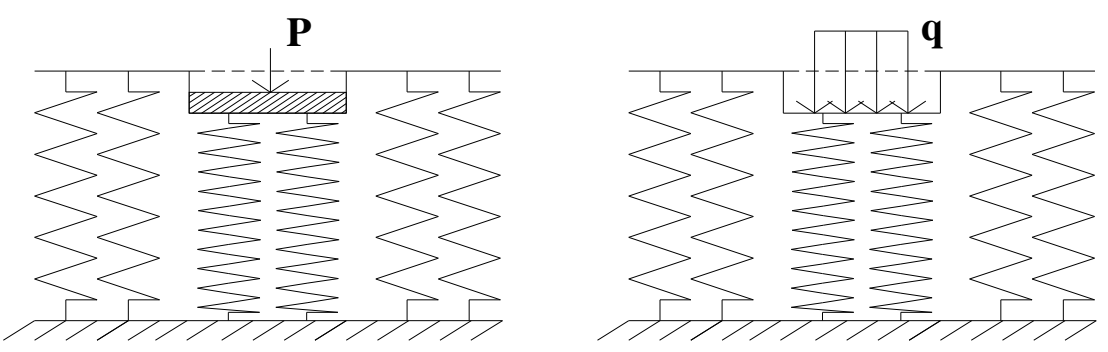

Figura 4.1 - Deslocamentos para os casos de carregamento rígido e uniformemente distribuído 


\subsection{2- Modelo do meio contínuo}

A superfície de deslocamentos, determinada pelo modelo Winkler, é delimitada pela região carregada, restringindo sua aplicabilidade a maciço de solos com baixa coesão. No entanto, a prática experimental mostra que a superfície de deslocamentos não se desenvolve apenas imediatamente abaixo da região carregada, mas também dentro de zonas limitadas fora da área carregada. Para atender a tendência de comportamento contínuo, o maciço de solos tem sido idealizado como meio elástico tridimensional.

O modelo do meio contínuo elástico pode ser subdividido em: isotrópico, anisotrópico e estratificado. Dentro do modelo isotrópico existem os subgrupos: problemas planos e problemas tridimensionais axissimétricos. Meio ortotrópico e meio nãohomogêneo (heterogêneo) são as opções de modelo anisotrópico.

BOUSSINESQ-CERUTTI (apud NAKAGUMA, 1979) apresentam as equações de determinação das componentes do tensor de tensões e do vetor de deslocamentos, para os casos de força perpendicular e de força paralela aplicadas na superfície do espaço semiinfinito representativo do meio homogêneo elástico linear.

$$
w(r, z)=\frac{P\left(1-v_{S}\right)}{2 \pi E_{S} R}\left[2\left(1-v_{S}\right)+\frac{z^{2}}{R^{2}}\right]
$$

Sendo $R^{2}=r^{2}+z^{2}$, não é difícil observar que a superfície de deslocamentos tende a zero quando $r$ tende a infinito, ou seja, pontos situados a grandes distâncias apresentam deslocamentos muito pequenos (Figura 4.2).

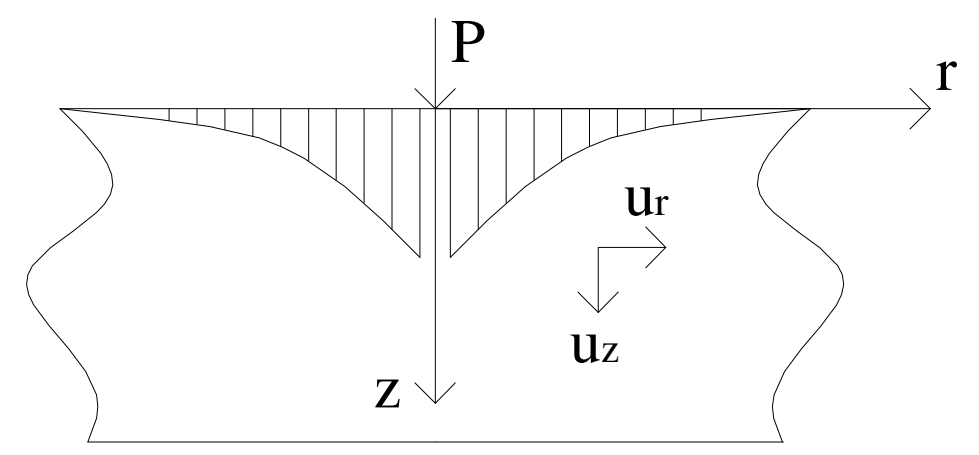

Figura 4.2 - Superfície de deslocamentos para o caso de carregamento no semi-espaço 
Em BURMISTER (1945) analisa-se o caso de força concentrada vertical agindo na superfície de meio limitado por uma base rígida (Figura 4.3). POULOS (1967) tabelou os valores numéricos de tensões e deslocamentos.

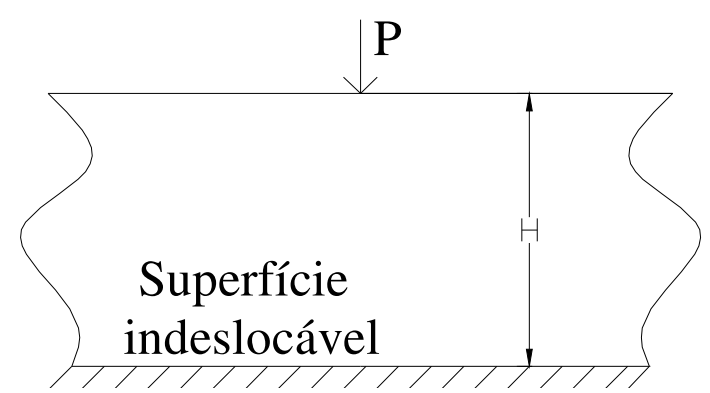

Figura 4.3 - Problema de BURMISTER (1945)

Embora o solo não seja um material perfeitamente elástico, homogêneo e isótropico, tensões e recalques elásticos induzidos por uma carga pontual vertical $P_{1}$ e por uma carga pontual horizontal $P_{2}$, como mostra a Figura 4.4, podem ser obtidos pelas equações de MINDLIN (1936). As forças $P_{1}$ e $P_{2}$ podem, diferentemente das consideradas por BURMISTER (1945), estar aplicadas em qualquer ponto do interior do meio semi-infinito.

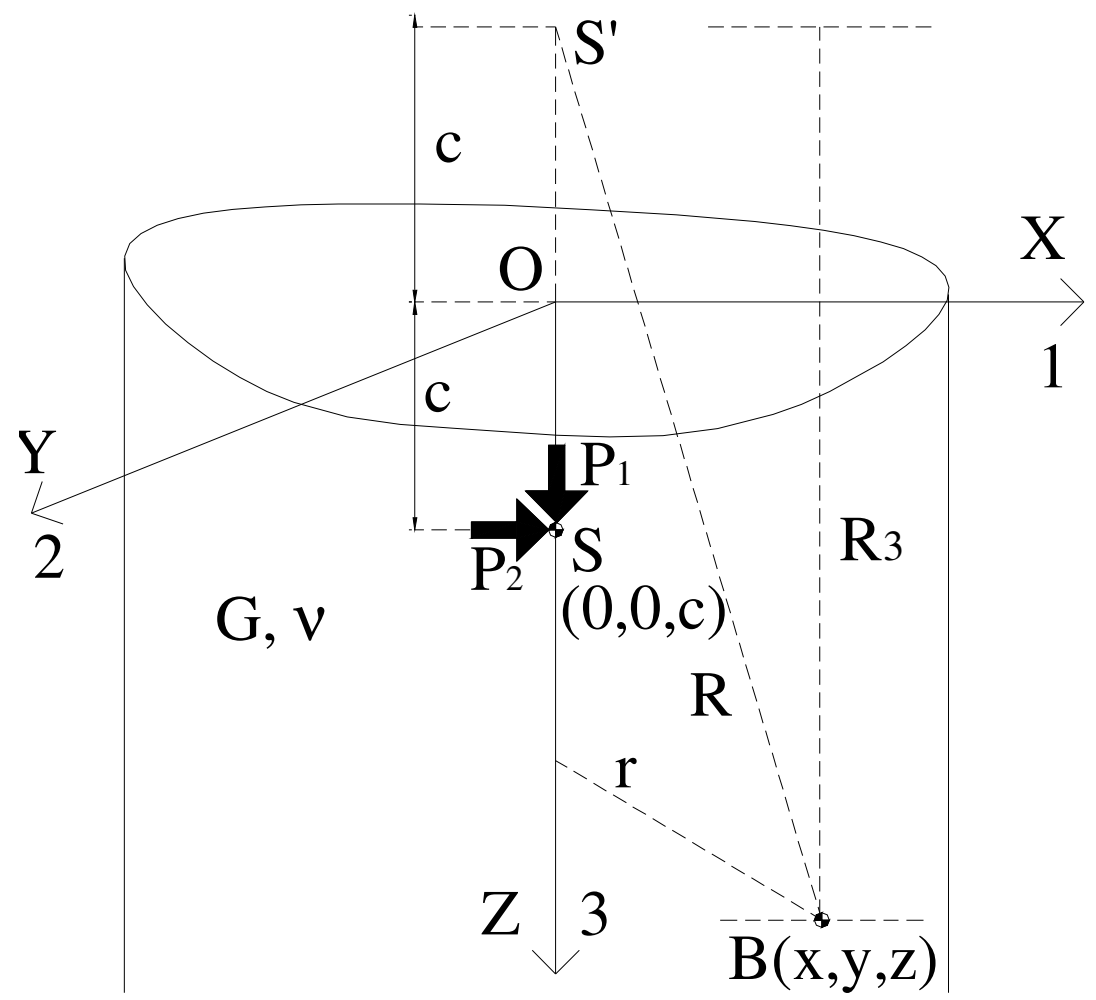

Figura 4.4 - Forças no interior de um espaço semi-infinito (MINDLIN, 1936) 
Seguem as expressões das componentes de deslocamento $u_{i j}$, onde $i$ é a direção das componentes e $j$ a direção das forças aplicadas.

$$
\begin{aligned}
& r_{i}=X_{i}(B)-X_{i}(S) \quad i=1,2,3 \\
& R_{i}=X_{i}(B)-X_{i}\left(S^{\prime}\right) \quad i=1,2,3 \\
& K_{d}=\frac{1}{16 \pi G(1-v)} \\
& C_{1}=1-v ; C_{2}=1-2 v ; C_{3}=3-4 v ; C_{4}=3-2 v ; C_{5}=5-4 v \\
& u_{11}=K_{d}\left\{\frac{C_{3}}{r}+\frac{r_{1}^{2}}{r^{3}}+\frac{1}{R}+\frac{C_{3} r_{1}^{2}}{R^{3}}+\frac{2 c z}{R^{3}}\left(1-\frac{3 r_{1}^{2}}{R^{2}}\right)+\frac{4 C_{1} C_{2}}{R+R_{3}}\left(1-\frac{r_{1}^{2}}{R\left(R+R_{3}\right)}\right)\right\} \\
& u_{12}=K_{d} r_{1} r_{2}\left\{\frac{1}{r^{3}}+\frac{C_{3}}{R^{3}}-\frac{6 c z}{R^{5}}-\frac{4 C_{1} C_{2}}{R\left(R+R_{3}\right)^{2}}\right\} \\
& u_{13}=K_{d} r_{1}\left\{\frac{r_{3}}{r^{3}}+\frac{C_{3} r_{3}}{R^{3}}-\frac{6 c z R_{3}}{R^{5}}-\frac{4 C_{1} C_{2}}{R\left(R+R_{3}\right)}\right\} \\
& u_{21}=u_{12} \\
& u_{22}=K_{d}\left\{\frac{C_{3}}{r}+\frac{r_{2}{ }^{2}}{r^{3}}+\frac{1}{R}+\frac{C_{3} r_{2}{ }^{2}}{R^{3}}+\frac{2 c z}{R^{3}}\left(1-\frac{3 r_{2}{ }^{2}}{R^{2}}\right)+\frac{4 C_{1} C_{2}}{R+R_{3}}\left(1-\frac{r_{2}{ }^{2}}{R\left(R+R_{3}\right)}\right)\right\} \\
& u_{23}=\frac{r_{2}}{r_{1}} u_{13} \\
& u_{31}=K_{d} r_{1}\left\{\frac{r_{3}}{r^{3}}+\frac{C_{3} r_{3}}{R^{3}}+\frac{6 c z R_{3}}{R^{5}}-\frac{4 C_{1} C_{2}}{R+R_{3}}\right\} \\
& u_{32}=\frac{r_{2}}{r_{1}} u_{31} \\
& u_{33}=K_{d}\left\{\frac{C_{3}}{r}+\frac{r_{3}^{2}}{r^{3}}+\frac{8 C_{1}{ }^{2}-C_{3}}{R}+\frac{C_{3} R_{3}{ }^{2}-2 c z}{R^{3}}+\frac{6 c z R_{3}}{R^{5}}\right\}
\end{aligned}
$$




$$
\begin{aligned}
& \sigma_{11}{ }^{1}=K_{s} r_{1}\left\{-\frac{C_{2}}{r^{3}}-\frac{3 r_{1}^{2}}{r^{5}}+\frac{C_{2} C_{5}}{R^{3}}-\frac{3 C_{3} r_{1}^{2}}{R^{5}}-\frac{4 C_{1} C_{2}}{R\left(R+R_{3}\right)^{2}}\left[3-\frac{r_{1}^{2}\left(3 R+R_{3}\right)}{R^{2}\left(R+R_{3}\right)}\right]+\frac{6 c}{R^{5}}\left[3 c-C_{4} R_{3}+\frac{5 r_{1}^{2} z}{R^{2}}\right]\right\} \\
& \sigma_{12}^{1}=K_{s} r_{2}\left\{-\frac{C_{2}}{r^{3}}-\frac{3 r_{1}^{2}}{r^{5}}+\frac{C_{2}}{R^{3}}-\frac{3 C_{3} r_{1}^{2}}{R^{5}}-\frac{4 C_{1} C_{2}}{R\left(R+R_{3}\right)^{2}}\left[1-\frac{r_{1}^{2}\left(3 R+R_{3}\right)}{R^{2}\left(R+R_{3}\right)}\right]+\frac{6 c z}{R^{5}}\left[1-\frac{5 r_{1}^{2}}{R^{2}}\right]\right\} \\
& \sigma_{13}{ }^{1}=K_{s}\left\{-\frac{C_{2} r_{3}}{r^{3}}-\frac{3 r_{1}^{2} r_{3}}{r^{5}}+\frac{C_{2} r_{3}}{R^{3}}-\frac{3 C_{3} r_{1}^{2} R_{3}}{R^{5}}-\frac{6 c}{R^{5}}\left[z R_{3}-C_{2} r_{1}^{2}+\frac{5 r_{1}^{2} z R_{3}}{R^{2}}\right]\right\} \\
& \sigma_{22}{ }^{1}=K_{s} r_{1}\left\{\frac{C_{2}}{r^{3}}-\frac{3 r_{2}^{2}}{r^{5}}+\frac{C_{2} C_{3}}{R^{3}}-\frac{3 C_{3} r_{2}^{2}}{R^{5}}-\frac{4 C_{1} C_{2}}{R\left(R+R_{3}\right)^{2}}\left[1-\frac{r_{2}^{2}\left(3 R+R_{3}\right)}{R^{2}\left(R+R_{3}\right)}\right]+\frac{6 c}{R^{5}}\left[c-C_{2} R_{3}+\frac{5 r_{1}^{2} z}{R^{2}}\right]\right\} \\
& \sigma_{23}{ }^{1}=K_{s} r_{1} r_{2}\left\{-\frac{3 r_{3}}{r^{5}}-\frac{3 C_{3} R_{3}}{R^{5}}+\frac{6 c}{R^{5}}\left[C_{2}+\frac{5 z R_{3}}{R^{2}}\right]\right\} \\
& \sigma_{33}{ }^{1}=K_{s} r_{1}\left\{\frac{C_{2}}{r^{3}}-\frac{3 r_{3}^{2}}{r^{5}}-\frac{C_{2}}{R^{3}}-\frac{3 C_{3} R_{3}^{2}}{R^{5}}+\frac{6 c}{R^{5}}\left[c+C_{2} R_{3}+\frac{5 z R_{3}^{2}}{R^{2}}\right]\right\} \\
& \sigma_{11}^{2}=K_{s} r_{2}\left\{\frac{C_{2}}{r^{3}}-\frac{3 r_{1}^{2}}{r^{5}}+\frac{C_{2} C_{3}}{R^{3}}-\frac{3 C_{3} r_{1}^{2}}{R^{5}}-\frac{4 C_{1} C_{2}}{R\left(R+R_{3}\right)^{2}}\left[1-\frac{r_{1}^{2}\left(3 R+R_{3}\right)}{R^{2}\left(R+R_{3}\right)}\right]+\frac{6 c}{R^{5}}\left[c-C_{2} R_{3}+\frac{5 r_{1}^{2} z}{R^{2}}\right]\right\} \\
& \sigma_{12}^{2}=K_{s} r_{1}\left\{-\frac{C_{2}}{r^{3}}-\frac{3 r_{2}^{2}}{r^{5}}+\frac{C_{2}}{R^{3}}-\frac{3 C_{3} r_{2}^{2}}{R^{5}}-\frac{4 C_{1} C_{2}}{R\left(R+R_{3}\right)^{2}}\left[1-\frac{r_{2}^{2}\left(3 R+R_{3}\right)}{R^{2}\left(R+R_{3}\right)}\right]-\frac{6 c z}{R^{5}}\left[1-\frac{5 r_{2}^{2}}{R^{2}}\right]\right\} \\
& \sigma_{13}^{2}=\sigma_{23}^{1} \\
& \sigma_{22}^{2}=K_{s} r_{2}\left\{-\frac{C_{2}}{r^{3}}-\frac{3 r_{2}^{2}}{r^{5}}+\frac{C_{2} C_{5}}{R^{3}}-\frac{3 C_{3} r_{2}^{2}}{R^{5}}-\frac{4 C_{1} C_{2}}{R\left(R+R_{3}\right)^{2}}\left[3-\frac{r_{2}^{2}\left(3 R+R_{3}\right)}{R^{2}\left(R+R_{3}\right)}\right]+\frac{6 c}{R^{5}}\left[3 c-C_{4} R_{3}+\frac{5 r_{2}^{2} z}{R^{2}}\right]\right\} \\
& \sigma_{23}^{2}=K_{s}\left\{-\frac{C_{2} r_{3}}{r^{3}}-\frac{3 r_{2}^{2} r_{3}}{r^{5}}+\frac{C_{2} r_{3}}{R^{3}}-\frac{3 C_{3} r_{3}^{2} R_{3}}{R^{5}}-\frac{6 c}{R^{5}}\left[z R_{3}+C_{2} r_{2}^{2}+\frac{5 z r_{2}^{2} R_{3}}{R^{2}}\right]\right\} \\
& \sigma_{33}^{2}=\frac{r_{2}}{r_{1}} \sigma_{33}^{1} \\
& \sigma_{11}{ }^{3}=K_{s}\left\{\frac{C_{2} r_{3}}{r^{3}}-\frac{3 r_{1}^{2} r_{3}}{r^{5}}+\frac{C_{2}\left(3 r_{3}-4 v R_{3}\right)}{R^{3}}-\frac{3 C_{3} r_{1}^{2} r_{3}}{R^{5}}-\frac{4 C_{1} C_{2}}{R\left(R+R_{3}\right)}\left[1-\frac{r_{1}^{2}}{R\left(R+R_{3}\right)}+\frac{r_{1}^{2}}{R^{2}}\right]+\frac{6 c R_{3}}{R^{5}}\left[C_{2} z-2 v c-\frac{5 r_{1}^{2} z}{R^{2}}\right]\right\}
\end{aligned}
$$




$$
\begin{gathered}
\sigma_{12}{ }^{3}=K_{s} r_{1} r_{2}\left\{-\frac{3 r_{3}}{r^{5}}-\frac{3 C_{3} r_{3}}{R^{5}}-\frac{30 c z R_{3}}{R^{7}}-\frac{4 C_{1} C_{2}}{R^{2}\left(R+R_{3}\right)}\left[\frac{1}{R+R_{3}}+\frac{1}{R}\right]\right\} \\
\sigma_{13}{ }^{3}=K_{s} r_{1}\left\{-\frac{C_{2}}{r^{3}}-\frac{3 r_{3}{ }^{2}}{r^{5}}+\frac{C_{2}}{R^{3}}-\frac{3 C_{3} z R_{3}}{R^{5}}+\frac{3 c(3 z+c)}{R^{5}}-\frac{30 c z R_{3}{ }^{2}}{R^{7}}\right\} \\
\sigma_{22}{ }^{3}=K_{s}\left\{\frac{C_{2} r_{3}}{r^{3}}-\frac{3 r_{2}{ }^{2} r_{3}}{r^{5}}+\frac{C_{2}\left(3 r_{3}-4 v R_{3}\right)}{R^{3}}-\frac{3 C_{3} r_{2}{ }^{2} r_{3}}{R^{5}}-\frac{4 C_{1} C_{2}}{R\left(R+R_{3}\right)}\left[1-\frac{r_{2}{ }^{2}}{R\left(R+R_{3}\right)}+\frac{r_{2}{ }^{2}}{R^{2}}\right]+\frac{6 c R_{3}}{R^{5}}\left[C_{2} z-2 v c-\frac{5 r_{2}{ }^{2} z}{R^{2}}\right]\right\} \\
\sigma_{23}{ }^{3}=K_{s} r_{2}\left\{-\frac{C_{2}}{r^{3}}-\frac{3 r_{3}{ }^{2}}{r^{5}}+\frac{C_{2}}{R^{3}}-\frac{3 C_{3} z R_{3}}{R^{5}}+\frac{3 c(3 z+c)}{R^{5}}-\frac{30 c z R_{3}{ }^{2}}{R^{7}}\right\} \\
\sigma_{33}{ }^{3}=K_{s}\left\{-\frac{C_{2} r_{3}}{r^{3}}-\frac{3 r_{3}{ }^{2}}{r^{5}}+\frac{C_{3} r_{3}}{R^{3}}-\frac{3 C_{3} z R_{3}{ }^{2}}{R^{5}}+\frac{3 c R_{3}(5 z-c)}{R^{5}} \frac{30 c z R_{3}{ }^{3}}{R^{7}}\right\}
\end{gathered}
$$

$v$ é o coeficiente de Poisson;

G é o módulo de elasticidade transversal.

A determinação de deslocamentos e tensões baseada nas equações de MINDLIN (1936) tem aplicação limitada, pois não considera a estratificação do maciço de solos, nem a presença, a uma determinada profundidade, de superfície de deslocamentos nulos. Para considerar tais situações, pode-ser recorrer ao procedimento de STEINBRENNER (apud ALONSO, 1989).

O procedimento de STEINBRENNER (1934) pode ser usado isoladamente para cada camada suposta homogênea, elástica e de espessura finita. O recalque de uma superfície carregada, repousando em estrato indeslocável, é determinado pela da diferença entre o recalque de uma massa semi-infinita no nível da aplicação da carga e o recalque na profundidade do indeslocável.

A proposição de STEINBRENNER (1934) pode ser generalizada para o caso em que existem várias camadas antes do indeslocável. Para ilustrar, considere-se um maciço formado por duas camadas de solos sobre um meio indeslocável (Figura 4.5). 


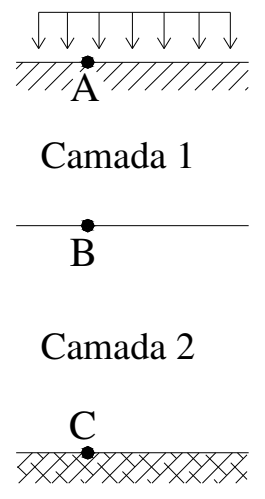

(a)

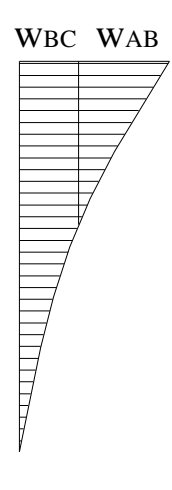

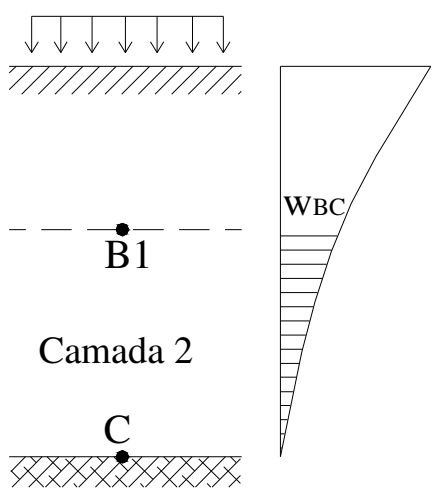

(b)

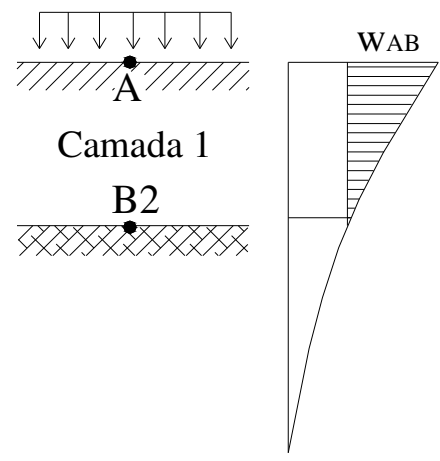

(c)

Figura 4.5 - Procedimento de STEINBRENNER (1934) para solos estratificados (JORDÃO, 2003)

O cálculo é feito, de baixo para cima, iniciando-se pela camada em contato com o indeslocável. Admite-se que todo o solo, do indeslocável para cima, seja do mesmo material da camada 2 (Figura 4.5b). Em seguida, calcula-se o recalque no nível do indeslocável e no topo da camada 2. O recalque nesta camada será $\mathrm{w}_{\mathrm{BC}}$, dado pela Eq.(4.34):

$$
\mathrm{w}_{\mathrm{BC}}=\mathrm{w}_{\mathrm{B} 1}-\mathrm{w}_{\mathrm{C}}
$$

$\mathrm{W}_{\mathrm{B} 1}$ - recalque do ponto $\mathrm{B}$, considerando o semi-espaço infinito homogêneo 2

$\mathrm{w}_{\mathrm{C}}$ - recalque do ponto $\mathrm{C}$, considerando o semi-espaço infinito homogêneo 2

O procedimento é repetido transladando o indeslocável para o topo da camada já calculada e, utilizando-se as características do solo imediatamente acima, calcula-se o recalque $\mathrm{w}_{\mathrm{AB}}$ (Figura $4.5 \mathrm{c}$ ); algebricamente tem-se a Eq.(4.35):

$$
\mathrm{w}_{\mathrm{AB}}=\mathrm{w}_{\mathrm{A}}-\mathrm{w}_{\mathrm{B} 2}
$$

$\mathrm{w}_{\mathrm{B} 2}$ - recalque do ponto $\mathrm{B}$, considerando o semi-espaço infinito homogêneo 1

$\mathrm{w}_{\mathrm{A}}$ - recalque do ponto $\mathrm{A}$, considerando o semi-espaço infinito homogêneo 1

O recalque no nível da aplicação da carga será obtido pela superposição dos recalques das camadas (Figura 4.5a):

$$
\mathrm{w}_{\mathrm{AC}}=\mathrm{w}_{\mathrm{AB}}-\mathrm{w}_{\mathrm{BC}}
$$




\subsection{3- Modelo elástico de dois parâmetros}

O termo dois parâmetros identifica que o modelo é definido por duas constantes elásticas independentes. A definição do modelo de dois parâmetros tem seguido duas abordagens distintas. A primeira delas parte do modelo de Winkler e elimina as descontinuidades pela incorporação da interação de molas individuais. Já a segunda metodologia utiliza os conceitos do modelo de meio contínuo e introduz hipóteses de restrições ou de simplificações na distribuição de tensão e de deslocamento. Vários autores elaboraram diferentes modelos de dois parâmetros, dentre os quais destacam-se FILONENKO-BORODICH (apud SELVADURAI, 1979), PASTERNAK (apud SELVADURAI, 1979), VLAZOV (apud SELVADURAI, 1979) e REISSNER (apud SELVADURAI, 1979).

\section{3 - Modelos elastoplásticos}

Os modelos elásticos para o comportamento do solo descritos anteriormente, por definição, não levam em conta qualquer característica elastoplástica do maciço de solos. A distinção básica entre o modelo puramente elástico e o modelo elastoplástico para o comportamento do solo está no fato de que neste as tensões e as forças impostas ao maciço de solo estão limitadas por um critério de ruptura, o que está de acordo com a realidade física.

\section{4 - Comportamento dependente do tempo}

Quando o maciço de solos exibe efeitos de consolidação ou de fluência, torna-se necessário considerar o comportamento dependente do tempo nos problemas de interação solo-estrutura. As tensões e as deformações em um maciço de solo granular normalmente não apresentam mudanças significativas ao longo do tempo. Entretanto, nos solos coesivos e nos solos saturados, as tensões e as deformações podem variar de maneira significante. A representação, em termos de consolidação devida à dissipação de poro-pressão, da deformação de uma amostra de solo saturado sujeita a carregamento foi formulada por TERZAGHI (apud SELVADURAI, 1979). 


\section{5 - CÓDIGO COMPUTACIONAL}

\section{1 - Considerações iniciais}

O programa mostra-se uma ferramenta de grande valor na análise dos problemas de interação solo-estrutura, mas são há algumas limitações que serão extintas na continuação deste trabalho por MOTA (2006). A primeira delas é quanto ao tipo de elemento estrutural de fundação. A hipótese de que o solo é um meio elástico linear é uma outra simplificação adotada no trabalho.

A metodologia empregada está baseada nas idéias contidas no método de AOKI \& LOPES (1975) que considera o cálculo estimativo de recalques e de tensões em pontos no interior do solo solicitado por elementos estruturais de fundação. A formulação desenvolvida abrange os casos de elementos estruturais de fundação direta, que são tratados como superfícies prescritas de carregamento (AOKI 2005), assentados sobre camadas (estratificações) que podem ser limitadas, ou não, por uma superfície admitida indeslocável (Figura 5.1).

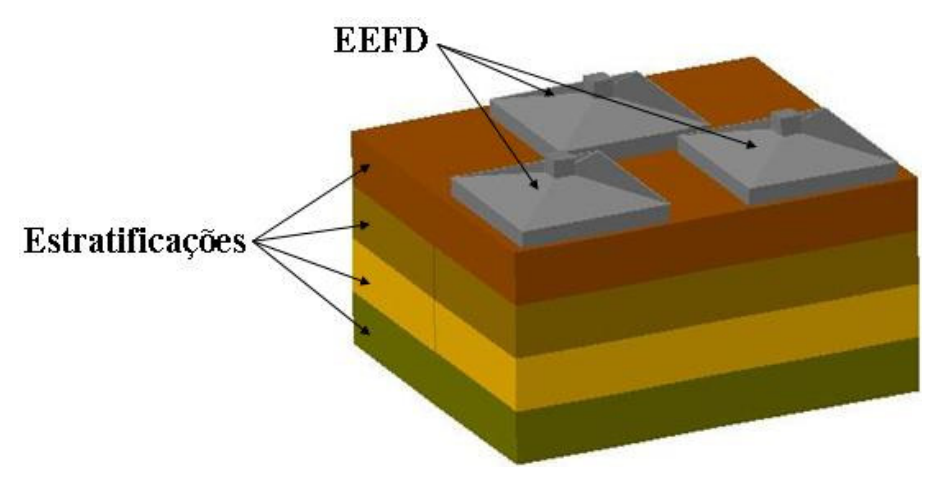

Figura 5.1 - Elementos estruturais de fundação direta apoiados sobre solo estratificado 


\section{2 - Metodologia}

A primeira tarefa realizada pelo programa é, a partir dos dados de entrada, a geração de malhas estruturadas para determinação das matrizes de coordenadas e de incidência dos nós. Então foi desenvolvida uma rotina simples para discretização dos elementos estruturais de fundação, com geometria retangular em elementos finitos planos triangulares com três nós.

A rede de nós, primeiramente criada no elemento estrutural de fundação, é espelhada na superfície de contato do solo. Desta forma há uma duplicidade de todos os pontos, ou seja, para um dado nó na malha do elemento estrutural de fundação, existe, na superfície de contato, um nó com as mesmas coordenadas e incidência (Figura 5.2).

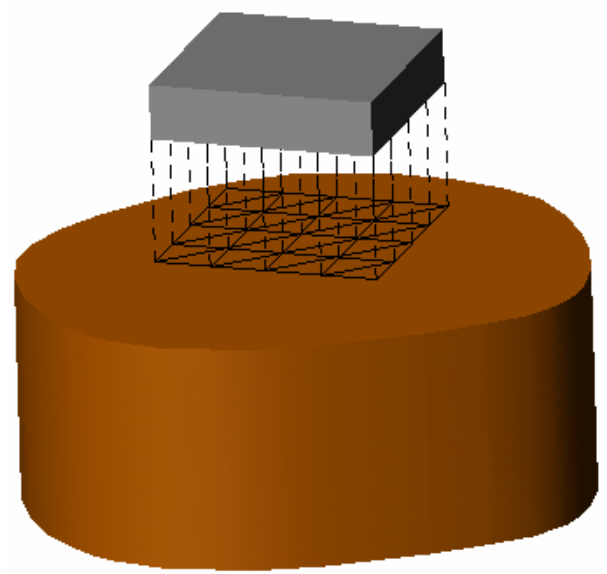

Figura 5.2 - Malha de nós do elemento estrutural de fundação espelhada no solo

O programa foi elaborado a partir da análise, separadamente, do elemento estrutural de fundação e do maciço de solos, como mostra a Figura 5.3.
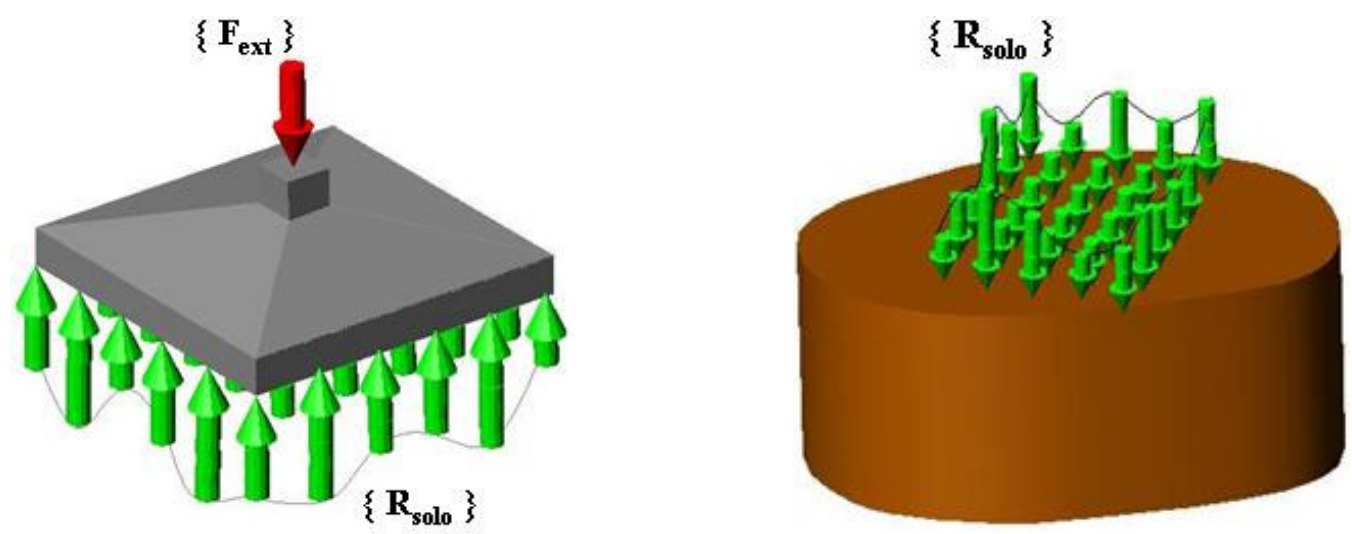

Figura 5.3 - Forças atuantes no elemento estrutural de fundação e no maciço de solos 
Isolando o elemento estrutural de fundação direta pode-se escrever:

$$
\left\{F_{\text {ext }}\right\}-\left\{R_{\text {solo }}\right\}=\left[K_{E E F}\right]\left\{u_{E E F}\right\}
$$

$\left\{F_{\text {ext }}\right\}$ é o vetor de forças externas aplicadas, que corresponde às reações dos pilares aos quais cada elemento estrutural de fundação está ligado; $\left\{R_{\text {solo }}\right\}$ é o vetor das componentes de reação do solo; $\left[K_{E E F}\right]$ é a matriz de rigidez do elemento estrutural de fundação; e $\left\{u_{E E F}\right\}$ é o vetor de deslocamentos do elemento estrutural de fundação.

Analogamente, para os pontos do solo, pode-se escrever:

$$
\left\{R_{\text {solo }}\right\}=\left[K_{\text {solo }}\right]\left\{u_{\text {solo }}\right\}
$$

$\left[K_{\text {solo }}\right]$ é a matriz de rigidez e $\left\{u_{\text {solo }}\right\}$ é o vetor de deslocamentos dos pontos do maciço de solos.

A lei de Hooke estabelece a seguinte relação entre força e deslocamentos, em meios elásticos lineares:

$$
\{F\}=[K]\{u\}
$$

$\{F\}$ representa o vetor de forças, $[K]$ a matriz de rigidez e $\{u\}$ o vetor de deslocamentos.

Isolando o vetor $\{u\}$ na Eq.(5.3), tem-se:

$$
[K]^{-1}\{F\}=\{u\}
$$

$\mathrm{Na}$ Eq.(5.4), $[K]^{-1}$ é a inversa da matriz de rigidez, ou seja, constitui a matriz de flexibilidade.

Voltando à Eq.(5.2) e reescrevendo-a em função da matriz de flexibilidade do solo:

$$
\left[K_{\text {solo }}\right]^{-1}\left\{R_{\text {solo }}\right\}=\left\{u_{\text {solo }}\right\}
$$

e denominando $\left[K_{\text {solo }}\right]^{-1}$ como $\left[\right.$ Flex $\left._{\text {solo }}\right]$, a Eq.(5.5) resulta em:

$$
\left[\text { Flex }_{\text {solo }}\right]\left\{R_{\text {solo }}\right\}=\left\{u_{\text {solo }}\right\}
$$

Analisando as expressões de MINDLIN (1936) para as componentes de deslocamentos pode-se observar que todas as equações podem ser escritas de forma semelhante à da Eq.(5.6), isto é:

$$
[C]\{P\}=\{x\}
$$

$\{x\}$ é o vetor das componentes $u, v$ e $w,\{P\}$ é o vetor de forças externas nas direções $x, y$ e $z$; e $[C]$ é uma matriz de coeficientes das equações de MINDLIN (1936). 
Para garantir a compatibilidade de deslocamentos e a continuidade na superfície de contato, entre o elemento estrutural de fundação e o maciço de solos, é necessário que em todos os pontos da interface seja válida a seguinte relação:

$$
\left\{u_{\text {solo }}\right\}=\left\{u_{\text {EEF }}\right\}
$$

Isolando $\left\{u_{E E F}\right\}$ na Eq.(5.1), chega-se a:

$$
\left[K_{E E F}\right]^{-1}\left(\left\{F_{\text {ext }}\right\}-\left\{R_{\text {solo }}\right\}\right)=\left\{u_{\text {EEF }}\right\}
$$

Igualando a Eq.(5.9) à Eq.(5.6), ou seja, impondo as condições de compatibilidade e de continuidade:

$$
\left[K_{E E F}\right]^{-1}\left(\left\{F_{\text {ext }}\right\}-\left\{R_{\text {solo }}\right\}\right)=\left[\text { Flex }_{\text {solo }}\right]\left\{R_{\text {solo }}\right\}
$$

Na Eq.(5.10), com exceção do vetor $\left\{R_{\text {solo }}\right\}$, todos os outros termos da expressão são conhecidos, isto é, $\left\{R_{\text {solo }}\right\}$ é a incógnita a ser determinada.

Operando matricialmente a Eq.(5.10) e isolando $\left\{R_{\text {solo }}\right\}$ :

$$
\left(\left[K_{\text {EEF }}\right]\left[\text { Flex }_{\text {solo }}\right]+I\right)\left\{R_{\text {solo }}\right\}=\left\{F_{\text {ext }}\right\}
$$

I é a matriz identidade de mesma ordem da matriz resultante do produto entre a matriz de rigidez do elemento estrutural de fundação e a matriz de flexibilidade do solo.

Para definir o vetor de deslocamentos, tanto no elemento estrutural de fundação quanto nos pontos da superfície de contato do solo, deve-se voltar à Eq.(5.6), e substituir o vetor $\left\{R_{\text {solo }}\right\}$ determinado pela solução da Eq.(5.10).

É importante observar que ao se tentar calcular o vetor de deslocamentos substituindo o vetor $\left\{R_{\text {solo }}\right\}$ na Eq.(5.1), encontra-se uma resposta sem significado físico, pois, procedendo desta maneira, impõe-se à matriz de rigidez do elemento estrutural de fundação uma condição de singularidade.

A montagem da matriz de flexibilidade é feita percorrendo-se todos os nós da discretização do solo com um triedro positivo de forças unitárias e determinando, pelas equações de MINDLIN (1936), os termos da matriz $[C]$. Na Figura 5.4 os círculos pretos indicam o centro de gravidade de cada elemento da malha do solo (local de aplicação do triedro de forças). 


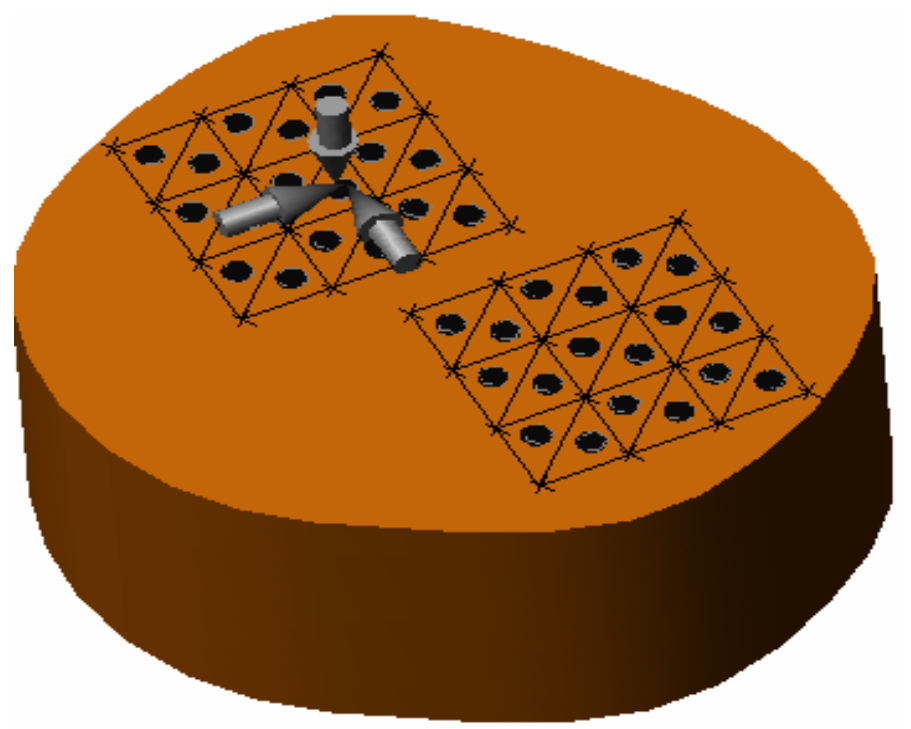

Figura 5.4 - Montagem da matriz de flexibilidade do solo

Conforme pode ser visto na Figura 5.5, os graus de liberdade correspondentes às rotações $\theta_{x}, \theta_{y}$ e $\theta_{z}$ não são considerados na montagem da matriz de flexibilidade do solo. As hachuras na Figura 5.5 indicam o preenchimento do elemento.

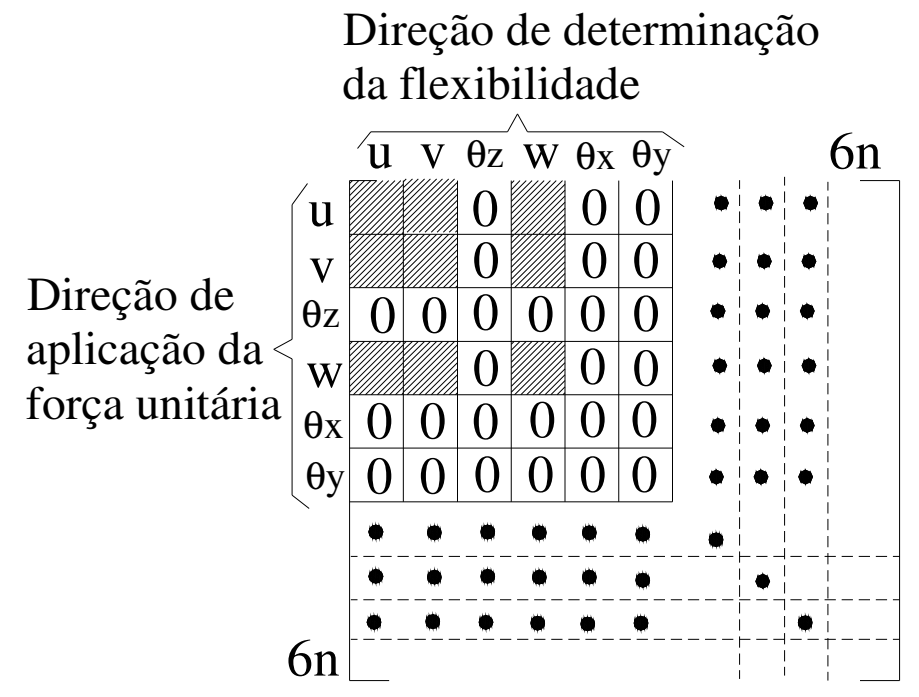

Figura 5.5 - Disposição dos elementos da matriz de flexibilidade

Em alguns trabalhos sobre interação solo-estrutura, o elemento estrutural de fundação é tratado como elemento finito de placa, isto é, o vetor de forças externas é composto somente pelas componentes de força na direção $z$, e o vetor de deslocamentos possui as componentes correspondentes aos graus de liberdade do elemento finitos de placa. 
Na formulação desenvolvida, o Método dos Elementos Finitos (MEF) é empregado na simulação do elemento estrutural de fundação como elemento finito plano de casca. Isso permite que os elementos estruturais de fundação estejam sob ação de forças nas três direções $x, y$ e $z$, possibilitando avaliar as componentes de deslocamentos $u, v$ e $w$ nas respectivas direções.

Fazendo uso do comportamento perfeitamente elástico adotado, o elemento plano de casca utilizado é obtido pela combinação do elemento finito de chapa, com graus de liberdade rotacionais implementados por PELETEIRO (1996), e o elemento finito de placa do tipo DKT com aproximação linear.

\section{3 - Método AOKI \& LOPES (1975)}

O método de AOKI \& LOPES (1975) estima o tensor de tensões $[\sigma]$ e o vetor de deslocamentos $\{u\}$, no interior do maciço de solos, através de integração numérica das equações de MINDLIN (1936).

A discretização da base do elemento estrutural de fundação depende da geometria da seção. O programa desenvolvido restringe-se aos casos de seções retangulares, em virtude da relativa complexidade da geração de malha estruturada, em outras geometrias.

A localização do elemento prismático, de dimensões $L$ e $B$, é definida pelo vértice A de coordenadas $\left(x_{A}, y_{A}, z_{A}\right)$ e pelo ângulo $\alpha$, formado pelo prolongamento do lado que contém o vértice A com o eixo X.

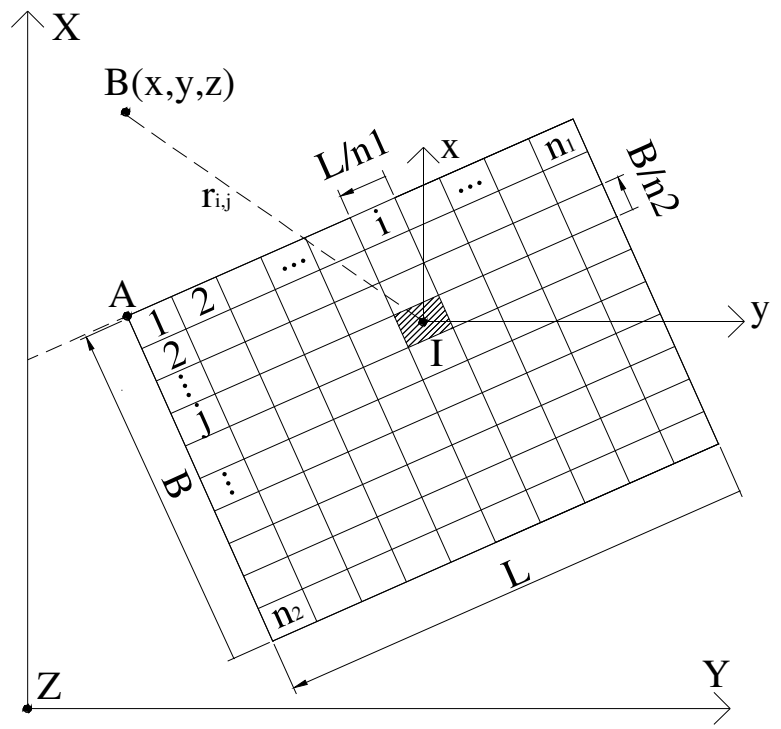

Figura 5.6 - Locação e discretização do elemento prismático de fundação (AOKI \& LOPES, 1975) 
$\mathrm{A}$ área da base é dividida em $\mathrm{n}_{1} \times \mathrm{n}_{2}$ retângulos de áreas iguais, sendo $\mathrm{n}_{1} \mathrm{o}$ número de divisões do lado de dimensão $\mathrm{L}$ e $\mathrm{n}_{2}$ o número de divisões do lado de dimensão $B$ (Figura 5.6a). A força correspondente a cada sub-área, obtida pela divisão da força aplicada pelo produto $n_{1} \mathrm{x} n_{2}$, ou seja:

$$
P_{i, j}=\frac{P}{n_{1} x n_{2}}
$$

$P_{i, j}$ é aplicada no ponto $\mathrm{I}_{\mathrm{i}, \mathrm{j}}$, centro de gravidade de cada sub-área, na cota $c=z_{A}$, sendo i e j varáveis que indicam a localização de cada sub-área retangular.

As Eqs.(5.13), (5.14) e (5.15) são necessárias para o desenvolvimento:

$$
\begin{gathered}
\boldsymbol{x}_{B}=\boldsymbol{X}_{B}-\boldsymbol{X}_{A}-\boldsymbol{L} \cos \alpha\left(\frac{2 \boldsymbol{i}-1}{2 \boldsymbol{n}_{1}}\right)+\boldsymbol{B} \operatorname{sen} \alpha\left(\frac{2 \boldsymbol{j}-1}{2 \boldsymbol{n}_{2}}\right) \\
\boldsymbol{y}_{B}=\boldsymbol{Y}_{B}-\boldsymbol{Y}_{A}-\boldsymbol{L} \operatorname{sen} \alpha\left(\frac{2 \boldsymbol{i}-1}{2 \boldsymbol{n}_{1}}\right)-\boldsymbol{B} \cos \alpha\left(\frac{2 \boldsymbol{j}-1}{2 \boldsymbol{n}_{2}}\right) \\
\boldsymbol{r}_{\boldsymbol{i}, j}=\left\{\left[\boldsymbol{X}_{A}-\boldsymbol{X}_{B}+\boldsymbol{L} \cos \alpha\left(\frac{2 \boldsymbol{i}-1}{2 \boldsymbol{n}_{1}}\right)-\boldsymbol{B} \operatorname{sen} \alpha\left(\frac{2 \boldsymbol{j}-1}{2 \boldsymbol{n}_{2}}\right)\right]^{2}+\left[\boldsymbol{Y}_{A}-\boldsymbol{Y}_{B}+\boldsymbol{L} \operatorname{sen} \alpha\left(\frac{2 \boldsymbol{i}-1}{2 \boldsymbol{n}_{1}}\right)+\boldsymbol{B} \cos \alpha\left(\frac{2 \boldsymbol{j}-1}{2 \boldsymbol{n}_{2}}\right)\right]^{2}\right\}^{1 / 2}
\end{gathered}
$$

\section{4 - Fluxograma}

O cógido computacional, desenvolvido em linguagem Fortran, está estruturado segundo uma seqüência lógica de procedimentos necessários para analisar o mecanismo de interação solo-estrutura.

Primeiramente o programa lê, do arquivo de entrada, as informações necessárias. Baseado nos dados de entrada, o código computacional realiza a geração de malha de elementos finitos. Em seguida, é feita a montagem da matriz de flexibilidade do solo. Feito isso, inicia-se a montagem da matriz de rigidez do elemento estrutural de fundação. Usando a condição de compatibilidade de deslocamentos, determina-se o sistema que, resolvido, fornece o vetor de deslocamentos, tanto do solo como da sapata.

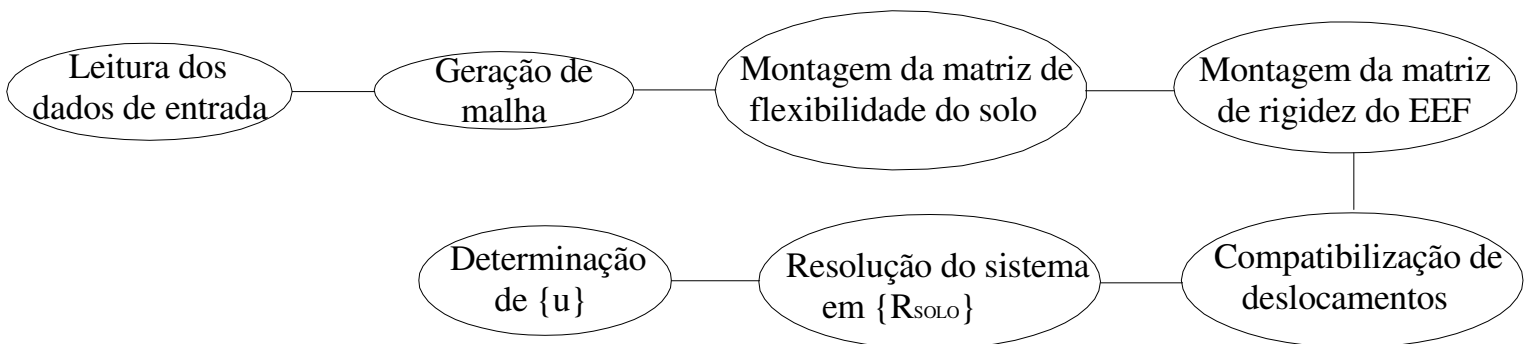

Figura 5.7 - Fluxograma do código computacional 


\section{5 - Interface gráfica}

Para tornar mais amigável a entrada de dados no programa, foi desenvolvida, em linguagem Delphi, uma interface gráfica. A primeira tela exibida pela interface é apenas uma apresentação do título do programa e dos membros envolvidos (Figura 5.8).

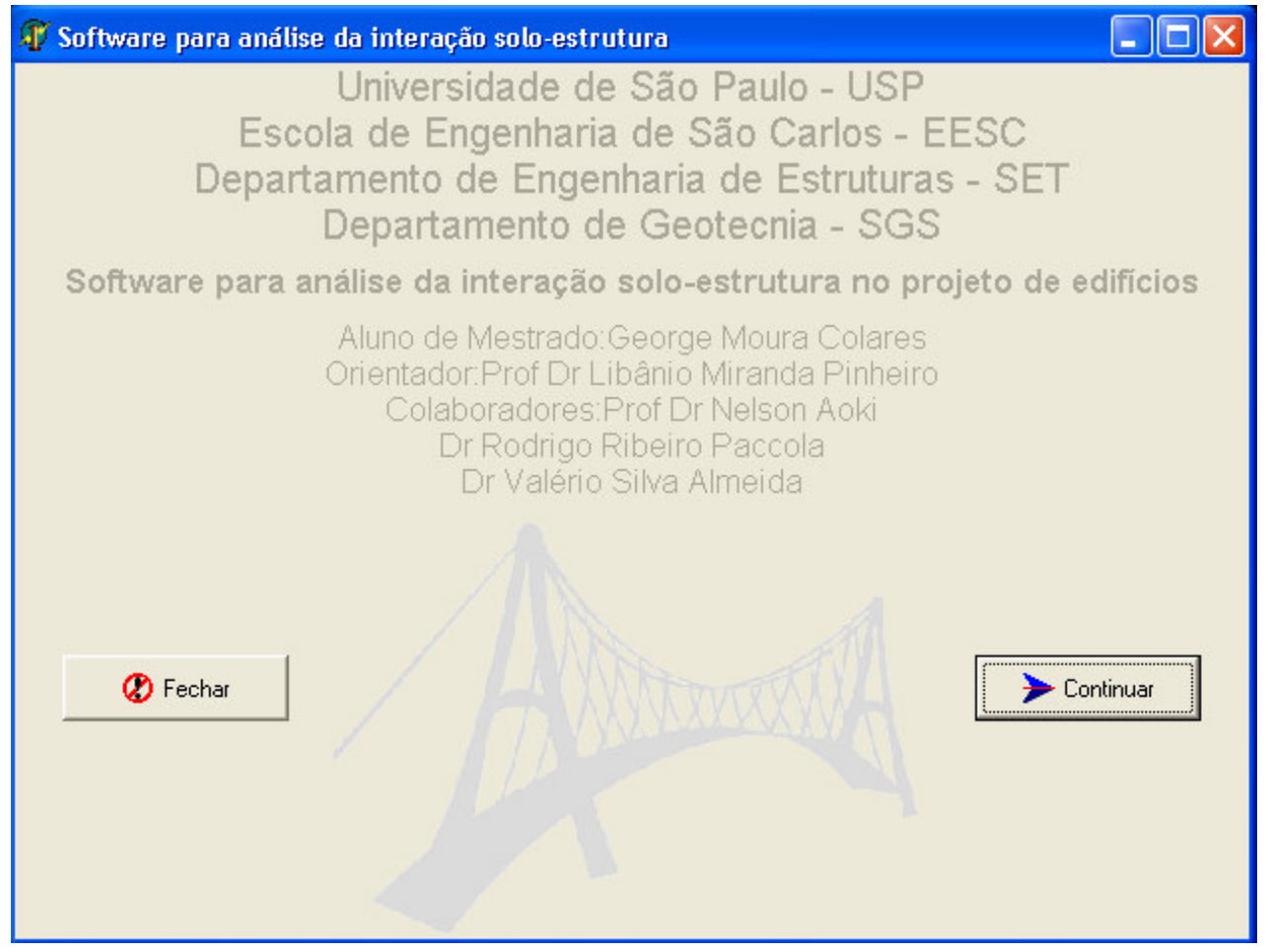

Figura 5.8 - Janela de apresentação da interface gráfica

Ao clicar em continuar, o usuário visualizará a janela edição dos dados de entrada necessários para o programa. $\mathrm{O}$ botão fechar finaliza o aplicativo.

\section{ISE}

Análise Help

Figura 5.9 - Janela de edição de dados de entrada 
Na barra de Menu, a opção Análise exibe as alternativas: Gerar Dados, Carregar Dados, Resultados e Sair. A página Help mostra, dividido em tópicos, o Manual de Utilização do programa.

A opção Gerar Dados carrega o formulário que deve ser preenchido para fornecer e montar o arquivo de dados.

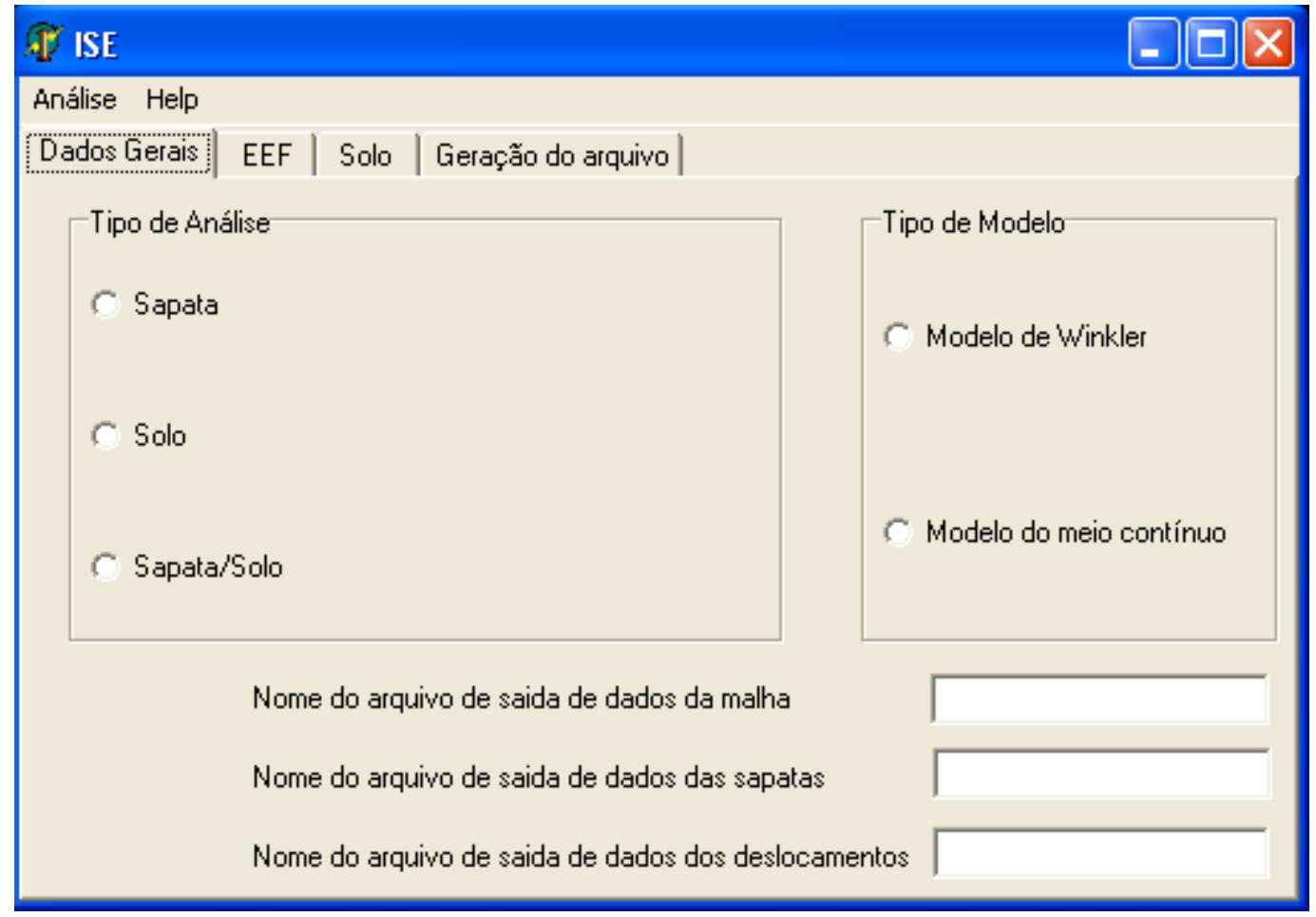

Figura 5.10 - Janela de exibição do formulário de dados gerais

Na Figura 5.10 observam-se as opções de Tipo de Análise e Tipo de Modelo que o usuário pode escolher. Na opção Sapata, dentro do grupo Tipo de Análise, é analisada apenas a estrutura, sem considerar a interação com o solo. Já o item Solo analisa somente o comportamento do solo quando submetido a um determinado carregamento. A interação solo-estrutura é estudada quando se escolhe a opção Sapata/Solo nos Tipos de Análises. Também na janela de Dados Gerais são atribuídos os nomes aos arquivos de saída da malha, das sapatas e dos deslocamentos. Assim, após o processamento é possível visualizar, separadamente, os arquivos de resultados. 
A página EEF refere-se aos dados dos elementos estruturais de fundação, como mostra a Figura 5.11.

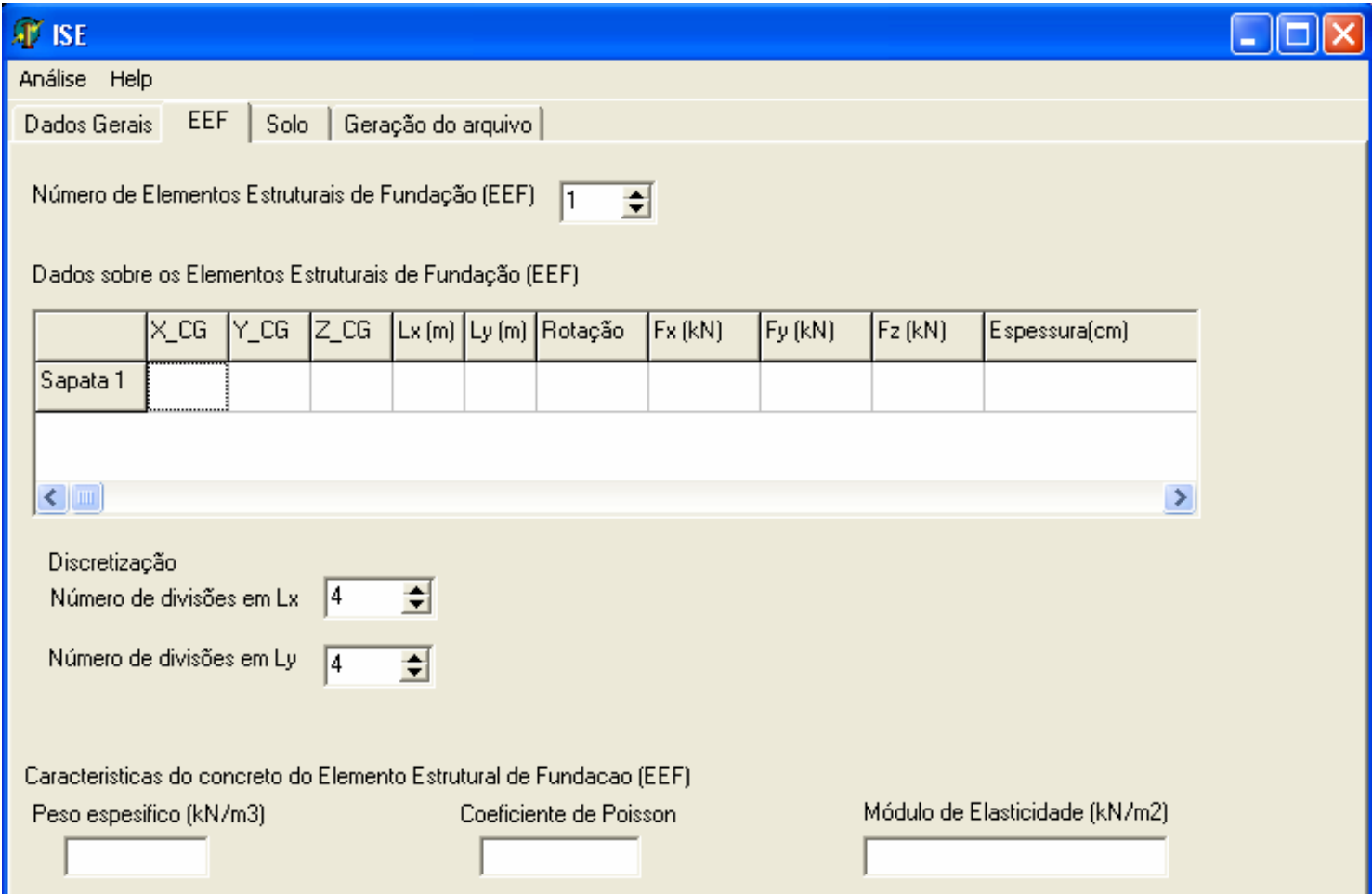

Figura 5.11 - Janela de preenchimento das informações dos elementos estruturais de fundação

A folha seguinte exibe os campos de informações do maciço de solos (Figura 5.12).

\section{AP ISE \\ Análise Help \\ Dados Gerais | EEF Solo |Geração do arquivo}

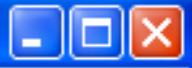

Número de camadas do maciço de solos

\begin{tabular}{|l|l|l|l|}
\hline & Módulo de Elasticidade & Coeficiente de Poisson & Profundidade \\
\hline Camada 1 & & & \\
\hline
\end{tabular}

Figura 5.12 - Informações do solo 


\section{6 - Exemplos de validação}

Os exemplos a seguir foram elaborados como forma de validar os resultados encontrados pelo programa desenvolvido.

\subsection{1- Placa rígida sobre meio semi-infinito}

Este problema encontra-se em PAIVA (1993) e trata-se de uma placa quadrada com $\mathrm{B}=12 \mathrm{~m}$, espessura $\mathrm{h}=0,1 \mathrm{~m}, \mathrm{E}_{\text {placa }}=1,1762122895.10^{12} \mathrm{kN} / \mathrm{m}^{2}$ e $\mathrm{v}_{\text {placa }}=0,15$. Para o solo, suposto meio semi-infinito, $E_{\text {solo }}=0,26 \cdot 10^{6} \mathrm{kN} / \mathrm{m}^{2}$ e $v_{\text {solo }}=0,3$. A placa é solicitada por uma força concentrada $P=1 \mathrm{~N}$ aplicada no centro, como mostra a Figura 5.13.

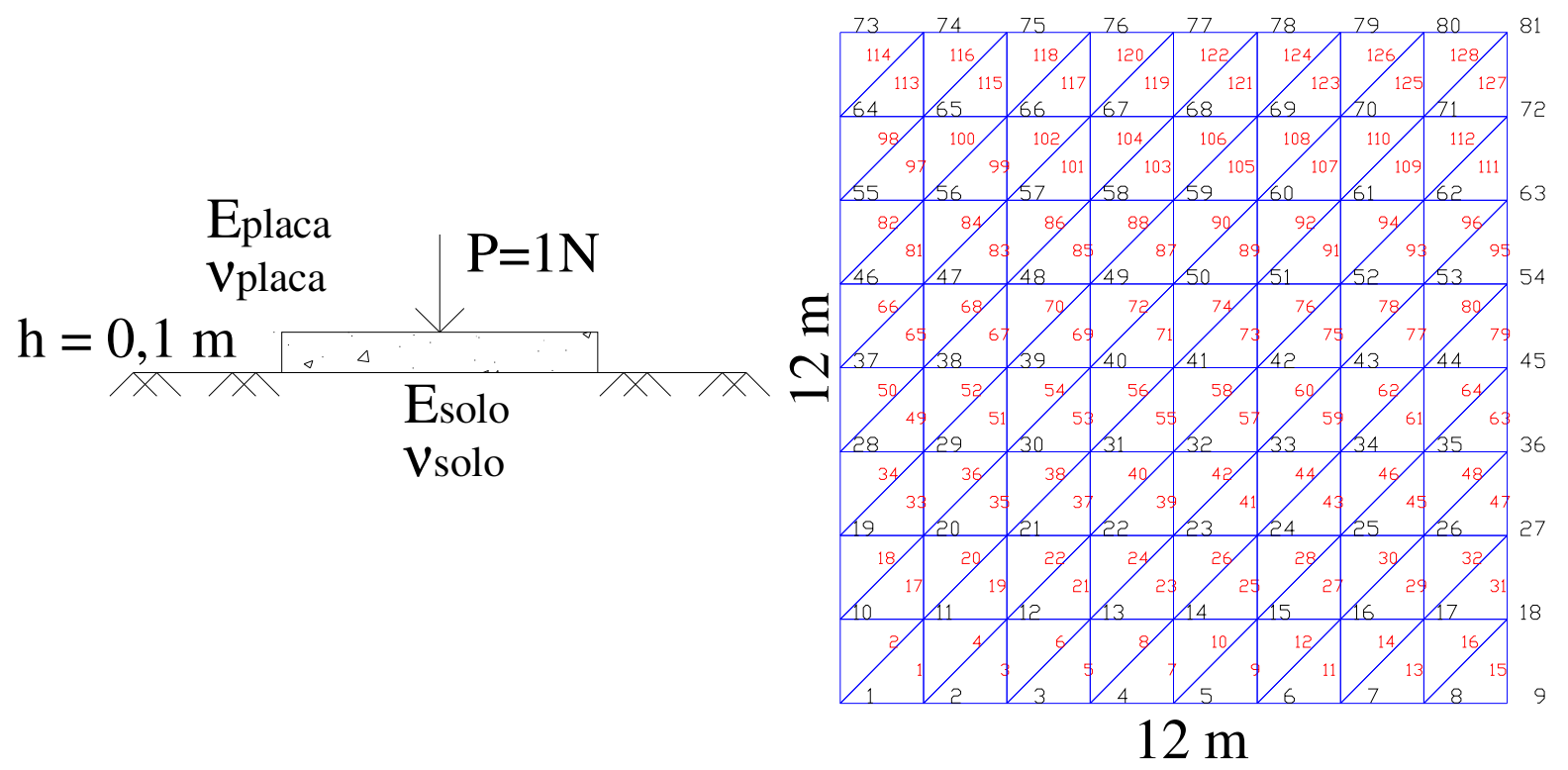

Figura 5.13 - Placa rígida com força concentrada aplicada no centro

FRASER \& WARDLE (1976) estabeleceram um parâmetro de rigidez relativa placa-solo $K_{p s}$ dado por:

$$
K_{p s}=\frac{4}{3} \frac{E_{p}\left(1-v_{p}^{2}\right) h^{3}}{E_{s}\left(1-v_{s}^{2}\right) B^{3}}
$$

Valores de $K_{p s}$ próximos de 0,5 representam um sistema de rigidez intermediária. Para valores de $K_{p s}$ próximos de zero e menores que 0,5 , o sistema placa-solo pode ser considerado flexível. Já para valores maiores de $K_{p s}$ que 0,5 , significa um caso rígido. 
Os deslocamentos verticais pouco variam ao longo do eixo médio da placa, o que confirma o comportamento de corpo rígido (Figura 5.14).

\section{Abscissa do eixo médio $(\mathrm{m})$}
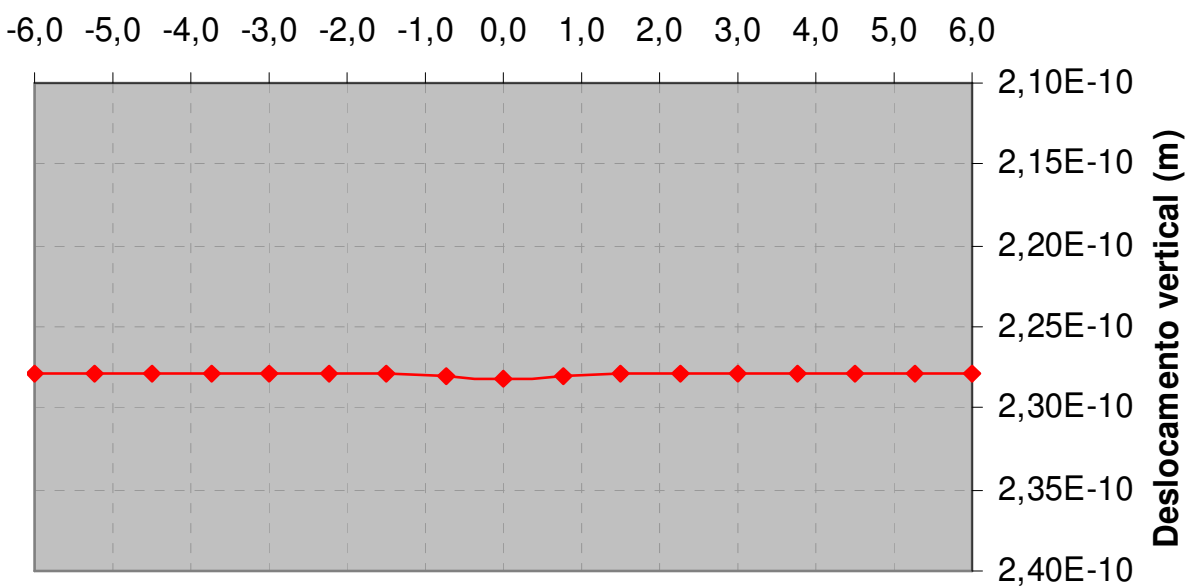

Figura 5.14 - Deslocamentos verticais ao longo do eixo médio para a malha da Figura 5.13

Refinando a malha de elementos finitos da placa, a resposta do programa apresenta um comportamento de convergência (Figura 5.15).

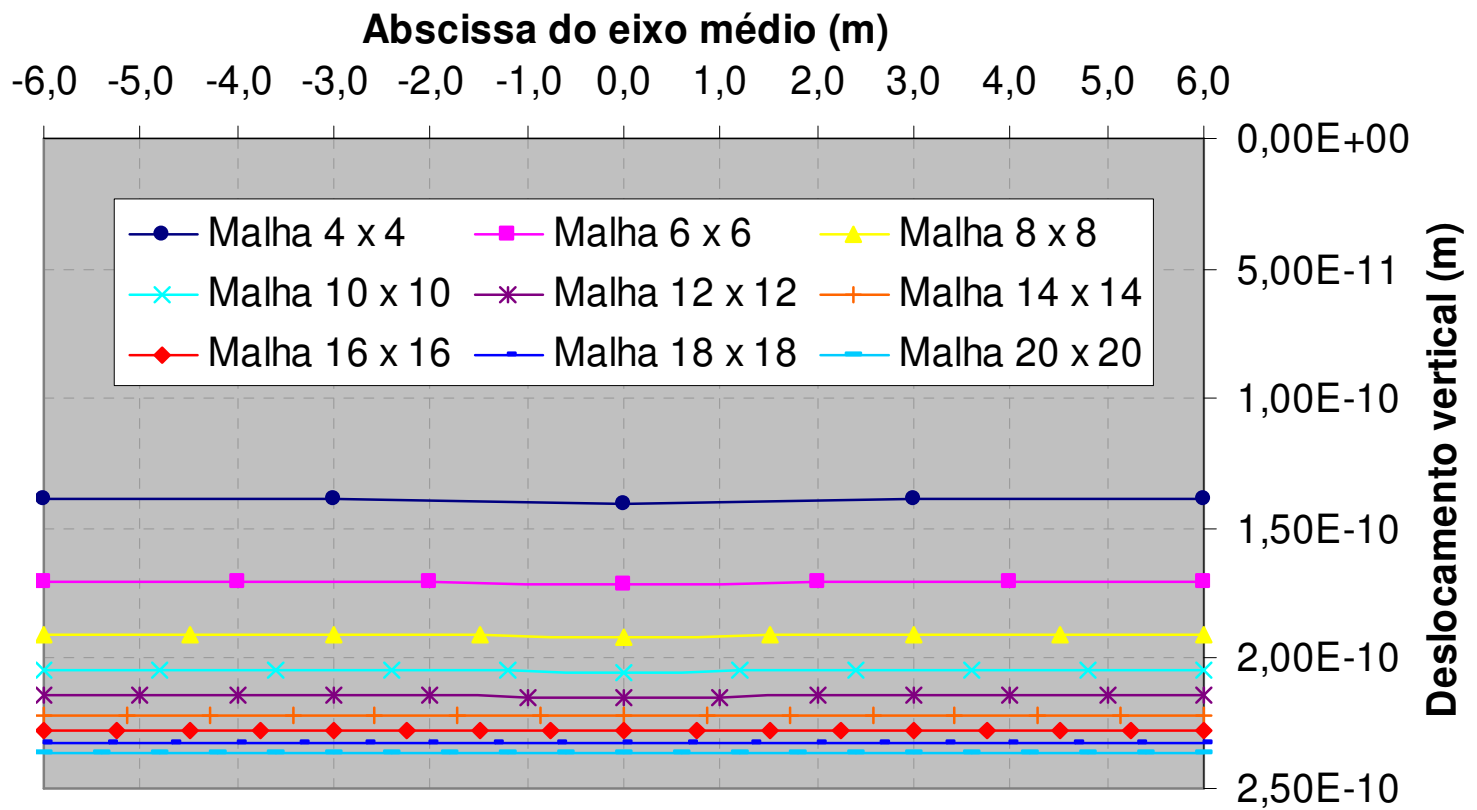

Figura 5.15 - Deslocamentos verticais ao longo do eixo médio para diferentes malhas 
PAIVA (1993) analisou o problema pelo acoplamento MEC-MEC. MENDONÇA (1997) utiliza o MEC para representar o solo e o MEF para simular a placa. MESSAFER \& COATES (1989) empregam o MEC para representar o solo e o MEF, com 100 elementos, para a placa. GORBUNOV-POSSADOV \& SEREBRJANI (1961) propõem soluções analíticas. ALMEIDA (2003b) representa o solo, segundo duas diferentes densidades de discretizacões, pelas equações de Kelvin.

\begin{tabular}{|c|c|}
\hline \multicolumn{2}{|c|}{ Tabela 5.1 - Valores de deslocamentos verticais do centro da placa rígida } \\
\hline Referência & w.10 $(\mathrm{m})$ \\
\hline PAIVA (1993) & 0,2160 \\
\hline MESSAFER \& COATES (1989) & 0,2400 \\
\hline GORBUNOV-POSSADOV \& SEREBRJANI $(1961)$ & 0,2600 \\
\hline MENDONÇA (1997) - HSM-MEC & 0,2122 \\
\hline MENDONÇA (1997) - DKT-MEC & 0,2124 \\
\hline ALMEIDA (2003b) - REDE 2 ( $\left.\mathrm{D}_{\text {solo }} / \mathrm{D}_{\text {placa }}=50\right)$ & 0,2599 \\
\hline ESTE TRABALHO - Malha $20 \times 20$ & 0,2534 \\
\hline
\end{tabular}

Ainda em PAIVA (1993) é estudada uma variação do exemplo anterior, modificando o módulo de elasticidade da placa $E_{\text {placa }}=9,7833076953.10^{10} \mathrm{kN} / \mathrm{m}^{2}$ e o coeficiente de Poisson $v_{\text {placa }}=0,3$. A placa passa a ser solicitada uniformemente por uma carga de $g=1 \mathrm{~N} / \mathrm{m}^{2}$. Os dados do solo são mantidos (Figura 5.16).

\section{Abscissa do eixo médio $(\mathrm{m})$}
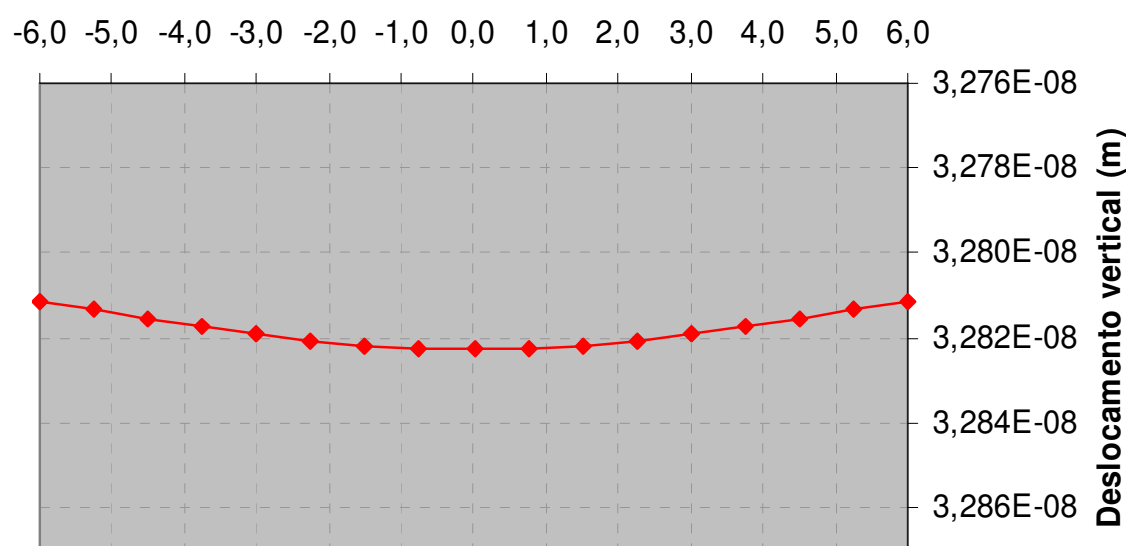

Figura 5.16 - Deslocamentos verticais ao longo do eixo médio da placa de rigidez intermediária 
A deformada de deslocamentos ao longo do eixo médio da placa mostra-se mais acentuada do que a deformada da placa rígida. A Tabela 5.2 mostra os valores para o deslocamento no centro da placa, segundo algumas referências.

Tabela 5.2 - Valores de deslocamentos verticais do centro da placa de rigidez intermediária

\begin{tabular}{|c|c|}
\hline Referência & w.10 $(\mathrm{m})$ \\
\hline PAIVA (1993) & 0,3262 \\
\hline MESSAFER \& COATES (1989) & 0,3632 \\
\hline ALMEIDA (2003b) - REDE 1 & 0,3851 \\
\hline ALMEIDA (2003b) - REDE 2 & 0,3786 \\
\hline ESTE TRABALHO & 0,3410 \\
\hline
\end{tabular}

A resposta do programa para o deslocamento vertical do centro da placa exibe uma tendência de convergência com o aumento da discretizacão na rede de elementos finitos (Figura 5.17).

$\rightarrow$ Malha $4 \times 4 \rightarrow$ Malha $6 \times 6-$ Malha $8 \times 8$
$-\times$ Malha $10 \times 10 \rightarrow$ Malha $12 \times 12 \multimap$ Malha $14 \times 14$
$\rightarrow$ Malha $16 \times 16-$ Malha $18 \times 18-$ Malha $20 \times 20$

\section{Abscissa do eixo médio $(\mathrm{m})$}
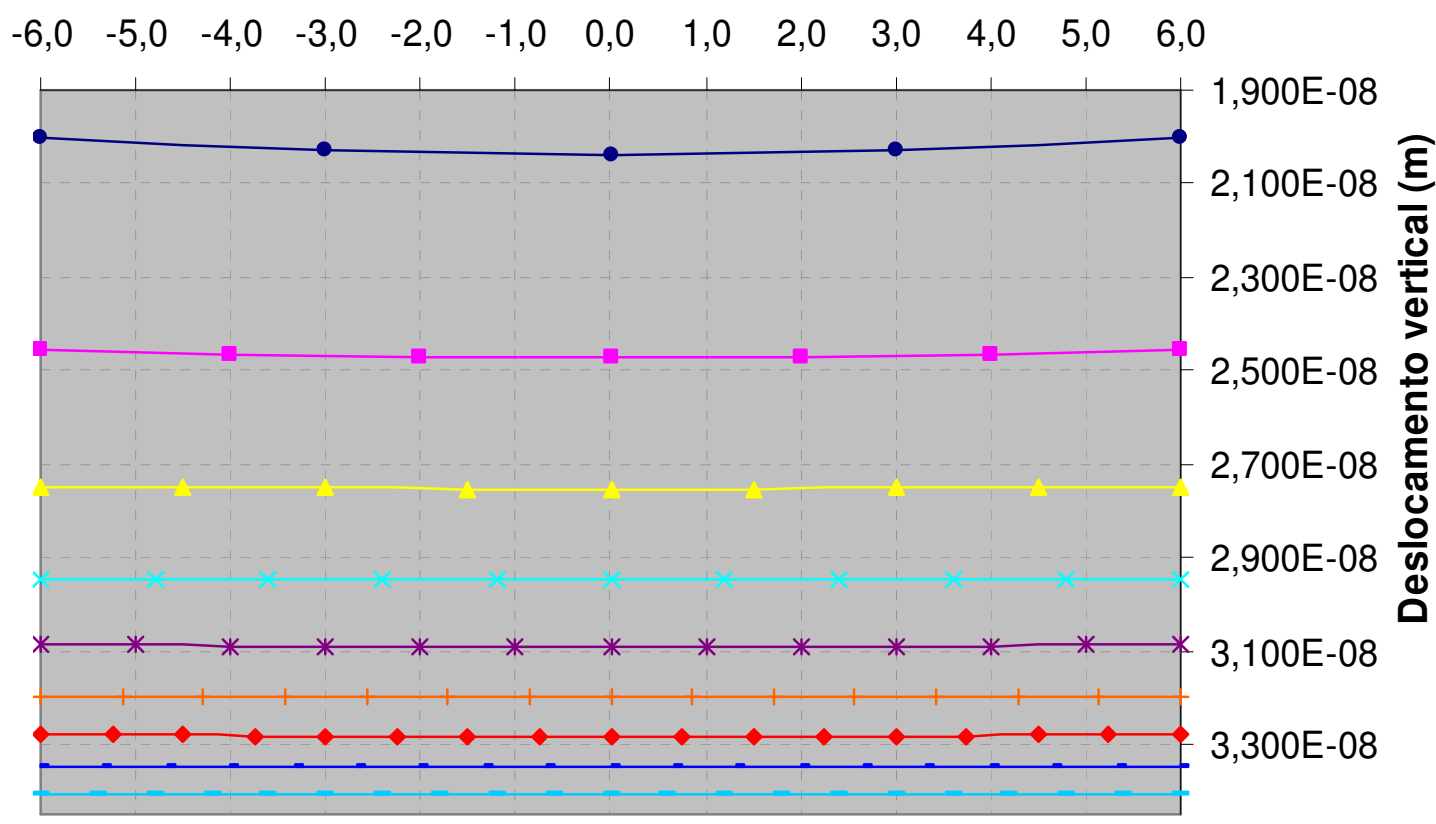

Figura 5.17 - Deformada de deslocamentos ao longo do eixo médio para diferentes malhas 
Outra variação do exemplo da placa rígida, também apresentada em PAIVA (1993), é o caso de uma placa flexível, submetida a uma força concentrada $(P=1 \mathrm{~N})$ aplicada no centro, com $E_{\text {placa }}=1,63827088358.10^{10} \mathrm{kN} / \mathrm{m}^{2}$ e $v_{\text {placa }}=0,15$. O solo é representado por um meio semi-infinito, com os mesmos valores do exemplo anterior, para módulo de elasticidade e coeficiente de Poisson.

\section{Abscissa do eixo médio $(\mathrm{m})$}
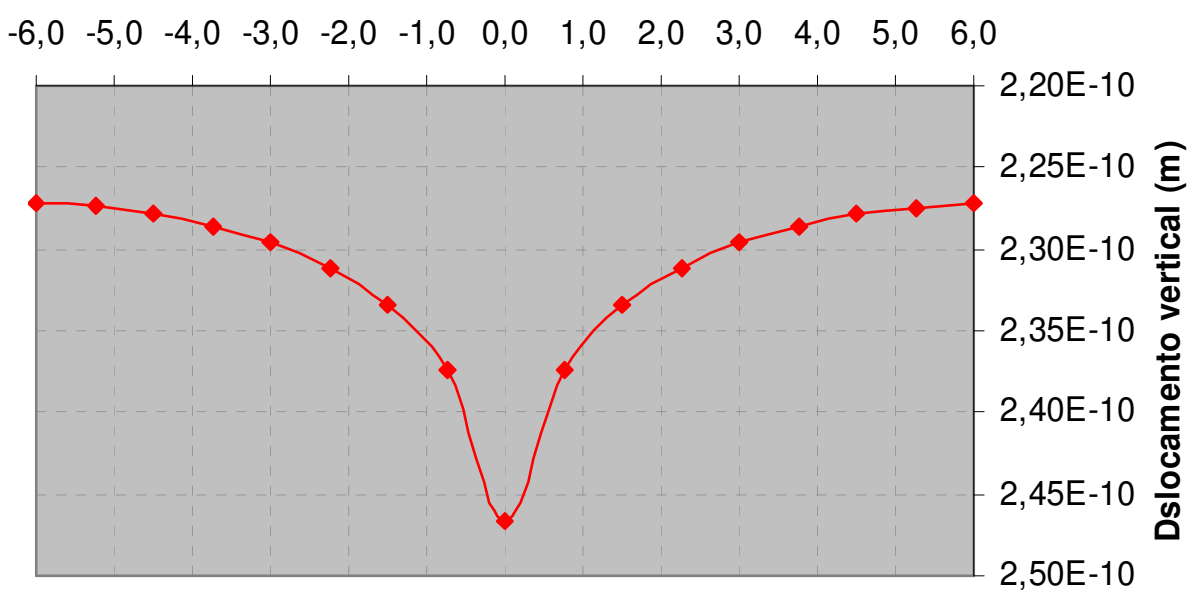

Figura 5.18 - Deslocamentos verticais ao longo do eixo médio para a malha da Figura 5.13

A diferença entre os valores da Tabela 5.3 pode ser explicada pelo fato de que, tanto em PAIVA (1993) quanto em MESSAFER \& COATES (1989), a formulação desenvolvida está baseada no elemento de placa, ou seja, deslocamentos $w$ apenas na direção $z$. Portanto, a formulação desenvolvida, baseada no elemento finito plano de casca, faz com que a deformada de deslocamentos da estrutura analisada seja bem mais suave, ou seja, os deslocamentos tornam-se menores, em virtude das restrições nas direções $x$ e $y$. Além disso, o módulo de elasticidade do solo $\left(E_{\text {solo }}=260 \mathrm{MPa}\right)$ é exageradamente grande em relação ao que se encontra na prática, pois para esse caso seria necessário um valor de $\mathrm{N}_{\mathrm{SPT}}$ da ordem de 100 .

\begin{tabular}{|c|c|}
\hline \multicolumn{2}{|c|}{ Tabela 5.3 - Valores de deslocamentos verticais do centro da placa flexível } \\
\hline Referência & w.10 $(\mathrm{m})$ \\
\hline PAIVA (1993) & 0,575 \\
\hline MESSAFER \& COATES (1989) & 0,575 \\
\hline ESTE TRABALHO - Malha 4 x 4 & 0,321 \\
\hline
\end{tabular}


Variando a malha de elementos finitos, a deformada de deslocamentos assume diferentes formas, como mostra a Figura 5.19.

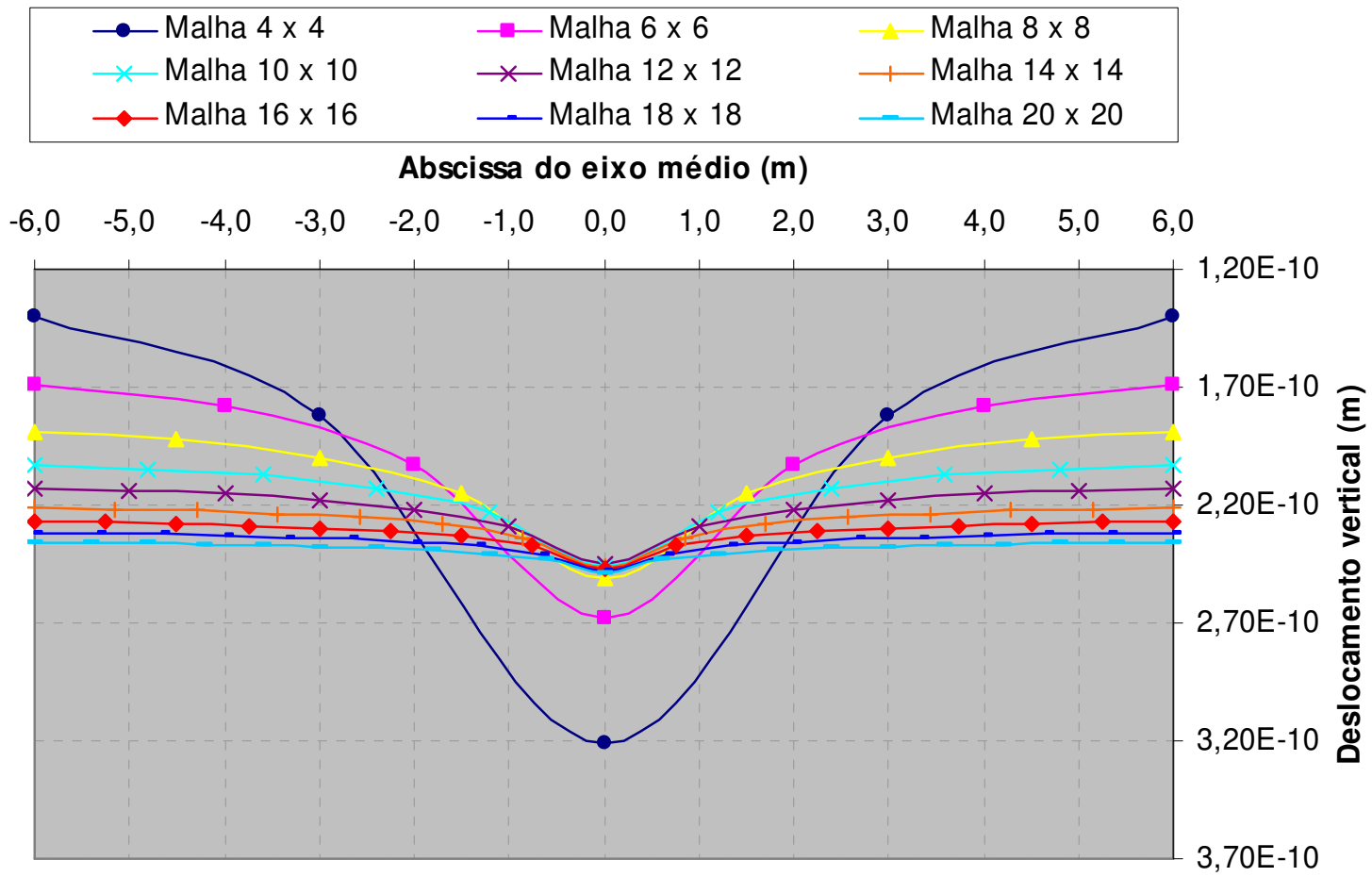

Figura 5.19 - Deformada de deslocamentos ao longo do eixo médio, para diferentes malhas

\subsection{2- Placa flexível sobre meio semi-infinito}

WANG et al (2001) analisaram diversos casos do mecanismo de interação placasolo variando, dentre outros fatores, o tipo de carregamento, a rigidez relativa estrutura-solo e a malha de discretização.

Um dos problemas apresentados é o caso de uma placa quadrada, cuja relação $\frac{h}{B}$ entre a espessura $(h)$ e o lado $(B)$ vale 0,1 , analisada para os valores de rigidez relativa placa-solo $K_{p s}=0,419$ (sistema rígido), $K_{p s}=0,0415$ (sistema com rigidez intermediária), $K_{p s}=0,0041$ (sistema flexível).

Os deslocamentos ao longo do eixo médio da placa são dados pela Eq.(5.17):

$$
w=\frac{P\left(1-v_{s}{ }^{2}\right)}{E_{s} B} I_{w}
$$


$P$ é a magnitude da força aplica, $v_{s}$ é o coeficiente de Poisson do solo, $E_{s}$ é o módulo de elasticidade do solo e $I_{w}$ é o coeficiente ponderador dos deslocamentos que depende do valor de $\frac{x}{L}$ e de $K_{p s}$ (Figura 5.20).

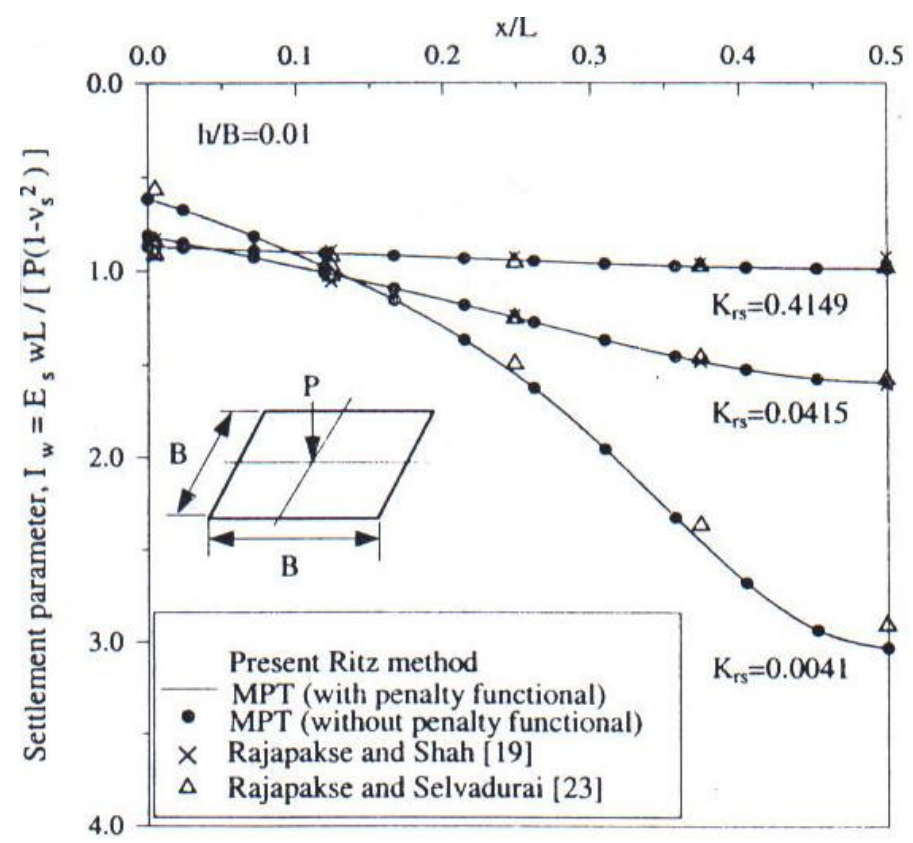

Figura 5.20 - Distribuição de deslocamentos WANG et al (2001)

A Tabela 5.4, retirada de WANG et al (2001), mostra, para $\frac{x}{L}=0,5$, os valores de $I_{w}$ para diferentes discretizações de acordo com os correspondentes $K_{p s}$.

\begin{tabular}{|c|c|c|c|}
\hline \multicolumn{4}{|c|}{ Tabela 5.4 - Coeficientes ponderadores dos deslocamentos } \\
\hline \multirow{2}{*}{$K_{p s}$} & \multicolumn{3}{|c|}{ Coeficiente de ponderação } \\
\cline { 2 - 4 } & Malha do solo 11 x 11 & Malha do solo 15 x 15 & Malha do solo 21 x 21 \\
\hline 0,0041 & 2,991 & 2,997 & 2,968 \\
\hline 0,0415 & 1,580 & 1,578 & 1,586 \\
\hline 0,4149 & 0,996 & 0,992 & 0,990 \\
\hline
\end{tabular}

Para $K_{p s}=0,0041, E_{s}=40 \mathrm{MPa}, v_{s}=v_{p}=0,3, B=1 \mathrm{~m}$ e $P=1 \mathrm{~N}$, tem-se:

$$
K_{p s}=0,0041 \Rightarrow 0,0041=\frac{4}{3} \frac{E_{p}\left(1-0,3^{2}\right)(0,01)^{3}}{40\left(1-0,3^{2}\right)(1)^{3}} \Rightarrow E_{p}=123000 \mathrm{MPa}
$$

Voltando na Eq.(5.17) e substituindo todos os parâmetros encontrados é possível determinar os deslocamentos do centro da placa para cada malha. 
Tabela 5.5 - Deslocamento no centro da placa para as malhas analisadas

\begin{tabular}{|c|c|c|c|}
\hline & Malha 11 x 11 & Malha 15 x 15 & Malha 21 x 21 \\
\hline $\mathrm{w} \cdot 10^{8}(\mathrm{~m})$ & 6,805 & 6,818 & 6,752 \\
\hline
\end{tabular}

Para este caso, o programa desenvolvido apresenta as respostas mostradas na Figura 5.21 .

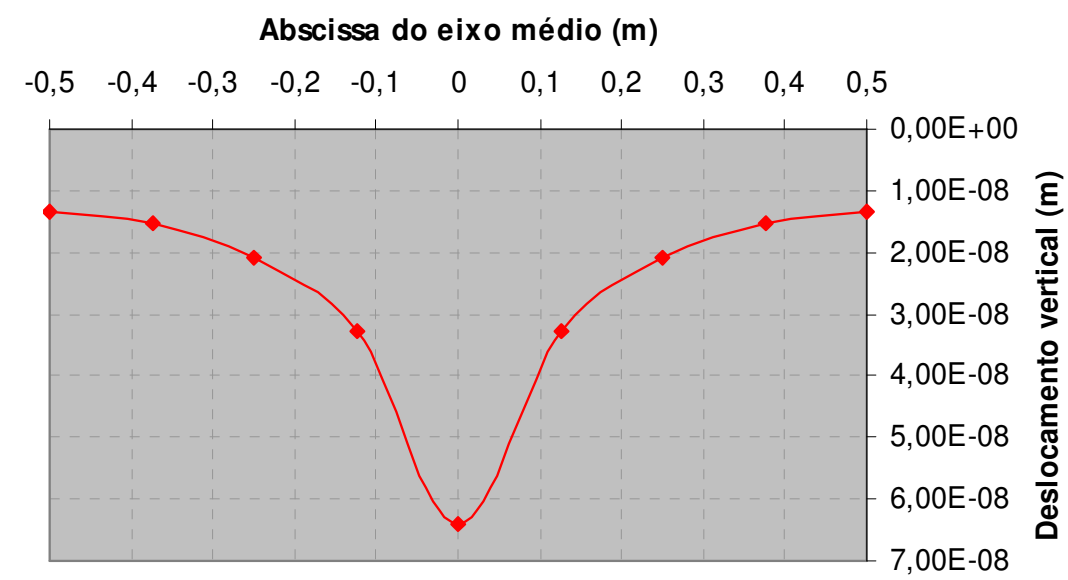

Figura 5.21 - Deslocamentos no centro da placa

Analisando o problema para diferentes discretizações, as respostas do programa são mostradas na Figura 5.22.

\section{Abscissa do eixo médio $(\mathrm{m})$}

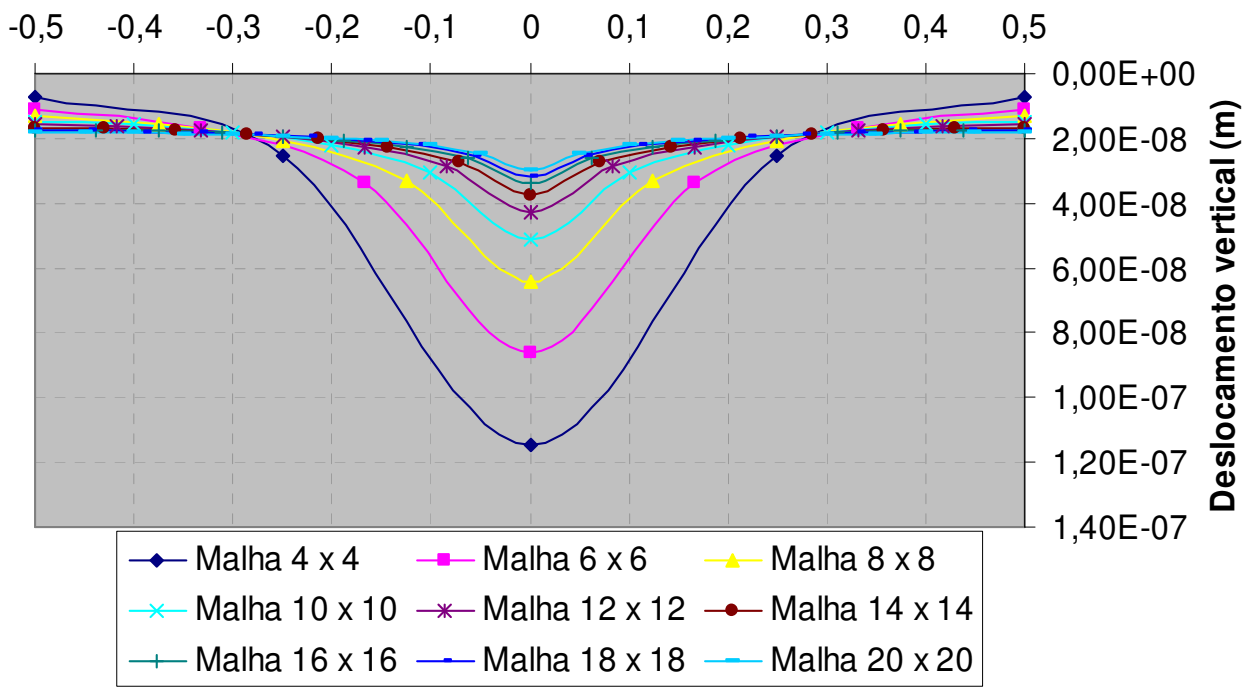

Figura 5.22 - Deformada de deslocamentos para várias discretizações 
A aparente discrepância entre os valores apresentados por WANG et al (2001) é conseqüência da diferente consideração para o comportamento do elemento estrutural de fundação. WANG et al (2001) consideram a estrutura como placa, só havendo, portanto, restrições de deslocamento na direção do carregamento. Já a formulação desenvolvida, como já foi dito, analisa a estrutura como elemento de casca com curvatura nula.

A Figura 5.22 mostra que o aumento do número de nós na malha de elementos finitos conduz a deslocamentos significativamente menores, principalmente no centro da placa. Isto se deve ao fato de que, como o elemento estrutural de fundação direta foi simulado como elemento finito de casca plano, as restrições a deslocamento nas direções $x$ e $y$ tornam a estrutura mais rígida, absorvendo parte da energia de deformação e impedindo que a mesma se comporte como se houvesse restrições apenas na direção vertical. E quando a discretização torna-se bastante refinada esse efeito fica ainda mais relevante.

\subsection{3- Placa com diferentes espessuras carregada uniformemente}

Este exemplo, estudado por PACCOLA (2004) e ALMEIDA (2003a), refere-se a uma placa quadrada com $L=20 \mathrm{~m}$, apoiada sobre meio semi-infinito e sujeita a um carregamento uniformemente distribuído em toda área $q=300 \mathrm{kN} / \mathrm{m}^{2}$. O sistema placa-solo é analisado para diferentes espessuras da placa, desde 0 (simulação de carregamento aplicado diretamente no solo) até $5 \mathrm{~m}$.

As informações da placa e do solo estão listadas na Tabela 5.6.

\begin{tabular}{|c|c|}
\hline \multicolumn{2}{|c|}{ Tabela 5.6 - Informações sobre a placa e sobre o solo } \\
\hline Placa & Solo \\
\hline$E=2,1.10^{4} \mathrm{MPa}$ & $E=2,1.10^{3} \mathrm{MPa}$ \\
\hline$v=0,25$ & $v=0,13$ \\
\hline
\end{tabular}

A Figura 5.23 mostra o problema a analisado por PACCOLA (2004), que emprega a formulação de Reissner para placas grossas, e ALMEIDA (2003a), que utiliza a teoria de placas de Kirchhoff. 

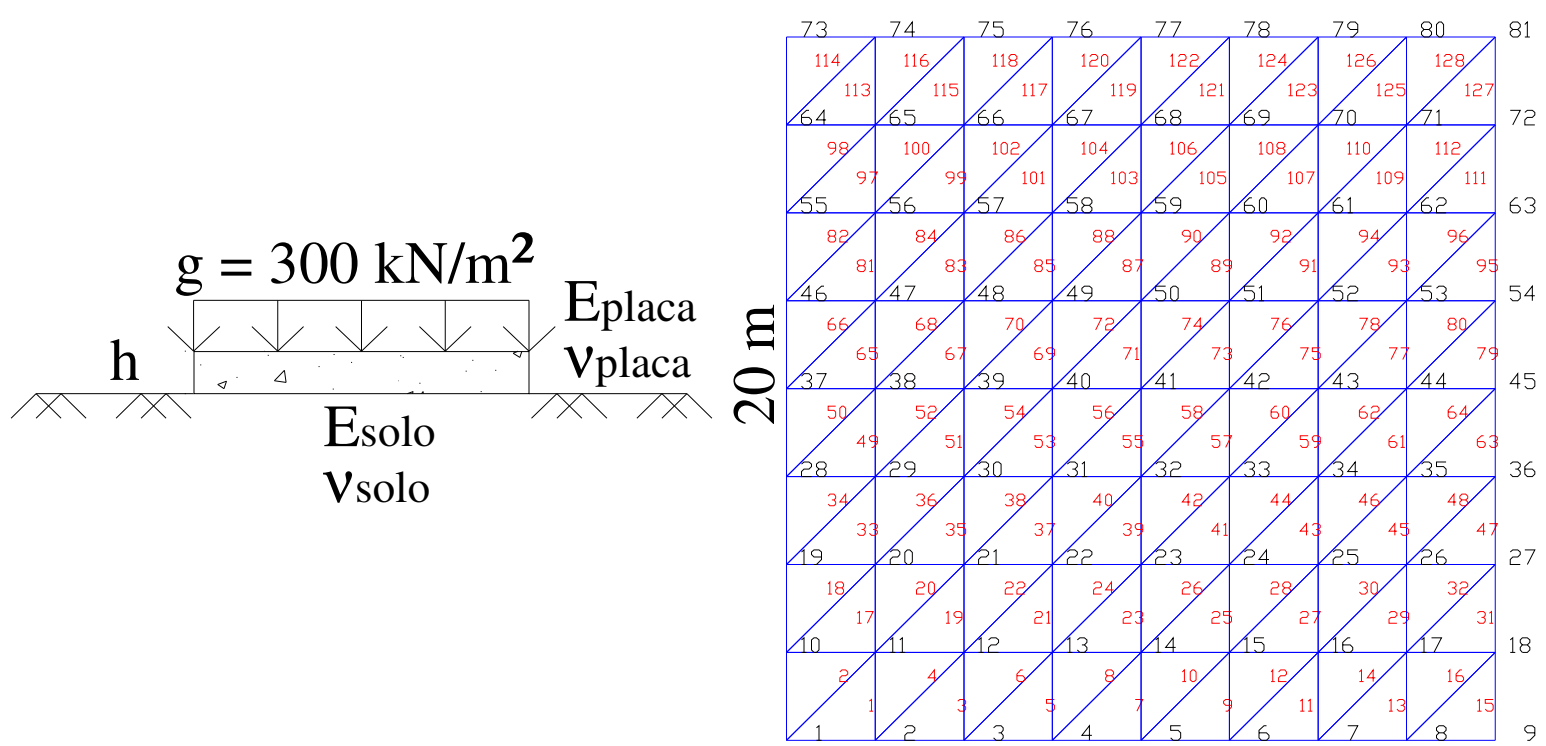

$20 \mathrm{~m}$

Figura 5.23 - Placa quadrada submetida a carregamento uniformemente distribuído

A Tabela 5.7 exibe os resultados dos deslocamentos no centro, para as diferentes espessuras da placa.

\begin{tabular}{|c|c|c|c|}
\hline \multicolumn{4}{|c|}{ Tabela 5.7 - Deslocamento vertical do centro da placa para as diferentes espessuras } \\
\hline $\mathrm{h}(\mathrm{m})$ & ALMEIDA (2003a) & PACCOLA (2004) & ESTE TRABALHO \\
\hline 5,0 & 2,4230 & 2,5158 & 2,4501 \\
\hline 2,5 & 2,7361 & 2,7945 & 2,4457 \\
\hline 1,5 & 2,8464 & 2,8744 & 2,4444 \\
\hline 0,5 & 2,9286 & 2,9265 & 2,625 \\
\hline 0,0 & 3,1202 & 3,1435 & 3,1075 \\
\hline
\end{tabular}

A diferença entre as respostas está ligada à discretização e à aproximação (grau da função de forma) de elementos finitos utilizadas. PACCOLA (2004) realiza o acoplamento MEC-MEF, entre os 3 graus de liberdade dos nós de contorno com a placa, para analisar o problema usando $6 \times 6$ divisões de elementos triangulares com aproximação cúbica de variáveis para representação da placa e 18 x 18 divisões de elementos triangulares com aproximação linear para representação do solo. 


\subsection{4- Bloco sobre meio semi-infinito}

Em RIBEIRO (2005) é analisado um bloco quadrado sem estacas e apoiado no solo, admitido, primeiramente, como meio semi-infinito.

O bloco tem dimensões $L=5 \mathrm{~m}$ e $h=1,25 \mathrm{~m}$, módulo de elasticidade $E_{\text {bloco }}=21000$ $\mathrm{MPa}$, coeficiente de Poisson $v_{\text {bloco }}=0,3$. Para o solo, $E_{\text {solo }}=40 \mathrm{MPa}, v_{\text {solo }}=0,3 \mathrm{Um}$ carregamento uniformemente distribuído é aplicado em toda área do bloco (Figura 5.24).

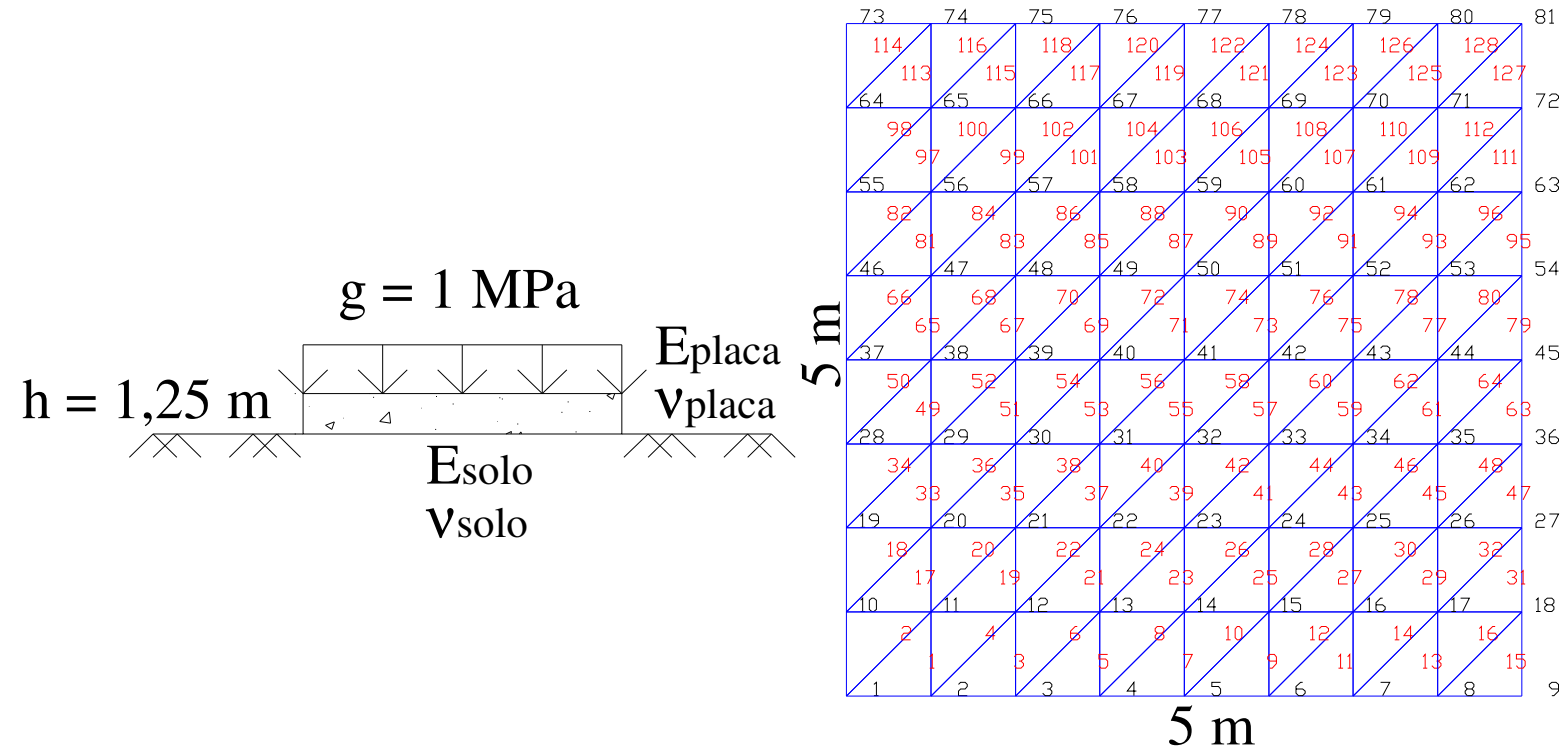

Figura 5.24 - Bloco sujeito a carregamento uniformemente distribuído

Na Figura 5.25, que mostra a deformada de deslocamentos ao longo do eixo médio do bloco, observa-se, como era de se esperar, o comportamento de corpo rígido, isto é, os deslocamentos são praticamente constantes para todos os pontos do bloco.

\section{Abscissa do eixo médio $(\mathrm{m})$}

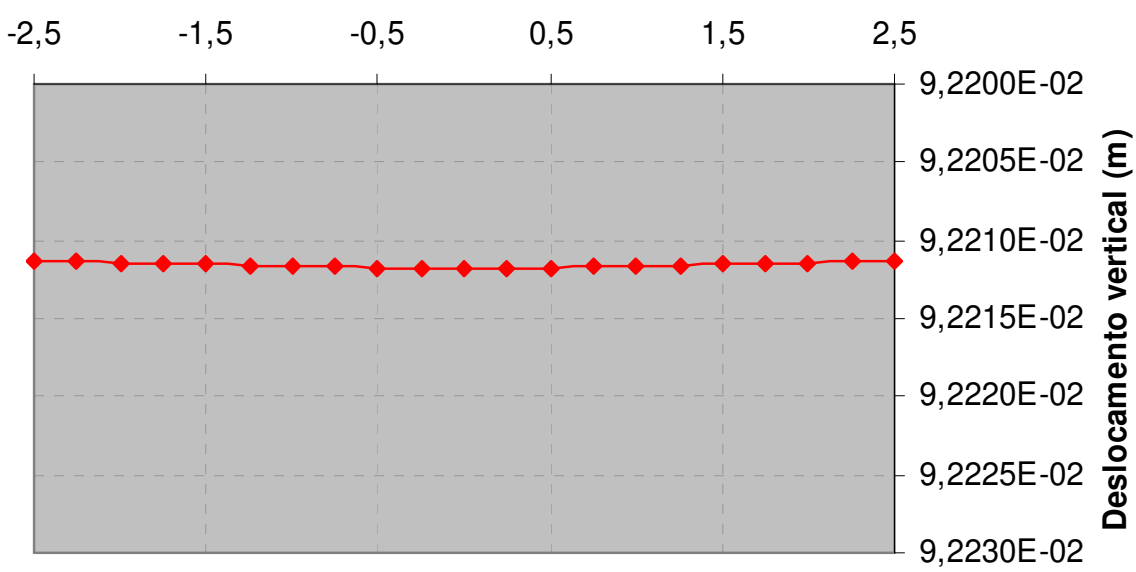

Figura 5.25 - Deslocamento vertical ao longo do eixo médio do bloco 
RIBEIRO (2005) estudou o problema modelando o bloco com o MEC tridimensional. Além disso, RIBEIRO (2005) utilizou o software Ansys 8.4 para avaliar a resposta da ferramenta desenvolvida. ALMEIDA (2003b) analisou o problema modelando, da mesma forma que no presente trabalho, o bloco pelo MEF com elementos finitos de casca planos. No entanto, diferentemente da formulação aqui desenvolvida, ALMEIDA (2003b) utiliza as equações de Kelvin para representar o solo. A Tabela 5.8 mostra os resultados obtidos nas análises.

\begin{tabular}{|c|c|c|c|}
\hline \multicolumn{4}{|c|}{ Tabela 5.8 - Deslocamento vertical do centro do bloco } \\
\hline RIBEIRO (2005) & ALMEIDA (2003b) & Ansys 8.4 & ESTE TRABALHO \\
\hline $9,26 \mathrm{~cm}$ & $9,39 \mathrm{~cm}$ & $8,84 \mathrm{~cm}$ & $9,22 \mathrm{~cm}$ \\
\hline
\end{tabular}

A diferença percentual entre as respostas, apresentada na Tabela 5.9, evidencia que a formulação desenvolvida está, de fato, coerente.

\begin{tabular}{|c|c|c|c|}
\hline \multicolumn{4}{|c|}{ Tabela 5.9 - Diferença entre as respostas } \\
\hline & ALMEIDA (2003b) & RIBEIRO (2005) & Ansys 8.4 \\
\hline ESTE TRABALHO & $1,84 \%$ & $0,04 \%$ & $4,29 \%$ \\
\hline
\end{tabular}

A Figura 5.26 mostra a convergência da resposta do programa quando se faz um refinamento da malha de elementos finitos.

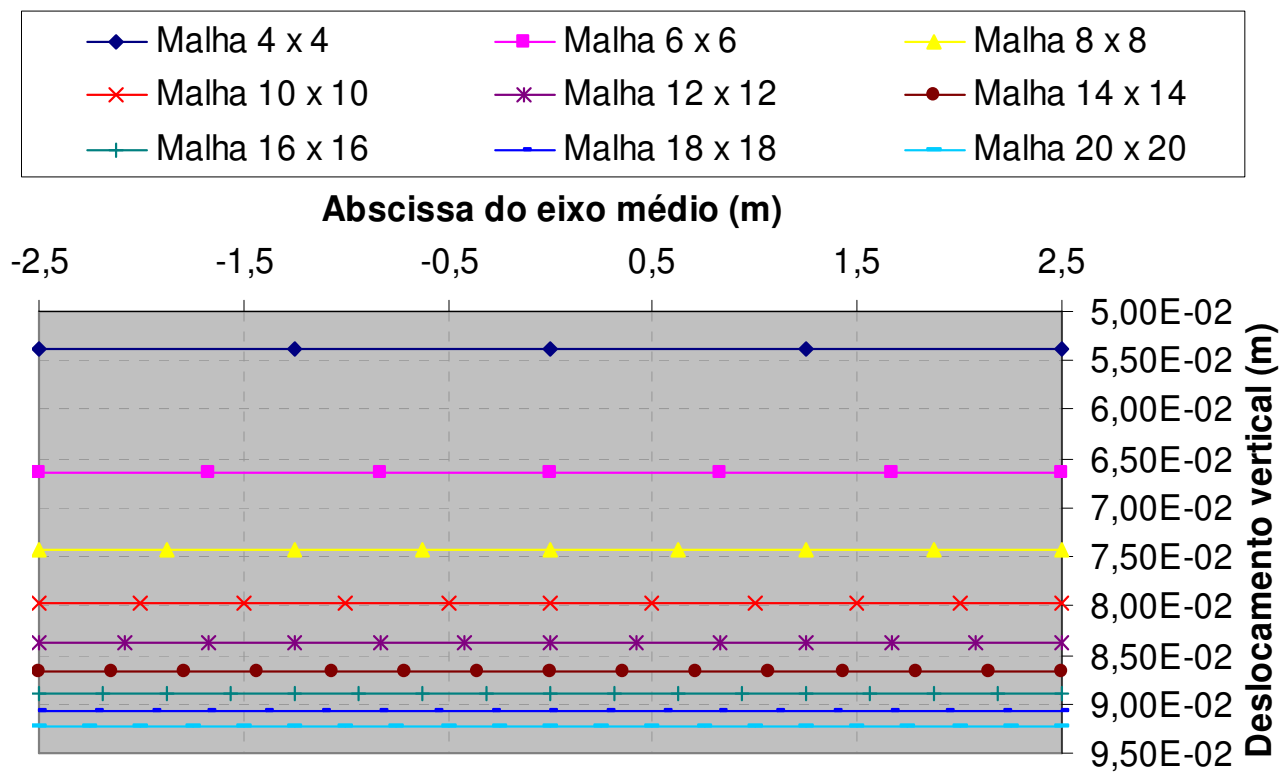

Figura 5.26 - Deformada de deslocamentos ao longo do eixo médio para diferentes discretizações 


\subsection{5- Bloco sobre camada finita de solo}

Também em RIBEIRO (2005) é estudada a influência da superfície de deslocamentos nulos, nos deslocamentos do bloco do exemplo anterior (Figura 5.27).

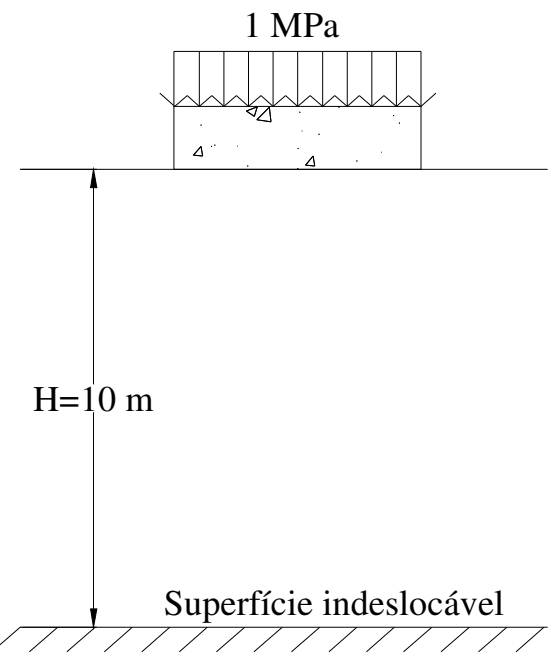

Figura 5.27 - Bloco sobre camada apoiada em superfície de deslocamentos nulos

A Tabela 5.10 mostra as respostas encontradas por RIBEIRO (2005) e um modelo criado no Ansys 8.4.

\begin{tabular}{|c|c|c|c|}
\hline \multicolumn{4}{|c|}{ Tabela 5.10 - Deslocamentos no centro do bloco } \\
\hline & RIBEIRO (2005) & Ansys 8.4 & ESTE TRABALHO \\
\hline $\mathrm{w}(\mathrm{cm})$ & 6,98 & 6,81 & 7,19 \\
\hline
\end{tabular}

Em relação ao exemplo do bloco sobre meio semi-infinito, a presença da camada indeslocável reduziu a resposta do programa em 22\%. Na formulação de RIBEIRO (2005) essa diferença foi de aproximadamente $24,6 \%$, ou seja, a presença da camada de deslocamentos nulos reduziu os deslocamentos de $9,26 \mathrm{~cm}$ para $6,98 \mathrm{~cm}$. Já para o modelo criado no Ansys 8.4 por RIBEIRO (2005), os novos deslocamentos são da ordem de 6,81 $\mathrm{cm}$, isto é, 29,8\% menores que os deslocamentos para o caso do bloco sobre meio semiinfinito (Tabela 5.11).

\begin{tabular}{|c|c|c|}
\hline \multicolumn{3}{|c|}{ Tabela 5.11 - Diferença das repostas } \\
\hline & RIBEIRO (2005) & Ansys 8.4 \\
\hline ESTE TRABALHO & $3,0 \%$ & $5,6 \%$ \\
\hline
\end{tabular}


A Figura 5.28 possibilita melhor visualizar o efeito da camada indeslocável sobre a deformada de deslocamentos.

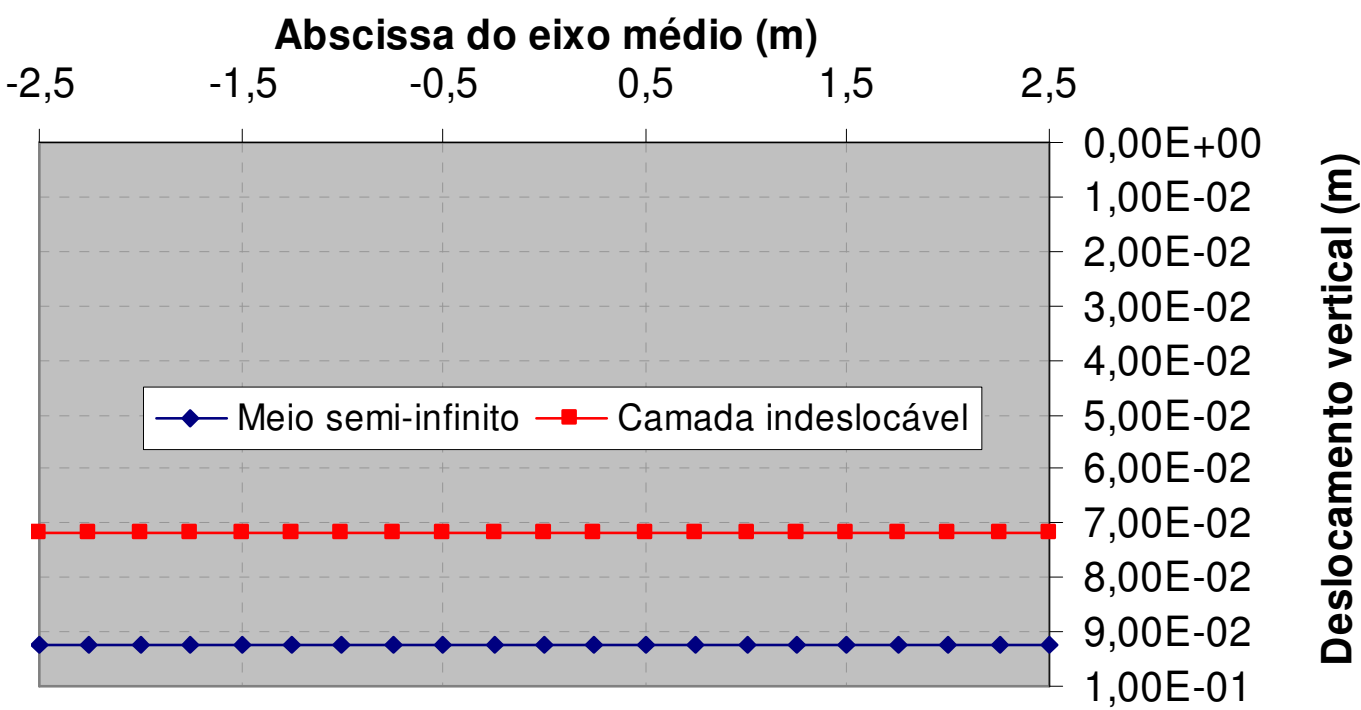

Figura 5.28 - Influência da camada indeslocável nos deslocamentos do bloco

\subsection{6- Blocos apoiados sobre meio semi-infinito}

Neste exemplo, elaborado por RIBEIRO (2005), verifica-se a interação de dois blocos afastados de certa distância entre si. Os dados, tanto para os blocos quanto para o solo, são mantidos os mesmos do exemplo 5.6.4-, e a disposição desses blocos sobre a superfície do terreno está mostrada na Figura 5.29.
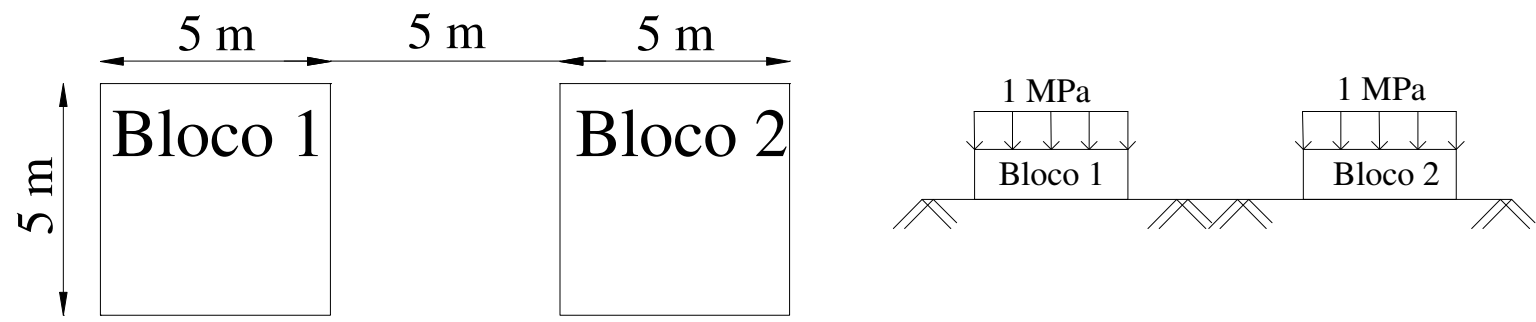

Figura 5.29 - Disposição dos blocos na superfície do solo

A Figura 5.30 mostra a deformada de deslocamentos do eixo médio dos blocos. É importante observar a inclinação dos blocos para o centro do sistema, fruto da influência do carregamento de um bloco sobre o outro, o que translada o deslocamento máximo. 


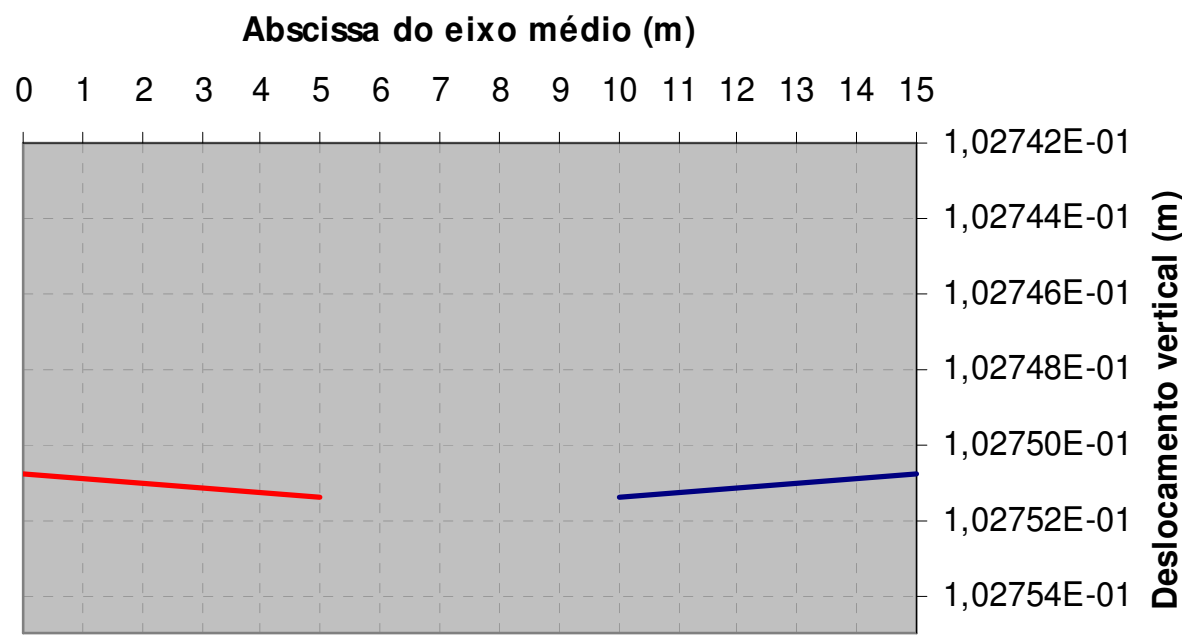

Figura 5.30 - Deformada de deslocamentos dos blocos

A Tabela 5.12 exibe a comparação entre os valores, segundo RIBEIRO (2005) e a formulação desenvolvida, de deslocamento máximo do bloco.

\begin{tabular}{|c|c|c|c|}
\hline \multicolumn{4}{|c|}{ Tabela 5.12 - Deslocamentos máximos } \\
\hline & RIBEIRO (2005) & ESTE TRABALHO & Diferença (\%) \\
\hline $\mathrm{w}(\mathrm{cm})$ & 9,88 & 10,275 & 3,99 \\
\hline
\end{tabular}




\section{6 - EXEMPLOS}

Visando comprovar, de maneira prática e real, a relevância do trabalho a ser realizado, a seguir serão mostrados casos simples, onde a consideração da interação soloestrutura será claramente evidenciada.

\section{1 - Edificação sobre blocos}

Em RIBEIRO (2005) é analisada uma edificação de um pavimento apoiada em quatro elementos estruturais de fundação do tipo bloco (Figura 6.1).

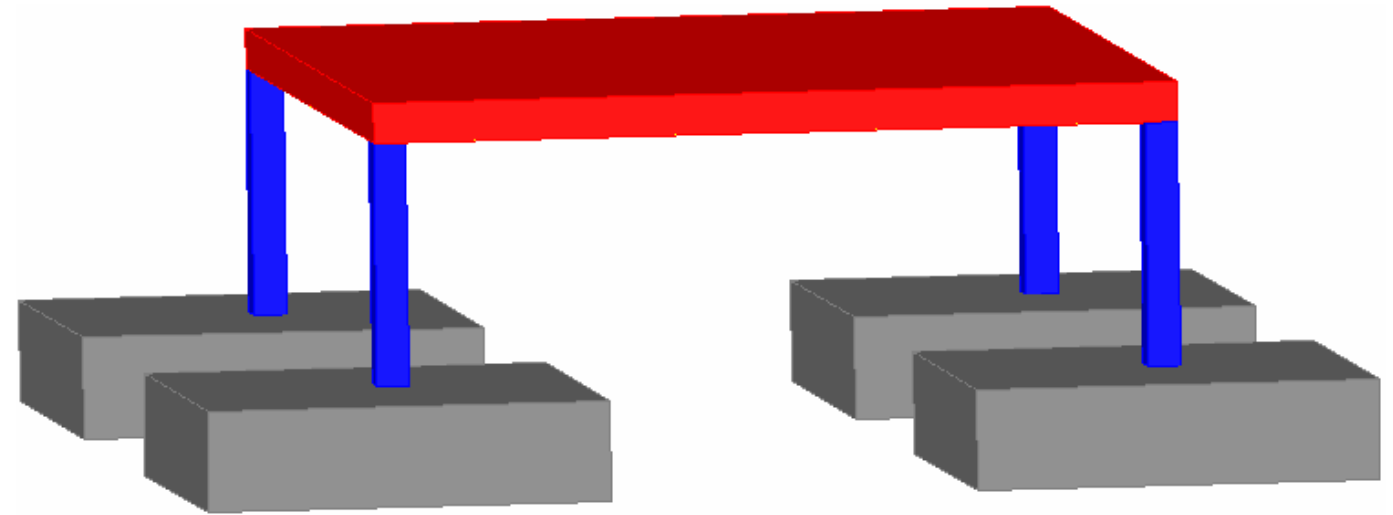

Figura 6.1 - Edificação a ser analisada

A geometria da edificação é definida por $10 \mathrm{~m}$ de vão entre pilares das duas direções e $3 \mathrm{~m}$ de altura. Os blocos de fundação têm $5 \mathrm{~m}$ por $5 \mathrm{~m}$ em planta, 1,25 m de altura, $E_{\text {bloco }}=21000 \mathrm{MPa}$, coeficiente de Poisson $v_{\text {bloco }}=0,3$. Os dados do solo são: $E_{\text {solo }}=$ $40 \mathrm{MPa}, v_{\text {solo }}=0,3$. Os elementos da superestrutura têm as mesmas propriedades físicas dos blocos, ou seja, $E_{\text {estrutura }}=E_{\text {bloco }}$ e $v_{\text {estrutura }}=v_{\text {bloco }}$, e $f_{c k}=20 \mathrm{MPa}$. 
Modelando a superestrutura no software SAP $2000^{\circledR}$ como prédio composto por pilares (seção $40 \mathrm{~cm}$ x $40 \mathrm{~cm}$ ), vigas (seção $40 \mathrm{~cm}$ x $80 \mathrm{~cm}$ ) e laje $(h=8 \mathrm{~cm}$ ), obtém-se o modelo mostrado na Figura 6.2.

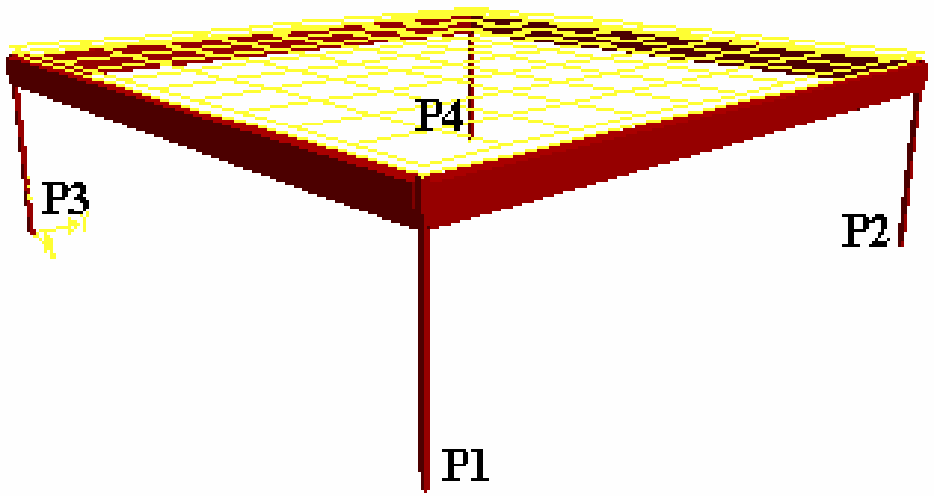

Figura 6.2 - Modelo gerado pelo SAP 2000 ${ }^{\circledR}$

A laje está sujeita, além do peso próprio das peças, a um carregamento vertical uniformemente distribuído de $5 \mathrm{kN} / \mathrm{m}^{2}$ e a duas forças horizontais concentradas aplicadas, no topo de P1 e de P3, na direção positiva do eixo $x$.

Supondo, primeiramente, a estrutura engastada na base, como se faz na metodologia tradicional do projeto de estruturas, a distribuição de momentos no pavimento acontece como mostra a Figura 6.3.

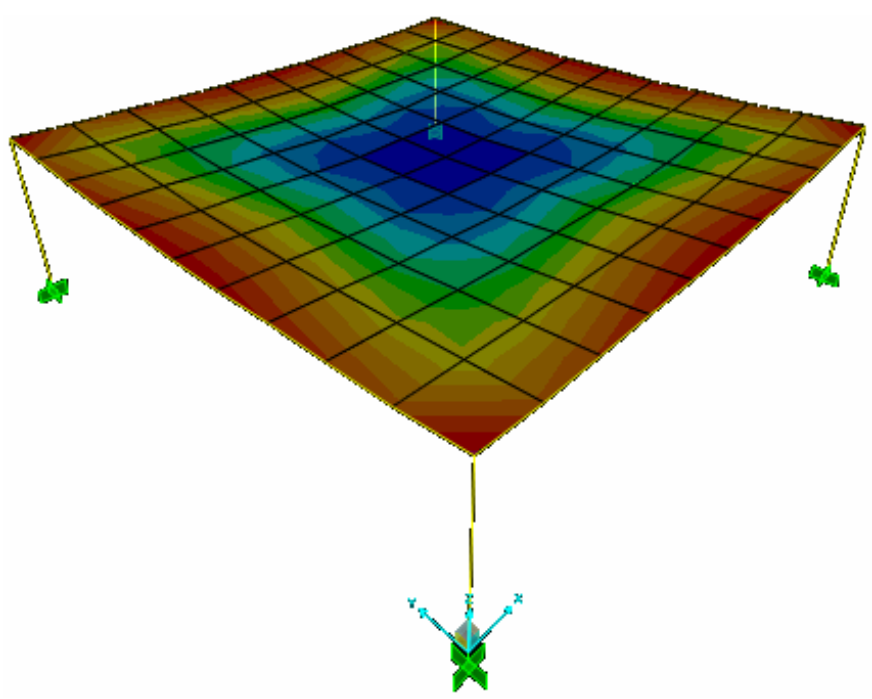

\section{$\begin{array}{llllllllllllll}-8,5 & -6,8 & -5,1 & -3,4 & -1,7 & 0,0 & 1,7 & 3,4 & 5,1 & 6,8 & 8,5 & 10,2 & 11,9 & 13\end{array}$}

Figura 6.3 - Distribuição dos momentos fletores $(\mathrm{kN} . \mathrm{m})$ na laje para o caso de base engastada 
As reações de apoio na base dos pilares da estrutura, para o caso de base indeformável, são apresentadas na Tabela 6.1.

Tabela 6.1 - Reações de apoio (em kN) na base dos pilares para o caso de base engastada

\begin{tabular}{|c|c|c|}
\hline & Direção $x$ & Direção $z$ \\
\hline P1 & 66 & 264 \\
\hline P2 & -86 & 270 \\
\hline P3 & 66 & 264 \\
\hline P4 & -86 & 270 \\
\hline
\end{tabular}

Usando os valores das reações de apoio $R_{x}$ e $R_{z}$ como dado de entrada para o programa, os deslocamentos verticais calculados para os centros dos pilares estão mostrados na Tabela 6.2 .

\begin{tabular}{|c|c|}
\hline \multicolumn{2}{|c|}{ Tabela 6.2 - Deslocamentos dos centros dos pilares } \\
\hline Pilar & W.10 $(\mathrm{m})$ \\
\hline P1 & 0,1185 \\
\hline P2 & 0,1255 \\
\hline P3 & 0,1185 \\
\hline P4 & 0,1255 \\
\hline
\end{tabular}

É importante salientar que os valores dos deslocamentos apresentados na Tabela 6.2 foram determinados usando uma malha de 10 x 10. E como já foi mostrado anteriormente, o refinamento da discretizacão conduz a respostas mais precisas. Por exemplo, no mesmo problema, quando analisado para uma malha de 8 x 8, os deslocamentos de P1 e P3 são, aproximadamente, $0,12 \cdot 10^{-2} \mathrm{~m}$, e os de P2 e P4 são da ordem de $0,13 \cdot 10^{-2} \mathrm{~m}$.

No entanto, devido à limitação de memória física dos computadores, uma malha muito densa para os quatro blocos torna-se praticamente inviável.

Impondo os recalques calculados como deslocamentos prescritos nos nós dos centros dos pilares, observa-se o aparecimento e a distribuição de momentos fletores não previstos na laje (Figura 6.4). 


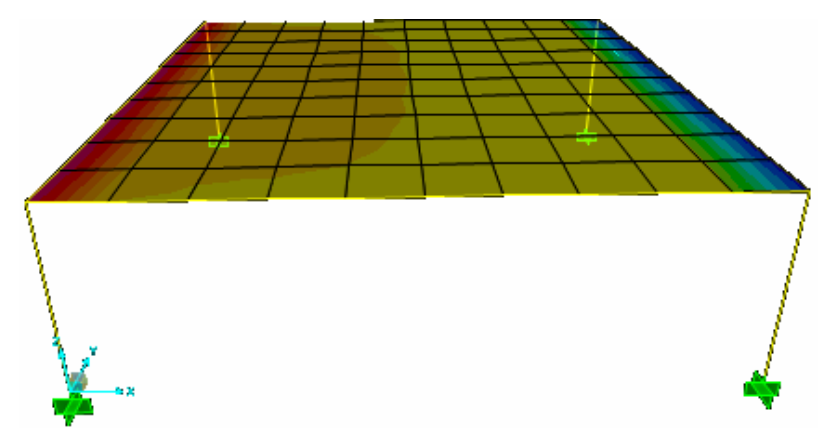

\section{$\begin{array}{llllllllllllll}-9,0 & -6,0 & -3,0 & 0,0 & 3,0 & 6,0 & 9,0 & 12,0 & 15,0 & 18,0 & 21,0 & 24,0 & 27,0 & 30\end{array}$}

Figura 6.4 - Momentos fletores (kN.m) na laje por imposição dos recalques nos pilares

Analisando a estrutura sob ação das forças externas e dos deslocamentos prescritos nos pilares, a nova configuração da distribuição de momentos na laje pode ser vista na Figura 6.5.

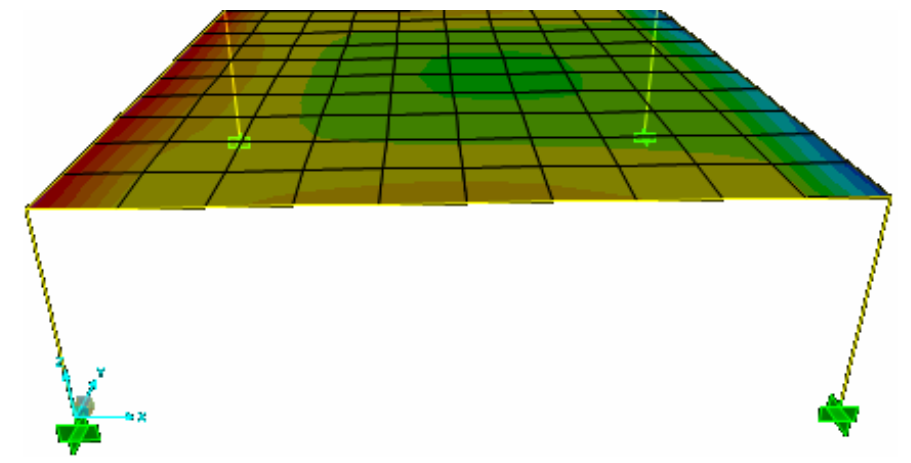

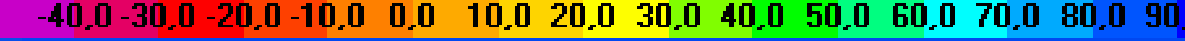

Figura 6.5 - Momentos fletores (kN.m) na laje considerando as forças externas e os recalques

Portanto, o momento máximo no centro da laje, que era aproximadamente $14.10^{-3}$ kN.m para o caso de base engastada, passou para algo em torno de $30.10^{-3}$ kN.m.

A força normal nos pilares também sofre significantes alterações, como mostra a Tabela 6.3.

\begin{tabular}{|c|c|c|c|c|c|c|c|c|c|}
\hline \multicolumn{7}{|c|}{ Tabela 6.3 - Convergência de recalques e de reações de apoio } \\
\hline \multirow{3}{*}{} & \multicolumn{3}{|c|}{$1^{\mathrm{a}}$ iteração } & \multicolumn{3}{c|}{$2^{\mathrm{a}}$ iteração } & \multicolumn{3}{c|}{$3^{\text {a }}$ iteração } \\
\cline { 2 - 11 } & $\mathrm{Rz}(\mathrm{kN})$ & $\mathrm{Rx}(\mathrm{kN})$ & $\mathrm{w}(\mathrm{cm})$ & $\mathrm{Rz}(\mathrm{kN})$ & $\mathrm{Rx}(\mathrm{kN})$ & $\mathrm{w}(\mathrm{cm})$ & $\mathrm{Rz}(\mathrm{kN})$ & $\mathrm{Rx}(\mathrm{kN})$ & $\mathrm{w}(\mathrm{cm})$ \\
\hline P1 & 264 & 66 & 0,1185 & 260 & 66 & 0,1166 & 262 & 66 & 0,118 \\
\hline P2 & 270 & -86 & 0,1255 & 274 & -86 & 0,1274 & 272 & -86 & 0,125 \\
\hline P3 & 264 & 66 & 0,1185 & 260 & 66 & 0,1166 & 262 & 66 & 0,118 \\
\hline P4 & 270 & -86 & 0,1255 & 274 & -86 & 0,1274 & 272 & -86 & 0,125 \\
\hline
\end{tabular}




\section{2 - Edificação sobre sapatas}

A estrutura possui três andares, cada um com 3,0 m de altura e vãos de 7,0 m e 7,5 $\mathrm{m}$, nas direções X e Y, respectivamente. As lajes tem $12 \mathrm{~cm}$ de espessura e sobre elas atua uma carga variável de $2,0 \mathrm{kN} / \mathrm{m}^{2}$. As vigas possuem seções retangulares de $0,30 \mathrm{~m}$ x 0,70 $\mathrm{m}$, e os pilares seções quadradas de $0,30 \mathrm{~m}$ x 0,30 m (Figura 6.6).

O concreto usado possui $\mathrm{f}_{\mathrm{ck}}=20 \mathrm{MPa}, \mathrm{E}=21287,4 \mathrm{MPa}, v=0,2$ e $\gamma=25 \mathrm{kN} / \mathrm{m}^{3}$.
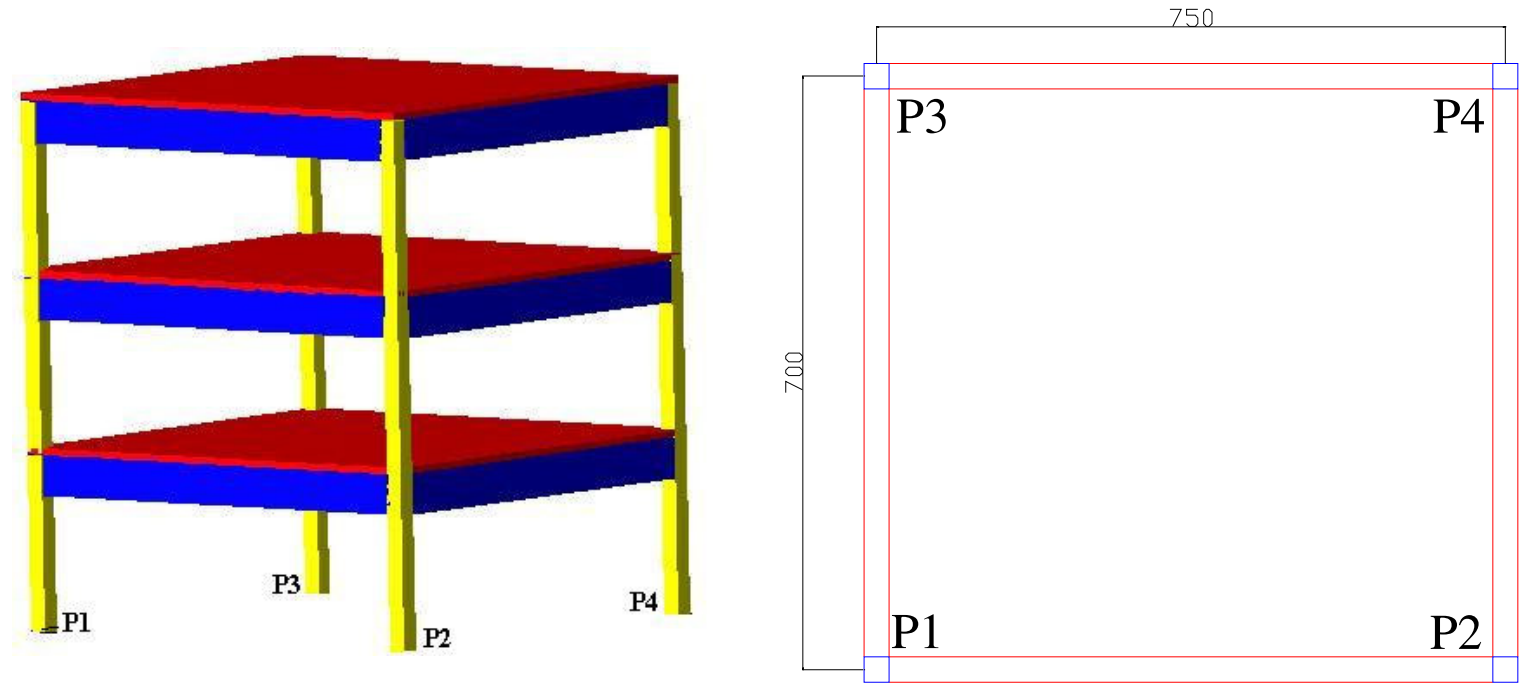

Figura 6.6 - Estrutura a ser analisada

O prédio é supostamente edificado no Campo Experimental da USP - São Carlos. $\mathrm{Na}$ consideração das características do maciço de solos, foram utilizados os valores de SPT e CPT obtidos da Figura 9.1 no Anexo A, publicados por GIACHETI et al (2004).

A região de São Carlos está assentada sobre as rochas do Grupo São Bento, constituídas pelos arenitos das Formações Botucatu e Pirambóia, e pelos derrames de rochas efusivas basálticas da Formação Serra Geral. Acima dessas rochas aparecem os conglomerados e arenitos do Grupo Bauru, e, logo a seguir, abrangendo toda a região, têmse os Sedimentos Cenozóicos, geralmente caracterizados como colapsíveis. O perfil do Campo Experimental da USP - São Carlos divide-se basicamente em duas camadas de areia fina e média, argilosa, pouco siltosa, separadas por uma linha de seixos a aproximadamente $6 \mathrm{~m}$ de profundidade. O perfil típico que ocorre no Campo Experimental assim, como os resultados das sondagens de simples reconhecimento, com medida de SPT e CPT, são apresentados na Figura 9.1 do Anexo. 
Os ensaios laboratoriais específicos foram realizados por MENEZES (1990), CINTRA et al (1991). Os resultados desses ensaios, apresentados a seguir, foram obtidos de amostras deformadas e indeformadas, retiradas de um poço, de metro em metro, a partir de $1,30 \mathrm{~m}$, até $10,30 \mathrm{~m}$. Os resultados dos ensaios de Caracterização (limites de consistência e granulometria) encontram-se na Tabela 9.1 do Anexo.

Os índices físicos estão apresentados na Tabela 9.2 (Anexo A), sendo que os pesos específicos naturais $\left(\gamma_{\text {nat }}\right)$, os pesos específicos secos $\left(\gamma_{d}\right)$, os teores-de-umidade (w) e os índices de vazios iniciais $\left(\mathrm{e}_{0}\right)$ foram obtidos da moldagem do corpo-de-prova para o ensaio de adensamento, e as porosidades (n) foram calculadas em função dos índices de vazios. Os parâmetros de resistência apresentados na Tabela 9.4 correspondem a resultados de ensaios triaxiais do tipo adensado rápido, ensaios triaxiais do tipo drenado, e compressão simples. Os resultados dos ensaios triaxiais estão apresentados em termos de tensão efetiva.

A NBR 6122:1996 - Projeto e Execução de Fundações - apresenta uma tabela (Tabela 9.3 do Anexo A) de tensões básicas, advertindo que os valores fixados servem de orientação inicial, que seu uso deve ser restrito a forças não superiores a $1.000 \mathrm{kN}$ por pilar, e que soluções melhores, técnica e economicamente, devem utilizar critérios específicos para cada situação.

Ainda de acordo com a NBR 6122:1996, a tensão admissível pode ser estimada segundo métodos teóricos, semi-empíricos, provas de carga sobre placa e empíricos.

As primeiras recomendações para estimativa da tensão admissível pelos métodos empíricos apareceram na forma de tabelas, em geral constante de códigos de obras de grandes cidades. No Brasil, um exemplo é dado por VARGAS (1955), sintetizando uma experiência na construção de edifícios em São Paulo, como mostra a Tabela 9.5.

O método mais usado na prática é o que utiliza o parâmetro de resistência média à penetração em sondagens $\left(\mathrm{N}_{\mathrm{SPT}}\right)$ com o amostrador Raymod-Terzaghi. Pode-se estimar a tensão admissível ( $\left.\sigma_{\mathrm{a}} \mathrm{em} \mathrm{MPa}\right)$ pela Eq.(6.1):

$$
\sigma_{\mathrm{a}}=0,02 \cdot \mathrm{N}_{\mathrm{SPT}}
$$

A correlação é válida para qualquer solo natural no intervalo $5 \leq \mathrm{N}_{\mathrm{SPT}} \leq 20$. O intervalo procura não permitir o emprego de fundação direta, quando o solo abaixo da sapata for mole ou fofo $\left(\mathrm{N}_{\mathrm{SPT}}<5\right)$ e limitar a tensão admissível máxima a 0,4 MPa. 
$\mathrm{O}$ valor de $\mathrm{N}_{\mathrm{SPT}}$ é calculado como a média aritmética dos valores de resistência à penetração, das camadas até a profundidade do bulbo de tensões $(\cong 1,5 \mathrm{~B}$, sendo $\mathrm{B}$ a menor dimensão da sapata).

A tensão admissível para projetos de sapatas também pode ser estimada com base nos valores de resistência de ponta $\left(\mathrm{q}_{\mathrm{c}}\right)$, medidos no ensaio de penetração estática de cone, como mostra as Eqs.(6.2) e (6.3):

Sapatas apoiadas sobre argilas $\left(\sigma_{\mathrm{a}} \mathrm{em} \mathrm{MPa}\right): \sigma_{a}=\frac{\boldsymbol{q}_{c}}{10}$

Sapatas apoiadas sobre areias $\left(\sigma_{\mathrm{a}} \mathrm{em} \mathrm{MPa}\right): \sigma_{a}=\frac{\boldsymbol{q}_{c}}{15}$

Essas expressões são recomendadas para solos com $\mathrm{q}_{\mathrm{c}}>1,5 \mathrm{MPa}$. O valor da tensão admissível estimada deverá ser limitada a 0,4 MPa e, assim como na correlação para $\mathrm{N}_{\mathrm{SPT}}$, o valor de $\mathrm{q}_{\mathrm{c}}$ empregado nas equações deve ser o valor médio, dentro da profundidade do bulbo de tensões.

O pórtico tridimensional é resolvido para a combinação das ações de peso próprio, carga variável da laje e forças de vento, supondo-se apoios indeslocáveis na base das colunas, ou seja, as barras verticais engastadas. Sob tais hipóteses, as reações de apoio são determinadas, conforme a Figura 6.7.

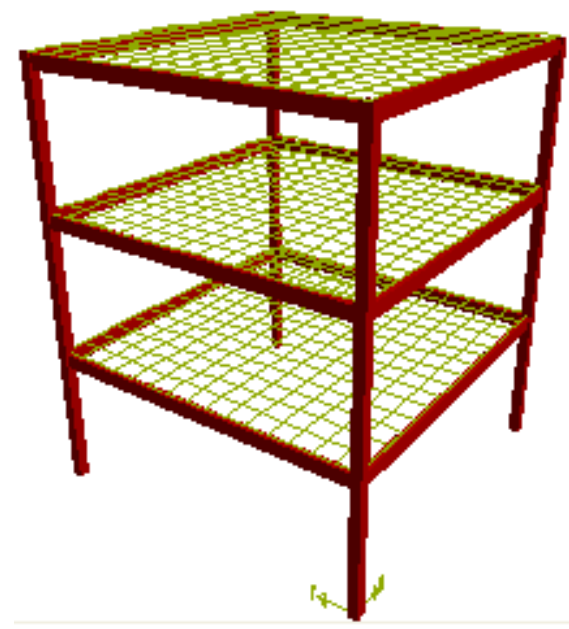

Figura 6.7 - Discretização do pórtico para a hipótese de engastamento na base

A Tabela 6.4 mostra as reações de apoio na base dos pilares para o carregamento vertical e forças horizontais concentradas de $30 \mathrm{kN}, 20 \mathrm{kN}$ e $10 \mathrm{kN}$ (valores adotados) aplicadas no topo dos pilares $\mathrm{P} 1$ e P3, respectivamente a $3 \mathrm{~m}, 6 \mathrm{~m}$ e $9 \mathrm{~m}$. 
Tabela 6.4 - Reações de apoio $(\mathrm{kN})$ para o caso de base engastada

\begin{tabular}{|c|c|c|}
\hline & Direção $x$ & Direção $z$ \\
\hline P1 & 25,7 & 734,63 \\
\hline P2 & 64,3 & 856,87 \\
\hline P3 & 25,7 & 734,63 \\
\hline P4 & 64,3 & 856,87 \\
\hline
\end{tabular}

Supondo B = 1,0 m para as sapatas S1 e S3, tem-se os valores da Figura 6.8:

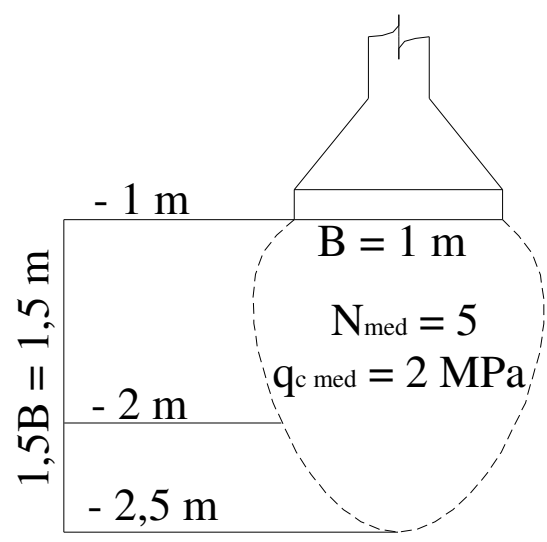

Figura 6.8 - Bulbo de tensões para $B=1,0 \mathrm{~m}$

Para verificação da tensão admissível $\left(\sigma_{a}\right)$ segue-se:

Correlação para SPT: $\sigma_{\mathrm{a}}=0,02 \cdot \mathrm{N}_{\mathrm{SPT}} \Rightarrow \sigma_{\mathrm{a}}=0,02 \times 5 \Rightarrow \sigma_{\mathrm{a}}=0,1 \mathrm{MPa}$

Correlação para CPT: $\sigma_{a}=\frac{\boldsymbol{q}_{c}}{15} \Rightarrow \sigma_{a}=\frac{2}{15} \Rightarrow \sigma_{a}=0,13 \mathbf{M P a}$

Por critério de segurança deve-se adotar $\sigma_{\mathrm{a}}=0,1 \mathrm{MPa}$. Pela definição de tensão é possível encontrar a dimensão da sapata para a tensão admissível estimada, daí:

$\sigma=\frac{F}{S} \Rightarrow 100=\frac{734,63}{S} \Rightarrow S \cong 7,35 m^{2} \Rightarrow B=\sqrt{S} \Rightarrow B=\sqrt{7,35} \Rightarrow B \cong 2,71 m \Rightarrow B_{1}=B_{3}=2,7 m$

Procedendo de modo análogo com as sapatas S2 e S3, vem:

$\sigma=\frac{F}{S} \Rightarrow 100=\frac{856,87}{S} \Rightarrow S \cong 8,57 m^{2} \Rightarrow B=\sqrt{S} \Rightarrow B=\sqrt{8,57} \Rightarrow B \cong 2,93 \Rightarrow B_{2}=B_{4}=3,0 m$ 
Observando os resultados dos ensaios SPT e CPT, vê-se que ambos os valores permanecem aproximadamente constantes $\left(\mathrm{N}_{\text {med }}=5\right.$ e $\left.\mathrm{q}_{\mathrm{c} \text { méd }}=2 \mathrm{MPa}\right)$ até a profundidade de $6 \mathrm{~m}$, onde se encontra a linha de seixos, e tais valores sofrem um pico. Assim sendo, para $\mathrm{B}_{1}=\mathrm{B}_{3}=2,7 \mathrm{~m}$ e $\mathrm{B}_{2}=\mathrm{B}_{4}=3,0 \mathrm{~m}$, a profundidade do bulbo de tensões alcança, no máximo, a cota de 5,5 m em relação ao nível do terreno.

Escolhendo um sistema de eixos adequados, a locação das sapatas (vértices A e centros C), pode ser vista na Figura 6.9:

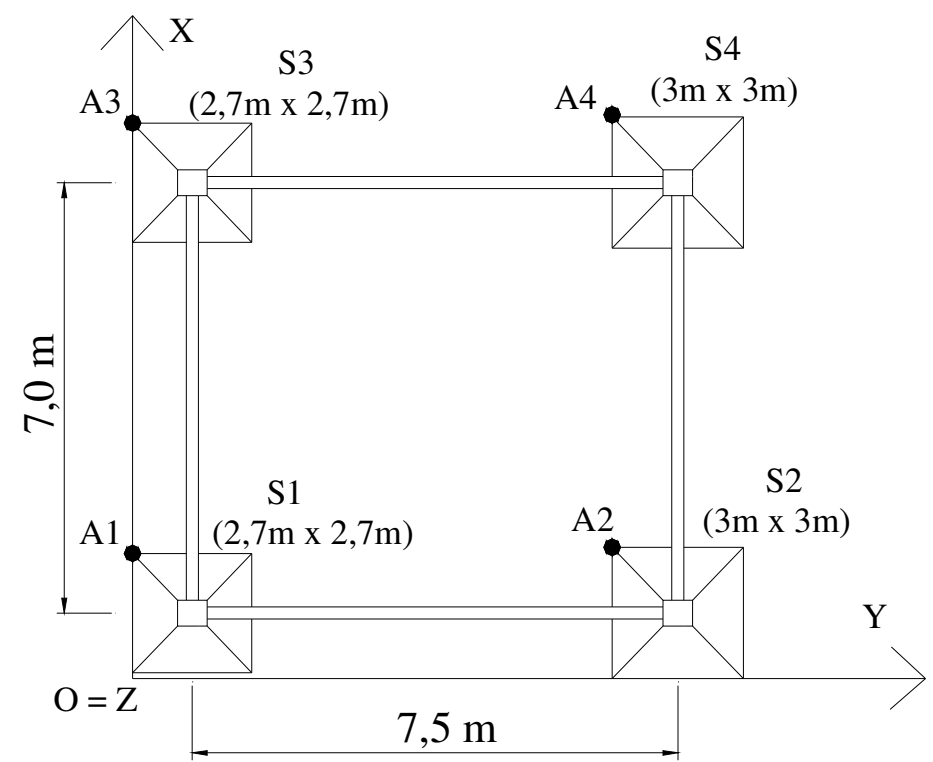

Figura 6.9 - Locação dos centros e dos vértices A das sapatas para o sistema de eixos adotado

Para estimativa do módulo de deformabilidade $\left(\mathrm{E}_{\mathrm{s}}\right)$ das camadas de solo, a partir dos resultados do Ensaio CPT, pode-se usar a correlação para as areias, dada pela Eq.(6.8):

$$
\mathrm{E}_{\mathrm{s}}=\alpha \cdot \mathrm{q}_{\mathrm{c}}
$$

$\mathrm{q}_{\mathrm{c}}$ é a resistência de ponta do ensaio de cone, na mesma unidade de $\mathrm{E}_{\mathrm{s}}$. Os valores de $\alpha$ variam, grosso modo, entre 1,5 e 8, sendo que os valores mais baixos estão associados aos solos arenosos, e os mais altos, aos compressíveis. Não se dispondo de melhores dados, para estimativa da ordem de grandeza do módulo de deformabilidade, podem ser tomados valores de $\alpha$ apresentados na Tabela 9.7 do Anexo.

Apesar da preferência pela obtenção diretamente do ensaio de cone, no caso de haver apenas resultados de SPT, aceita-se o uso da correlação dada pela Eq.(6.9): 


$$
K=\frac{q_{c}}{N_{S P T}}
$$

Em função do tipo de solo, TEIXEIRA (1993) propõe os valores de K apresentados na Tabela 9.8.

MELLO (1971) sugere uma correlação empírica para estimativa de $E_{\mathrm{s}}$, em areias, a partir do Ensaio SPT:

$$
\mathrm{E}_{\mathrm{s}}=3\left(\mathrm{~N}_{\mathrm{SPT}}-3\right)
$$

O valor do módulo de deformabilidade para cada uma das correlações está apresentado na Tabela 6.5.

\begin{tabular}{|c|c|c|}
\hline \multicolumn{3}{|c|}{ Tabela 6.5 - Valores do módulo de deformabilidade $\left(\mathbf{E}_{\mathrm{s}}\right)$} \\
\hline \multirow{2}{*}{} & Correlação com SPT & Correlação com CPT \\
\cline { 2 - 3 } & $\mathrm{N}_{\mathrm{SPT}}=5$ & $\mathrm{q}_{\mathrm{c}}=2 \mathrm{MPa}$ \\
\hline $\mathrm{E}_{\mathrm{S}}(\mathrm{MPa})$ & 6 & 6 \\
\hline
\end{tabular}

Para determinação do coeficiente de Poisson (v) utiliza-se a Tabela 9.6 do Anexo A, onde para cada tipo de solo há um valor, ou intervalo, estimativo para v.

A Tabela 6.6 mostra os recalques nos centros dos pilares calculados pelo programa. Devido à simetria e simplicidade da estrutura, os deslocamentos ocorridos tornam-se pouco relevantes, sem gerar acentuada redistribuição de esforços.

\begin{tabular}{|c|c|c|c|c|}
\hline \multicolumn{5}{|c|}{ Tabela 6.6 - Valores de recalque nos centros dos pilares } \\
\hline & P1 & P2 & P3 & P4 \\
\hline W $(\mathrm{cm})$ & 4,71 & 5,1 & 4,71 & 5,1 \\
\hline
\end{tabular}

A Figura 6.10 mostra a distribuição dos momentos fletores nas lajes devido aos recalques nas bases dos pilares. Em virtude da simetria da edificação, os efeitos da deformabilidade do solo desaparecem nos pavimentos superiores. 


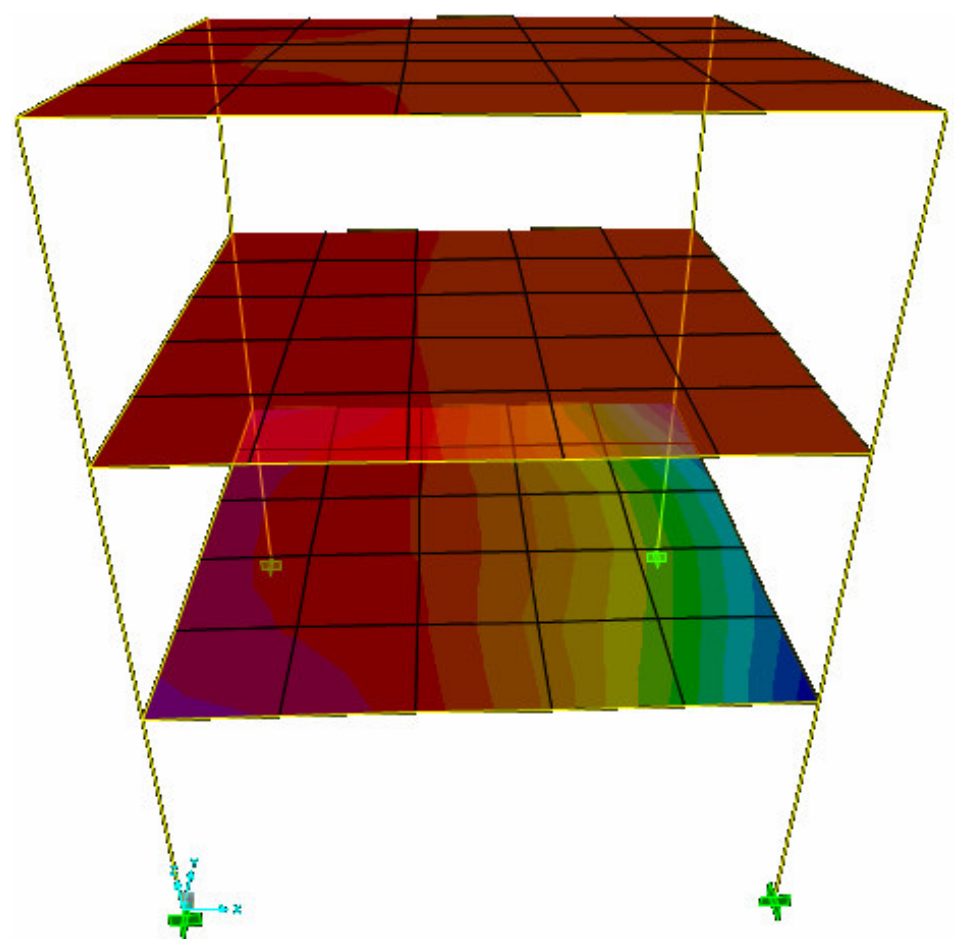

\section{$\begin{array}{llllllllllllll}-8,0 & -4,0 & 0,0 & 4,0 & 8,0 & 12,0 & 16,0 & 20,0 & 24,0 & 28,0 & 32,0 & 36,0 & 40,0 & 44,\end{array}$}

Figura 6.10 - Momentos fletores nas lajes, devido aos recalques dos pilares

Apesar de não acarretarem significativos acréscimos de momento nos elementos da superestrutura, os recalques provocam expressivas distorções angulares, principalmente nas paredes de vedação. Isso pode ser comprovado com os limites sugeridos na Figura 2.4, como mostra a Tabela 6.7 .

\begin{tabular}{|c|c|c|}
\hline \multicolumn{3}{|c|}{ Tabela 6.7 - Comparação dos limites de distorção angular } \\
\hline Situação & Limite de distorção angular & Distorção angular da estrutura \\
\hline Trincas em paredes & 0,003 & 0,0006 \\
\hline Inclinação visível & 0,004 & 0,0006 \\
\hline Danos estruturais & 0,006 & 0,0006 \\
\hline
\end{tabular}

O procedimento iterativo adotado no exemplo 6.1 deve ser realizado neste exemplo para que os resultados encontrados estejam dentro da tolerância desejada. 


\section{7 - CONCLUSÃO}

Observando os efeitos resultantes da interação solo-estrutura, é notável que a desconsideração deste mecanismo no projeto estrutural é uma atitude contra a segurança e a economia, itens de enorme importância nos projetos, em especial na Engenharia Civil.

\section{1 - Considerações finais}

Como pode ser visto nos exemplos apresentados, a ferramenta computacional desenvolvida mostrou-se eficaz e eficiente na análise dos problemas de interação soloestrutura apresentados, além de relativa velocidade de processamento, para casos não muito complexos.

Apesar das simplificações, das hipóteses e das restrições adotadas, a formulação desenvolvida representa, na visão da engenharia, de modo adequado o mecanismo de influência mútua entre a superestrutura e o sistema de fundação.

A simulação do elemento estrutural de fundação direta como elemento finito de casca plano talvez não seja a escolha mais apropriada, pois a consideração dos seis graus de liberdade torna a estrutura mais rígida, o que diminui, de maneira considerável, os valores de deslocamentos. Por isso, o mais adequado seria, talvez, usar o elemento finito de casca plano somente para os casos onde também houvesse carregamento fora da direção vertical, caso contrário, a sapata seria analisada como elemento finito de placa, como se faz na maioria dos casos onde há apenas forças perpendiculares à superfície, ou como elemento finito de chapa, para as situações onde as forças atuam paralelamente ao plano médio da sapata. Desta maneira a formulação do elemento finito de casca plano se degeneraria em elemento finito de placa ou de chapa, a depender dos tipos de forças atuantes. 
A implementação de outros tipos de elementos finitos (HSM, DKT com seis nós, por exemplo), com funções de aproximação mais ricas, pode fornecer resultados bem mais coerentes e precisos.

Quanto ao procedimento para montagem da matriz de flexibilidade do solo, convém citar que inicialmente tinha-se pensado em colocar o triedro positivo de forças unitárias atuando sobre cada nó da malha do solo. No entanto, esse procedimento origina forte singularidade nas equações de Mindlin quando se quer determinar as componentes de flexibilidade no ponto onde está sendo aplicado o triedro de forças. Por isso optou-se por aplicar o triedro positivo de forças unitárias no centro de gravidade de cada elemento da discretização do maciço de solos. Desta maneira, foge-se do problema da singularidade, e ao refinar-se a malha, cada vez mais a resposta do programa convergirá.

A restrição para o caso de elementos estruturais de fundação direta, apesar de limitar a utilização da ferramenta, abrange boa parte dos casos reais de projetos de edifícios. Entretanto, a depender das condições do subsolo, o uso de elementos estruturais de fundação profunda torna-se obrigatório.

\section{2 - Sugestões para pesquisas futuras}

Como sugestões para pesquisas futuras indica-se:

- Inclusão da rotina de cálculo das forças de superfície (forças de Cauchy) na superfície de contato do solo;

- Incorporação do modelo não-linear físico para representar o comportamento do solo;

- Implementação do elemento estrutural de fundação profunda (estaca, tubulão);

- Aperfeiçoar o procedimento de STEIBRENNER (1934) para cálculo de recalques em meios estratificados;

- Acoplamento com cógido computacional de análise de edifício 


\section{8 - REFERÊNCIAS BIBLIOGRÁFICAS}

AOKI, N. (1987). Modelo simples de transferência de carga de estaca vertical sujeita a carga axial de compressão. Anais do Ciclo de Palestras sobre Fundações. Associação Brasileira de Mecânica dos Solos - Núcleo Regional do Nordeste. Recife.

AOKI, N. (2005). /Comunicação pessoal/.

AOKI, N.; LOPES, F. R. (1975). Estimating stress and settlements due to deep foundation. In: V Congresso Panamericano de Mecânica dos Solos e Engenharia de Fundações, v.1, p.377-386, Buenos Aires.

ALONSO, U. R. (1989). Dimensionamento de fundações profundas. São Paulo:Edgard Blücher.

ALMEIDA, F. P. A. (2003). Aplicação do acoplamento entre o MEC e o MEF para o estuda da interação dinâmica elastoplástica entre o solo e a estrutura. 285p. Tese (Doutorado) - Escola de Engenharia de São Carlos, Universidade de São Paulo, São Carlos, Brasil.

ALMEIDA, V. S. (2003). Análise da interação solo não-homogêneo/estrutura via acoplamento MEC/MEF. 192p. Teste (Doutorado) - Escola de Engenharia de São Carlos, Universidade de São Paulo, São Carlos, Brasil. 
BARATA, F. E. (1984). Propriedades mecânica dos solos: Uma introdução ao projeto de fundações. 1.ed. Rio de Janeiro, Livros Técnicos e Científicos.

BURLAND, J. B.; BROMS, B. B.; de MELLO, V. F. B. (1977). Behavior of foundations and structures. In: INTERNATIONAL CONFERENCE ON SOIL MECHANICS AND FOUNDATION ENGINEERING, 9., 1977, Tóquio. v.2.

BURLAND, J. H.; BURBIDGE, M. C. (1985). Settlements of foundation on sand and gravel. Proceedings of the Institution of Civil Engineers, Part I, v.78.

BURMISTER, D. M. (1945). The general theory of stresses and displacements in layered soil systems. In: Journal of Applied Physics, v.16, n.2, p.89-96.

CHAMECKI, S. (1954). Consideração com rigidez da estrutura no cálculo dos recalques da fundação. In: CONGRESSO BRASILEIRO DE MECÂNICA DOS SOLOS, 1., 1954, Porto Alegre. v.1.

CHEUNG, Y. K.; ZIENKIEWICZ, O. C. (1965). Plates and tanks on elastic foundations on application of finite element method. Int. J. Solids. Struct, v.1, p. 451-461.

CINTRA, J. C. A.; CARVAlHO, D.; GIACHETI, H. L.; BORTOLUCCI, A. A.; ALBIERO, J. H. (1991). Campo experimental de fundações em São Carlos. In: SEMINÁRIO DE ENGENHARIA DE FUNDAÇÕES ESPECIAIS (SEFE). São Paulo.

CLEMENTE, J. L. M. (1990). Analysis of pile groups with variable shaft-load over point load ratios. In: JOURNAL OF GEOTECHNICAL DIVISION. v.116, American Society of Civil Engineering (ASCE).

DANZIGER, F. A. B.; DANZIGER, B. R; CRISPEL, F. A. (2000). A medida dos recalques desde o início da construção como um controle de qualidade das fundações. Anais do IV Seminário de Engenharia de Fundações Especiais e Geotecnia, v.1, p.191-202, São Paulo. 
FRASER, R. A.; WARDLE, L. J. (1976). Numerical analysis of rectangular rafts on layered foundations. Géotechnique. v.26.

GIACHETI, H. L.; PEIXOTO, A. S. P; MONDELLI, G. (2004). Comparação entre resultados de Ensaios de Penetração com os Cones Elétricos e Mecânicos em solos tropicais. Solos e Rochas. v.27.

GOLOMBEK, S. C. (1979). Reforço de fundações. Palestra na Sociedade Mineira de Engenheiros. Belo Horizonte.

GORBUNOV-POSSADOV, M; SEREBRJANY, R. V. (1961). Design of structures on elastic foundations. In: Conference of Soil Mechanics and Foundation Engineering., 5, Proc., v.1, p. 643-648.

GUSMÃO, A.D. (1990). Estudo da interação solo-estrutura e sua influência em recalques de edificações. Dissertação (Mestrado) - Universidade Federal do Rio de Janeiro - COPPE, Rio de Janeiro.

GUSMÃO, A. D.; GUSMÃO FILHO, J. A. (1994). Avaliação da influência da interação solo-estrutura. In. X COBRAMSEF, Foz do Iguaçu, PR, ABMS, Anais, v.1, p.68-74.

GUSMÃO, A. D. (2004). Monitoramento de recalques de edifícios sobre fundação direta desde o início da construção e avaliação da interação solo-estrutura. Revista Solos e Rochas, v.27 (2), p.215-229.

HOLANDA, O. G. J. (1998). Interação solo-estrutura para edifícios de concreto armado sobre fundações diretas. 191p. Dissertação (Mestrado) - Escola de Engenharia de São Carlos, Universidade de São Paulo, São Carlos, Brasil.

IWAMOTO, R.K. (2000). Alguns aspectos dos efeitos da interação solo-estrutura em edifícios de múltiplos andares com fundação profunda. 140p. Dissertação (Mestrado) Escola de Engenharia de São Carlos, Universidade de São Paulo, São Carlos, Brasil. 
JORDÃO, D. R. (2003). Estabilidade global de edifícios sobre fundações profundas, considerando a interação estrutura-solo. 142p. Dissertação (Mestrado) - Escola de Engenharia de São Carlos, Universidade de São Paulo, São Carlos, Brasil.

LOPES, F. R. (1988). Notas de Apoio às Aulas de Fundações I. Universidade Federal do Rio de Janeiro - COPPE. Rio de Janeiro.

MENDONÇA, A. V. (1997). Análise da interação placa-estaca-solo via combinação do Método dos Elementos Finitos com o Método dos Elementos de Contorno. 151p. Dissertação (Mestrado) - Escola de Engenharia de São Carlos, Universidade de São Paulo, São Carlos, Brasil.

MENEZES, S. M. (1990). Correlações entre os ensaios de penetração (SPT e CPT) e os resultados de ensaios de laboratório para a região de São Carlos-SP. Dissertação (Mestrado) - Escola de Engenharia de São Carlos, Universidade de São Paulo, São Carlos. MESSAFER, T; COATES, L. E. (1989). An application of FEM/BEM coupling to foundation analysis. Advances in Boundary Methods. Eds. C.A. Brebbia \& Connor, Computacional Mechanics Publications: Southampton and Boston, p.211-221.

MEYERHOF, G.G. (1953). Some recent foundation research and its application to design. STRUCTURAL ENGINEERING. Londres.

MEYERHOF, G.G. (1959). Compaction of sands and bearing capacity of piles. In: JOURNAL OF THE SOIL MECHANICS AND FOUNDATION DIVISION. v.85. American Society of Civil Engineering (ASCE).

MINDLIN, R. D. (1936). Force at a point in the interior of a semi-infinite solid. Physics. v.7.

MOTA, Magnólia. M. C. (2006). Análise da interação solo-estrutura de sistemas estruturais de edifícios: Análise numérica e resultados observados in situ. Doutorado em 
andamento. Escola de Engenharia de São Carlos, Universidade de São Paulo, São Carlos, Brasil.

PAIVA, J, B. (1993). Formulação do Método dos Elementos de Contorno para análise da interação solo-estrutura. 183p. Tese (Livre-Docência) - Escola de Engenharia de São Carlos, Universidade de São Paulo, São Carlos, Brasil.

PELETEIRO, S. C. (1996). Utilização da formulação livre para desenvolvimento de um elemento finito de membrana com liberdade rotacionais. São Carlos. 101p. Dissertação (Mestrado) - Escola de Engenharia de São Carlos, Universidade de São Paulo.

POLO, J. M.; CLEMENTE, J. L. M. (1988). Pile group settlement using independent shaft and point loads. In: JOURNAL OF GEOTECHNICAL ENGINEERING DIVISION. v.114. American Society of Civil Engineering (ASCE).

POULOS, H. G. (1967). Stresses and displacements in an elastic layer underlain by a rough rigid base. In: Geotechnique, v.17, p.378-410.

POULOS, H. G. (1975). Settlement analysis of structural foundation systems. In: SOUTHEAST ASIAN CONFERENCE ON SOIL ENGINEERING, 4., Malásia.

POULOS, H. G.; DAVIS, E. H. (1980). Pile foundations analysis and design. John Willey \& Sons.

REIS, J. H. C. (2000). Interação solo-estrutura de grupos de edifícios com fundações superficiais em argila mole. 148p. Dissertação (Mestrado) - Escola de Engenharia de São Carlos, Universidade de São Paulo, São Carlos, Brasil.

REZENDE, M. E. B. (1995). Análise de recalques de grupos de estacas escavadas de pequeno diâmetro através de provas de carga in situ e modelos centrifugados. Tese (Doutorado) - Escola de Engenharia de São Carlos, Universidade de São Paulo, São Carlos. 1995. 
SADECKA, L. (2000). A finite/infinte element analysis of thick plate on layered foundation. Computers \& Structures, v.76, p. 603-610.

SANTA MARIA, P. E. L.; SANTA MARIA, F. C. M.; SANTOS, A. B. (1999). Análise de vigas contínuas com apoios viscoelásticos e sua aplicação a problemas de interação soloestrutura. Solos e Rochas. v.22.

SCHMERTMANN, J. H. (1970). Static cone to compute settlements over sand. JOURNAL OF THE SOIL MECHANICS AND FOUNDATION DIVISION. v.96. American Society of Civil Engineering (ASCE).

SELVADURAI, A. P. S. (1979). Elastic analysis of soil-foundation interaction. Elsevier Scientific Publication Company.

SOWERS, G. F.; MARTIN, C. B.; WILSON, L. L. (1961). Bearing capacity of friction pile groups in homogeneous clay from model studies. In: INTERNATIONAL CONFERENCE ON SOIL MECHANICS AND FOUNDATION ENGINEERING, 5., 1961, Paris.

SOWERS, G. B.; SOWERS, G. F. (1970). Introductory soil mechanics and foundations. McMillan Co. New York.

TEIXEIRA, A. H. (1993). Um aperfeiçoamento das sondagens de simples reconhecimento à percussão - Anais da mesa redonda Solos do Interior de São Paulo.

TIMOSHENKO, S. P.; GOODIER, J. N. (1970). Theory of Elasticity. McGraw-Hill, New York, 3.ed.

VÉSIC, A. S. (1969). Experiments with instrumented pile group in sand. In: SYMPOSIUM ON PEFORMANCE OF DEEP FOUNDATIONS, v.444. American Society for Testing and Materials (ASTM).

WANG, C. M; CHOW, Y. K.; HOW, Y. C. (2001). Analysis of rectangular thick rafts on an elastic haf-space. Computers \& Geotechnics, v.28, p. 161-184. 


\section{9 - ANEXOS}

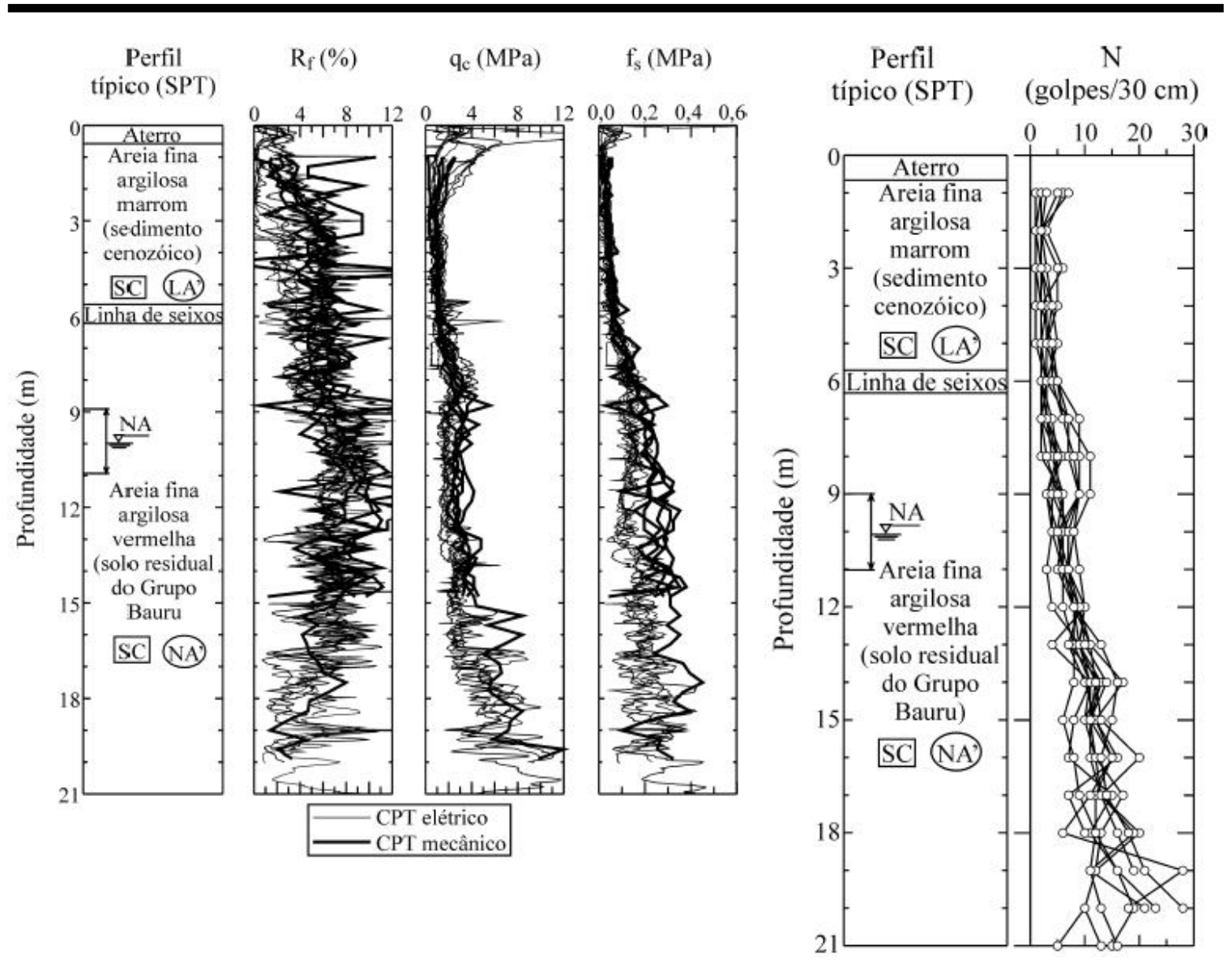

Figura 9.1 - Resultados dos ensaios CPT e SPT 
Tabela 9.1 - Resultados dos ensaios de caracterização EESC - USP

\begin{tabular}{|c|c|c|c|c|c|c|}
\hline \multirow{2}{*}{ Profundidade (m) } & \multicolumn{2}{|c|}{$\begin{array}{c}\text { Limites } \\
\text { Consistência }\end{array}$} & \multicolumn{5}{c|}{ Granulometria } \\
\cline { 2 - 7 } & LL (\%) & LP (\%) & Argila(\%) & Silte (\%) & Areia fina (\%) & Areia média (\%) \\
\hline 1,30 & 24 & 17 & 26 & 11 & 51 & 12 \\
\hline 2,30 & 26 & 18 & 21 & 14 & 55 & 10 \\
\hline 3,30 & 27 & 20 & 31 & 8 & 51 & 10 \\
\hline 4,30 & 28 & 18 & 28 & 11 & 56 & 5 \\
\hline 5,30 & 30 & 10 & 20 & 17 & 54 & 9 \\
\hline 6,30 & 31 & 22 & 22 & 16 & 54 & 8 \\
\hline 7,30 & 31 & 22 & 19 & 14 & 57 & 10 \\
\hline 8,30 & 34 & 20 & 21 & 9 & 54 & 16 \\
\hline 9,30 & 30 & 10 & 17 & 10 & 56 & 17 \\
\hline 10,30 & 32 & 10 & 20 & 8 & 56 & 16 \\
\hline
\end{tabular}

Tabela 9.2 - Índices físicos CE-EESC

\begin{tabular}{|c|r|r|r|}
\hline Profundidade $(\mathrm{m})$ & $\gamma_{\text {nat }}\left(\mathrm{kN} / \mathrm{m}^{3}\right)$ & $\gamma_{s}\left(\mathrm{kN} / \mathrm{m}^{3}\right)$ & $\gamma_{d}\left(\mathrm{kN} / \mathrm{m}^{3}\right)$ \\
\hline 1,30 & 15,6 & 27,5 & 13,8 \\
\hline 2,30 & 15,5 & 26,8 & 13,3 \\
\hline 3,30 & 15,8 & 27,0 & 13,5 \\
\hline 4,30 & 16,9 & 27,3 & 14,6 \\
\hline 5,30 & 17,2 & 27,6 & 14,9 \\
\hline 6,30 & 17,0 & 27,5 & 14,5 \\
\hline 7,30 & 18,3 & 27,3 & 15,9 \\
\hline 8,30 & 19,0 & 27,7 & 16,5 \\
\hline 9,30 & 18,4 & 27,7 & 15,9 \\
\hline 10,30 & 18,9 & 27,6 & 16,1 \\
\hline
\end{tabular}

Tabela 9.3 - Tensões básicas

\begin{tabular}{|c|c|c|}
\hline Classe & Descrição & $\sigma_{0}(\mathrm{MPa})$ \\
\hline 1 & Rocha sã, maciça, sem laminação ou sinal de decomposição & 3,0 \\
\hline 2 & Rochas laminadas, com pequenas fissuras, estratificadas & 1,5 \\
\hline 3 & Rochas alteradas ou em decomposição & $*$ \\
\hline 4 & Solos granulares concrecionados, conglomerados & 1,0 \\
\hline 5 & Solos pedregulhosos compactos a muito compactos & 0,6 \\
\hline 6 & Solos pedregulhosos fofos & 0,3 \\
\hline 7 & Areias muito compactas $\left(\mathrm{N}_{\mathrm{SPT}}>40\right)$ & 0,5 \\
\hline 8 & Areias compactas $\left(19 \leq \mathrm{N}_{\mathrm{SPT}} \leq 40\right)$ & 0,4 \\
\hline 9 & Areias medianamente compactas $\left(9 \leq \mathrm{N}_{\mathrm{SPT}} \leq 18\right)$ & 0,2 \\
\hline 10 & Argilas duras $\left(\mathrm{N}_{\mathrm{SPT}}>19\right)$ & 0,3 \\
\hline 11 & Argilas rijas $\left(11 \leq \mathrm{N}_{\mathrm{SPT}} \leq 19\right)$ & 0,2 \\
\hline 12 & Argilas médias $\left(6 \leq \mathrm{N}_{\mathrm{SPT}} \leq 10\right)$ & 0,1 \\
\hline 13 & Siltes duros $($ muito compactos) & 0,3 \\
\hline 14 & Siltes rijos $($ compactos) & 0,2 \\
\hline 15 & Siltes médios (medianamente compactos) & 0,1 \\
\hline
\end{tabular}

- Levar em conta a natureza da rocha matriz e o grau de decomposição ou alteração 
Tabela 9.4 - Parâmetros de resistências EESC - USP

\begin{tabular}{|c|c|c|c|c|c|}
\hline \multirow{2}{*}{ Profundidade $(\mathrm{m})$} & \multicolumn{2}{|c|}{$\begin{array}{c}\text { Triaxial Adensado } \\
\text { Rápido }\end{array}$} & \multicolumn{2}{c|}{ Triaxial drenado } & Compressão Simples \\
\cline { 2 - 6 } & $c(\mathrm{kPa})$ & $\phi\left(^{\circ}\right)$ & $C_{D}(\mathrm{kPa})$ & $\phi\left(^{\circ}\right)$ & $R_{c}(\mathrm{kPa})$ \\
\hline 1,30 & 10,0 & 32,0 & 6,0 & 30,5 & 39,3 \\
\hline 2,30 & 12,5 & 26,0 & 5,0 & 29,5 & 40,9 \\
\hline 3,30 & 14,0 & 24,5 & 6,0 & 30,0 & 37,8 \\
\hline 4,30 & 16,0 & 27,0 & 12,5 & 29,0 & 30,0 \\
\hline 5,30 & 13,0 & 29,5 & 1,0 & 31,0 & 65,5 \\
\hline 6,30 & 23,0 & 23,0 & 25,5 & 25,0 & 41,3 \\
\hline 7,30 & 24,0 & 23,0 & 4,5 & 28,0 & 69,9 \\
\hline 8,30 & 30,5 & 20,0 & 18,0 & 23,0 & 60,4 \\
\hline 9,30 & 19,0 & 27,5 & 9,0 & 26,0 & 42,5 \\
\hline 10,30 & 49,5 & 13,0 & 43,0 & 14,0 & 34,1 \\
\hline
\end{tabular}

Tabela 9.5 - Valores de tensões admissíveis (VARGAS, 1955)

\begin{tabular}{|l|c|}
\hline \multicolumn{1}{|c|}{ Tipo de Solo } & Tensão admissível (MPa) \\
\hline Rocha, conforme sua natureza geológica, textura e estado & $20-100$ \\
\hline $\begin{array}{l}\text { Alteração de rocha de qualquer espécie (mantendo ainda a estrutura da } \\
\text { rocha-mãe necessitando martelete pneumático ou pequenas cargas de } \\
\text { dinamite para desmonte) }\end{array}$ & $4-20$ \\
\hline $\begin{array}{l}\text { Alteração de rocha eruptiva ou metamórfica (necessitando, quando } \\
\text { muito, picareta para escavação) }\end{array}$ & $<4$ \\
\hline $\begin{array}{l}\text { Pedregulho ou areia grossa compacta (necessitando picareta para } \\
\text { escavação), argila dura (que não pode ser moldada nos dedos) }\end{array}$ & $4-6$ \\
\hline Argila rija (dificilmente moldada nos dedos) & $2-4$ \\
\hline Areia grossa média, areia fina compacta & $2-3$ \\
\hline Areias fofas, argila mole (escavação a pá) & $<1$ \\
\hline
\end{tabular}

\begin{tabular}{|c|c|}
\hline \multicolumn{2}{|c|}{ Tabela 9.6 - Valores do coeficiente de Poisson } \\
\hline Tipo de solo & $v$ \\
\hline Areia pouco compacta & 0,2 \\
\hline Areia compacta & 0,4 \\
\hline Silte & $0,3-0,5$ \\
\hline Argila saturada & $0,4-0,5$ \\
\hline Argila não saturada & $0,1-0,3$ \\
\hline
\end{tabular}

Tabela 9.7 - Valores de $\alpha$

\begin{tabular}{|c|c|}
\hline Tipo de solo & $\alpha$ \\
\hline Areia & 3 \\
\hline Argila & 7 \\
\hline Silte & 5 \\
\hline
\end{tabular}




\begin{tabular}{|c|c|}
\hline \multicolumn{2}{|c|}{ Tabela 9.8 - Valores de K para a correlação entre $\mathbf{N}_{\text {SPT }}$ e $\mathbf{q}_{\mathbf{c}}$ (TEIXEIRA, 1993) } \\
\hline Tipo de solo & $\mathrm{K}(\mathrm{MPa})$ \\
\hline Areia com pedregulhos & 1,1 \\
\hline Areia & 0,9 \\
\hline Areia siltosa & 0,7 \\
\hline Areia argilosa & 0,55 \\
\hline Silte arenoso & 0,45 \\
\hline Silte & 0,35 \\
\hline Argila arenosa & 0,3 \\
\hline Silte argiloso & 0,25 \\
\hline Argila siltosa & 0,2 \\
\hline
\end{tabular}

